\title{
Estudio de la obtención de mentol a partir de citronelal y citral con catalizadores de zirconia sulfatada
}

Tesis que presenta

César Augusto Barrales Cortés

Para obtener el grado de

Doctor en Ciencias (Ingeniería Química)

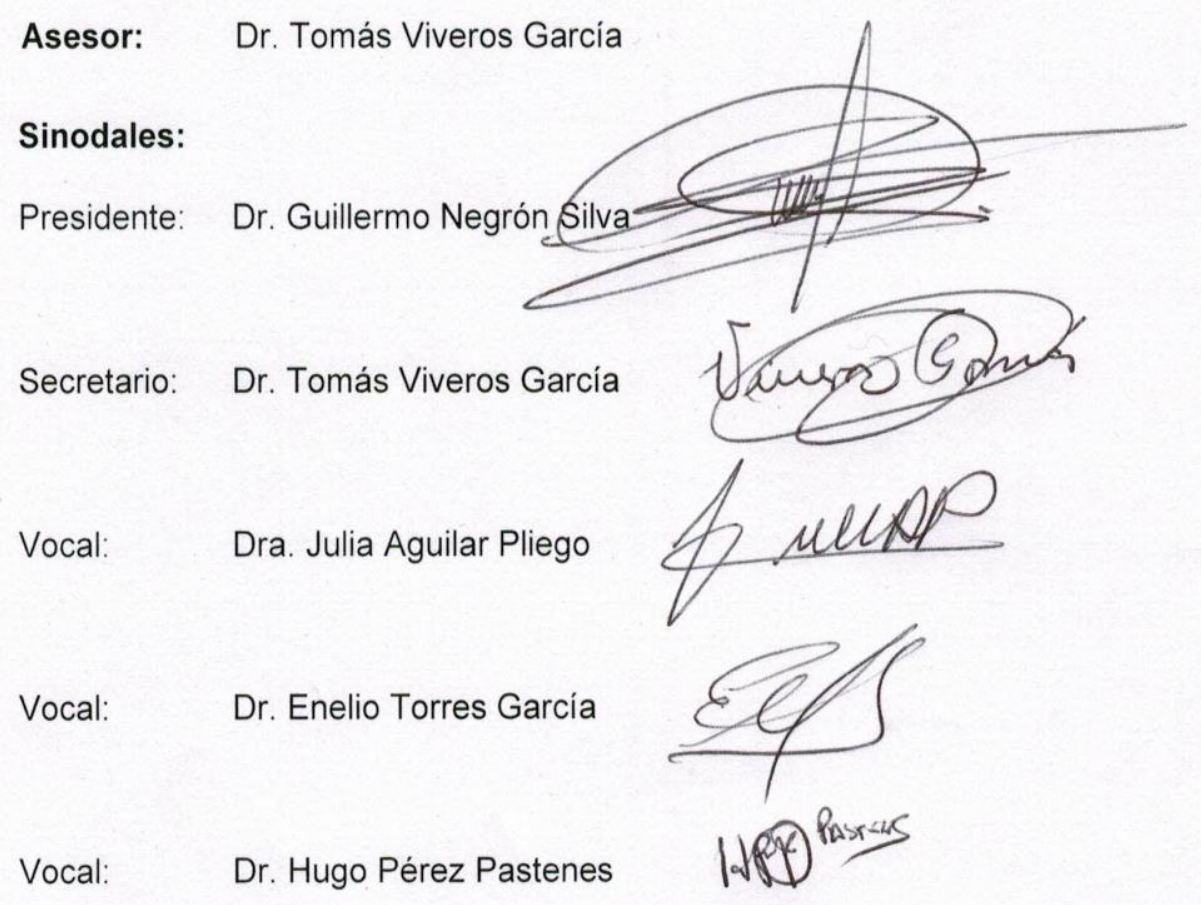

México D. F. 4 de Diciembre 2014 
"Un cientifico debe tomarse la libertad de plantear cualquier cuestión, de dudar de cualquier afirmación, de corregir errores"

Robert Oppenheimer 
A Isis Kenia

A mis padres
Pedro y Lidia 


\section{Agradecimientos}

Al Consejo Nacional de Ciencia y Tecnología (CONACyT) por la beca otorgada con número de registro 179594.

Al Consejo Nacional de Ciencia y Tecnología (CONACyT) por el apoyo a través del proyecto 12511080, Desarrollo de catalizadores sólidos para la química fina.

Agradezco enormemente a mi asesor el Dr. Tomás Viveros García por el apoyo, impulso y motivación que me brindo, por su paciencia, generosidad y lo remarco, por su paciencia.

Al Dr. Guillermo Negrón, Dr. Enelio Torres, Dr. Hugo Pérez y Dra. Julia Aguilar por su valiosa colaboración y crítica hacia este trabajo.

A todos los profesores del Departamento de Ingeniería de Procesos e Hidráulica y a mis compañeros del posgrado que participaron activa y moralmente en este trabajo, especialmente al Dr. Alberto Ochoa y al Dr. Eduardo Pérez Cisneros.

Agradezco al Dr. Gustavo Pérez López por su generosa transmisión de conocimientos y por su amistad sincera; al Dr. Hugo Pérez Pastenes por su apoyo solidario y por los momentos de sano esparcimiento que convivimos; al M. en C. Juan Carlos Piña Victoria por su apoyo moral, por su colaboración intelectual, por los valiosos consejos y por su valiosísima amistad.

Agradezco a mi padre Pedro Barrales por enseñarme que el verdadero camino hacia el éxito no está formulado, se va construyendo paso a paso a pesar de las adversidades. A mi madre Lidia Cortés por confiar en mí y por mostrarme que la humildad en los sentimientos siempre atrae lo positivo de la vida. A mis hermanos Pedro y Olga por el apoyo y cariño que me han brindado en los buenos momentos y hasta en los momentos más difíciles de mi vida. A mi sobrina Kathya por darme momentos de alegría con su humor y frescura.

Kenia te agradezco por brindarme tu apoyo y amor, por creer en mí y por tu confianza, por ser la fuente generadora de mi inspiración y por hacer de este tu fiel admirador una mejor persona. Te amo. 


\section{CONTENIDO}

RESUMEN

$\begin{array}{lc}\text { 1. INTRODUCCIÓN } & 8\end{array}$

2. ANTECEDENTES 12

2.1. Acerca del citral y citronelal 12

2.2. Hidrogenación de citral y citronelal 14

2.3. Ciclización de citronelal 20

2.4. Síntesis de mentol en una sola etapa 25

2.5. Zirconia sulfatada en reacciones de isomerización-ciclización 27

2.6. El rol de las mezclas mecánicas de catalizadores 30

$\begin{array}{ll}\text { 3. OBJETIVOS } & 31\end{array}$

3.1 Justificación de la investigación y Planteamiento de la hipótesis 31

3.2. Objetivo general y objetivos particulares 34

4. METODOLOGÍA EXPERIMENTAL 35

4.1. Preparación de zirconia sulfatada por el método sol-gel 35

4.2. Preparación de Ni-zirconia sulfatada por el método sol-gel 36

4.3. Preparación de los catalizadores soportados 36

4.4. Métodos de caracterización fisicoquímica de los catalizadores 36

4.4.1. Análisis termogravimétrico (ATG) y térmico diferencial (ATD) 36

4.4.2. Propiedades texturales. Fisisorción de nitrógeno 37

4.4.3. Estructura cristalina. Difracción de rayos X (DRX) 37

4.4.4. Termodesorción de piridina y espectroscopia de infrarrojo (FTIR-Py) 37

4.4.5. Cantidad de Ni. Absorción atómica (AA) 38

4.4.6. Cantidad de sitios activos hidrogenantes. Quimisorción de hidrógeno $\left(\mathrm{Q}-\mathrm{H}_{2}\right)$

4.5. Métodos de caracterización catalítica 38

4.5.1. Ciclización de citronelal 38

4.5.2 Obtención de mentol a partir de ( \pm )-citronelal $\quad 40$

4.5.3 Obtención de mentol a partir de citral $\quad 40$ 


\section{RESULTADOS Y DISCUSIÓN DE CARACTERIZACIÓN FISICOQUÍMICA DE MATERIALES CATALÍTICOS}

5.1. Análisis termogravimétrico (ATG) y térmico diferencial (ATD) 42

5.2. Propiedades texturales. Fisisorción de nitrógeno 46

5.3. Estructura cristalina de los materiales. Difracción de rayos $X(D R X)$

5.4. Cantidad de sulfatos $\quad 50$

5.5. Termodesorción de piridina y espectroscopia de infrarrojo (FTIR-Py)

5.6. Cantidad de Ni. Absorción Atómica 59

5.7. Cantidad de sitios activos hidrogenantes. Quimisorción de hidrógeno $\left(Q-H_{2}\right)$

6. RESULTADOS Y DISCUSIÓN DE LA ACTIVIDAD CATALÍTICA 61

A. Ciclización de citronelal $\quad 61$

B. Obtención de mentol a partir de citronelal $\quad 67$

C. Obtención de mentol a partir de citral $\quad 71$

D. Efecto de la zirconia sulfatada en la obtención de mentol 83

$\begin{array}{lr}\text { 7. CONCLUSIONES } & 85\end{array}$

$\begin{array}{lr}\text { 7. REFERENCIAS } & 87\end{array}$

$\begin{array}{ll}\text { Apéndice A } & 92\end{array}$

$\begin{array}{lr}\text { Apéndice B } & 97\end{array}$ 


\section{RESUMEN}

La presente investigación establece como objetivo obtener sólidos con propiedades ácidas utilizados como soportes para níquel como catalizador, y llevar a cabo la reacción en una etapa de citral y ( \pm )-citronelal para la obtención de mentol. Los sólidos ácidos considerados en este trabajo están comprendidos de óxido de zirconio o zirconia modificados con sulfatos (ZrSx), en donde se varía la composición de los sulfatos ( $\mathrm{x}=$ variación de la relación molar $\mathrm{S} / \mathrm{Zr}$ ) y así observar el efecto que tiene sobre el tipo, la acidez y la cantidad de sitios ácidos en estos materiales. A su vez se analiza el efecto de la adición de sulfatos en las propiedades fisicoquímicas de los materiales sólidos y en la actividad catalítica para la reacción de isomerización-ciclización de citronelal. Se utilizó el método sol-gel para obtener zirconia sulfatada variando la relación molar de $\mathrm{S} / \mathrm{Zr}$ en $0.1,0.2$ y 0.5 usando $\mathrm{H}_{2} \mathrm{SO}_{4}$ Como catalizador de síntesis y agente sulfatante. Por el método de impregnación húmeda incipiente se adicionó $\mathrm{Ni}$ a la zirconia sulfatada para evaluar la actividad catalítica en la obtención de mentol en una sola etapa a partir de citronelal. Se utilizaron mezclas mecánicas de $\mathrm{Ni} / \mathrm{SiO}_{2}$ y zirconia sulfatada, con diferentes composiciones de la mezcla, para evaluar la actividad catalítica de la zirconia sulfatada en la obtención de mentol a partir de citral. El efecto de los parámetros de estudio sobre las propiedades de los sólidos resultantes se examinó con las siguientes técnicas de caracterización: ATD-ATG, DRX, FTIR de piridina, fisisorción de $\mathrm{N}_{2}$, quimisorción de $\mathrm{H}_{2}$. Los resultados muestran que la adición de sulfatos a la zirconia le otorga estabilidad térmica a la fase amorfa cuando la zirconia sulfatada se calcina a $450^{\circ} \mathrm{C}$. La variación de la relación $\mathrm{S} / \mathrm{Zr}$ le concede distintas características ácidas a la zirconia sulfatada, donde existe una variación en la relación entre sitios ácidos Lewis y Brønsted con respecto a la cantidad de S. La actividad catalítica de zirconia sulfatada en la ciclización de citronelal se ve modificada por la relación de sitios ácidos Lewis/Brønsted, ya que cuando existe mayor cantidad de sitios ácidos Lewis, la actividad es menor con respecto a los materiales con cantidad mayor de sitios ácidos Brønsted. En la obtención de mentol a partir de citronelal se obtuvieron resultados destacados con los materiales de Ni/ZrS2 y NiZrS2. Estos materiales permiten una alta actividad catalítica y una selectividad de la mezcla de mentoles de $100 \%$. En estos materiales no se utiliza un tratamiento de reducción de $\mathrm{Ni}$ y se observa que la fase de níquel no reducida presente en los materiales es funcional para la reacción de hidrogenación de isopulegol. Las mezclas mecánicas de $\mathrm{Ni} / \mathrm{SiO}_{2}+\mathrm{ZrS} 2$ permiten obtener altas conversiones

y altas selectividades de mentoles, pero una proporción alta de ZrS2 lleva la reacción en su 
etapa inicial a la producción de compuestos no deseados de la ciclización de citral. La relación que otorgo mayor rendimiento hacia mentoles fue la mezcla mecánica $\mathrm{Ni} / \mathrm{SiO}_{2}+\mathrm{ZrS} 2$ 90:10. 


\section{INTRODUCCIÓN}

Ante la problemática ambiental que se vive hoy en día se requiere que los procesos industriales convencionales sean modificados o sustituidos por aquellos que sean amigables con el medio ambiente. Uno de los retos, de la denominada "Química Verde", es el de diseñar procesos que impulsen el desarrollo de productos útiles para la vida cotidiana y que se encuentren dentro de las normas ambientales impuestas en los últimos años. Esto implica utilizar las bases científicas y tecnológicas para desarrollar procesos alternativos que permitan desarrollar materiales en pro del medio ambiente y que sustituyan a los ya establecidos, ya que estos últimos son utilizados copiosamente para la producción de consumibles que por años han deteriorado nuestro ecosistema.

Dentro de la industria química se encuentra el área de los químicos de alto valor agregado, comúnmente denominados como químicos finos, que son de gran importancia en la industria de saborizantes, perfumería y fármacos. Tradicionalmente, los compuestos que se utilizan en esta área se obtienen por extracción natural con producción limitada y por ende son de alto valor agregado. En la actualidad existen varios métodos para la obtención de este tipo de compuestos que implican el manejo de diversas etapas de síntesis orgánica y uso de reactivos, que en la mayoría de los casos, no son recuperados y tienen que ser desechados provocando un desequilibrio ambiental. Por lo anterior se están realizando diversas investigaciones en el área de catálisis, tratando de crear procesos eficientes que permitan obtener rendimientos altos (>95\%) hacia los productos deseados, y con esto disminuir los costos de producción, en donde la mayor parte del consumo se encuentra en la recuperación y tratamiento de desechos.

Dentro de la gran variedad de químicos de alto valor agregado, el mentol es un componente que le otorga la sensación de frescura a consumibles tales como: pasta de dientes, goma de mascar, dulces, cigarros, ungüentos, cremas, etc., y por lo tanto se utiliza ampliamente dentro de la industria de saborizantes, perfumería y fármacos. En la actualidad, la demanda de mentol es provista por los procesos industriales Takasago y BASF. La industria Takasago es la encargada de proveer la mayor cantidad de este compuesto a la mayoría de las industrias antes mencionadas a nivel mundial [1]. El proceso Takasago, para la producción de mentol, consta de varias etapas de síntesis, de las cuales se puede mencionar el craqueo térmico, telomerización, isomerización asimétrica, hidrólisis enzimática, ciclización e hidrogenación (ver Figura 1.1), y en los cuales se hace uso de 
solventes tóxicos, soluciones corrosivas, complejos organometálicos no re-utilizables y una gran cantidad de consumo energético para la síntesis y separación de productos.

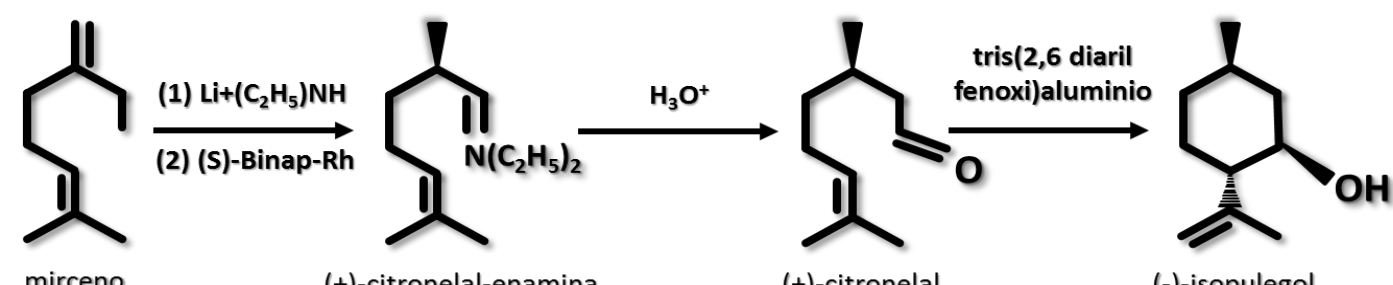

TAKASAGO

(-)-mentol

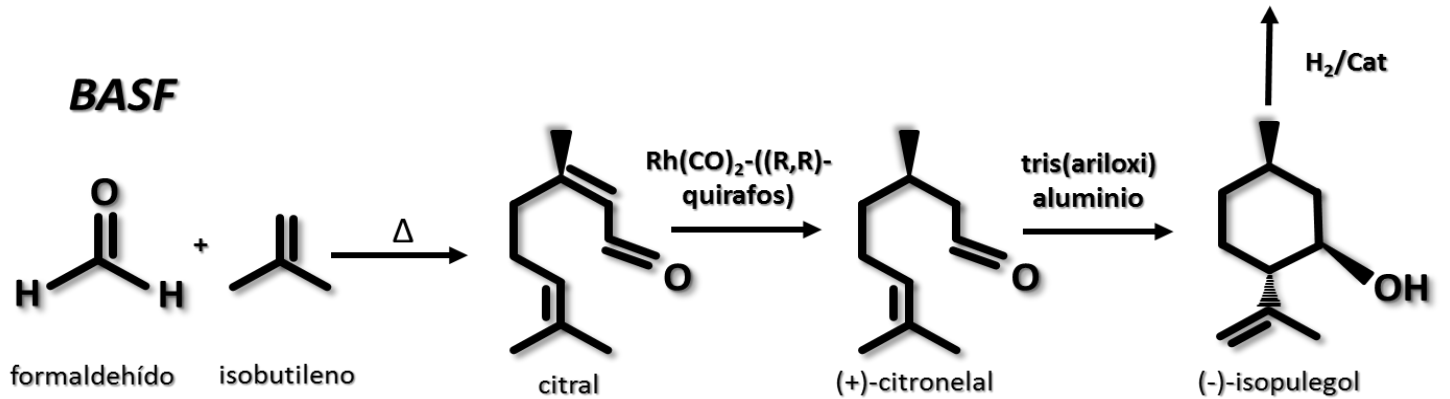

Figura 1.1. Esquema de producción de (-)-mentol por el proceso Takasago y BASF [1,2].

En los últimos años se han implementado materiales sólidos catalíticos para la producción de mentol, obteniendo altos rendimientos del estereoisómero (-)-mentol de interés para la industria de químicos finos. Diversas investigaciones se han realizado para producir mentol en una sola etapa a partir de terpenos como citronelal y citral, que son aldehídos que se extraen del zacate limón. El proceso consiste de las reacciones de hidrogenación y ciclización en una sola etapa como se muestra en la Figura 1.2. Recientemente se ha intentado implementar sistemas reactivos utilizando catalizadores heterogéneos, donde las propiedades de los sólidos catalíticos necesariamente deben aportar altos rendimientos hacia un compuesto específico. Para lograr este fin, las propiedades principales radican en la especificidad del metal activo para hidrogenar selectivamente a la molécula de citral para producir citronelal; y las propiedades superficiales ácidas del soporte para realizar la reacción posterior de isomerización-ciclización (RIC) para producir isopulegol (Figura 1.2). 


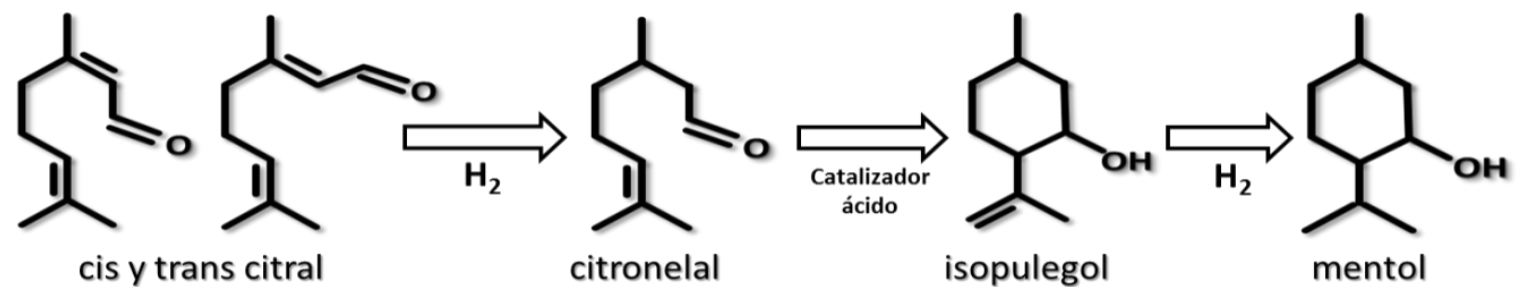

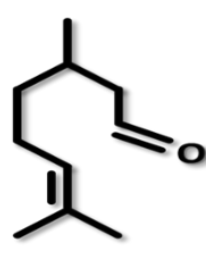

citronelal

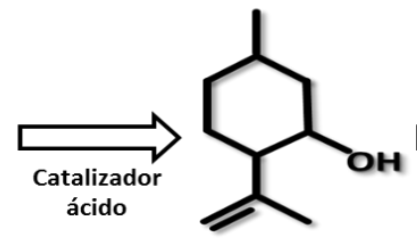

isopulegol

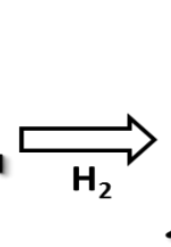

mentol

Figura 1.2. Esquema de síntesis de mentol en una sola etapa a partir de citral y citronelal.

En el caso anterior, la estereoselectividad inducida por los catalizadores es muy importante, ya que existen 8 diferentes estereoisómeros de isopulegol y la posterior hidrogenación también produce 8 diferentes estereoisómeros de mentol, de donde el (-)-mentol es el componente de mayor interés por sus propiedades odoríferas que le dan la sensación de frescura a este componente. Los enantiómeros (+) y (-) del mentol son los más estables conformacionalmente (conformación de ciclohexano) dentro de los 8 estereoisómeros. Con el anillo en conformación silla, los tres grupos voluminosos se pueden orientar en posiciones ecuatoriales, lo cual explica su estabilidad [1] (ver Figura 1.3).

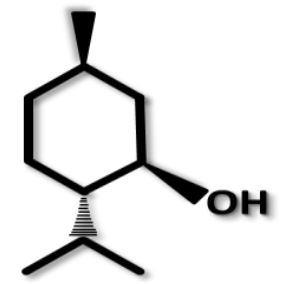

(-)-mentol (1R, 2S, 5R)

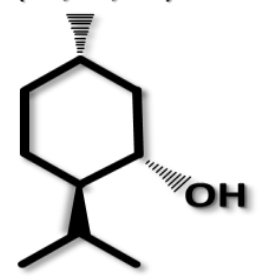

(+)-mentol (1S, 2R, 5S)

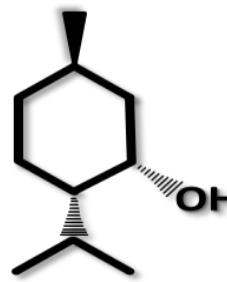

(+)-neo mentol (1S, 2S, 5R)

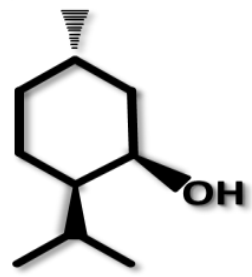

(-)-neo mentol (1R, 2R, 5S)

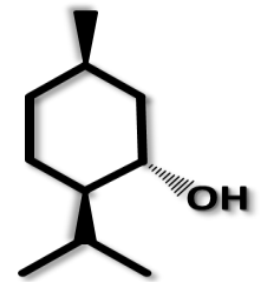

(+)-iso mentol (1S, 2R, 5R)

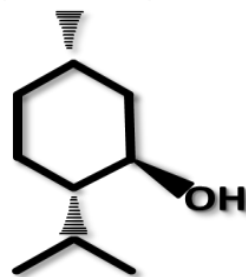

(-)-iso mentol (1R, 2S, 5S)

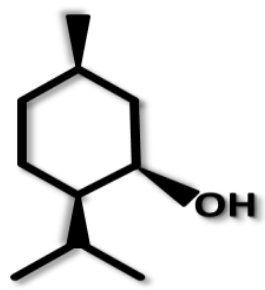

(+)-neoiso mentol (1R, 2R, 5R)

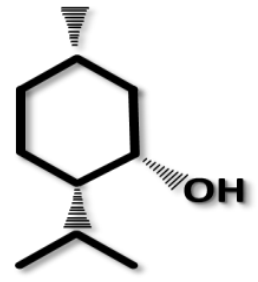

(-)-neoiso mentol (1S, 2S, 5S)

Menthol $\rightarrow$ (configuración de centro quiral)-2-isopropil-5-metilciclohexanol

Figura 1.3. Diferentes estereoisómeros de mentol. 
Comúnmente en la obtención de isopulegol a partir de citronelal se han utilizado las propiedades ácidas (densidad, tipo de sitio y acidez) de determinados materiales catalíticos para promover la reacción de ciclización, tales como $\mathrm{Al}_{2} \mathrm{O}_{3}-\mathrm{SiO}_{2}, \mathrm{SiO}_{2}-\mathrm{ZrO}_{2}, \mathrm{ZrOH}, \mathrm{MCM}-$ 41 , Zeolita $\mathrm{Y}, \mathrm{ZnCl}_{2}$, etc., y diversas conjeturas y conclusiones se desprenden del desarrollo experimental de las investigaciones donde se utilizan dichos materiales y que son discutidas en los antecedentes.

Como primera etapa de este trabajo se presenta el planteamiento del problema, de donde se desprenden la formulación de los objetivos e hipótesis que están fundamentados y relacionados directamente con la revisión crítica de la literatura. Por otro lado se presentan los métodos experimentales que permitirán la obtención de los materiales catalíticos propuestos para cumplir con los objetivos propuestos; además se presentan las técnicas de caracterización de los sólidos catalíticos que permitan representar y correlacionar los resultados experimentales de las pruebas catalíticas con los fundamentos teóricos. 


\section{ANTECEDENTES}

\subsection{Acerca del citral y citronelal}

El citral (3,7-dimetil-2,6-octadienal o lemonal, fórmula química: $\left.\mathrm{C}_{10} \mathrm{H}_{16} \mathrm{O}\right)$ es un aldehído clasificado como un compuesto monoterpenoide de la serie 3,6-dimetiloctano, caracterizado por la unión de dos subunidades isoprenoides. El "efecto cítrico" de muchos productos de consumo humano se debe al olor del citral, que es también un componente importante en la industria de química fina para la producción de carotenoides, vitaminas y otros sabores y fragancias [3]. En la naturaleza se encuentra como una mezcla no racémica que en estereoquímica se clasifican como estereoisómeros aquirales cis y trans ( $E$ y Z citral, Figura 2.1).

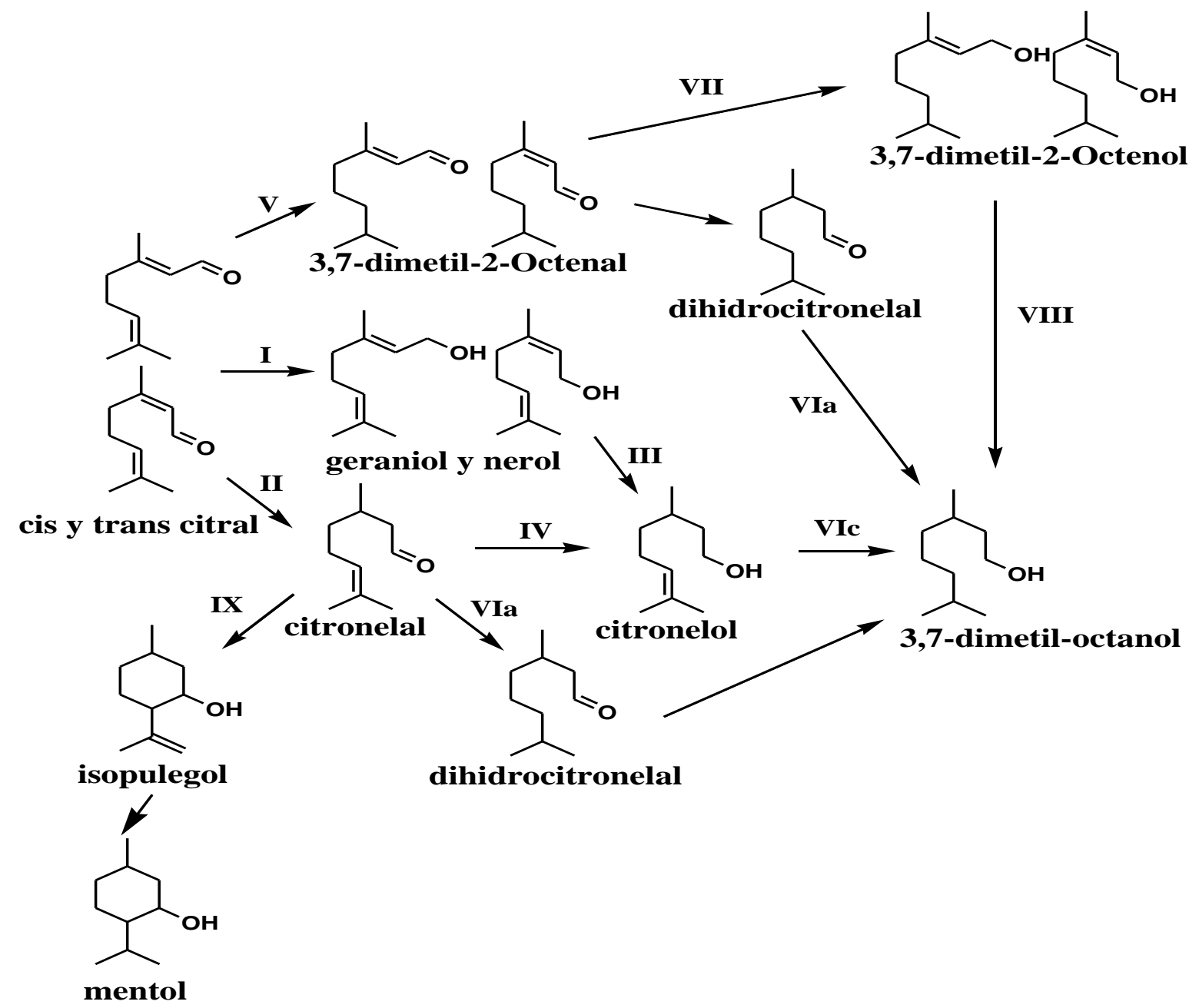

Figura 2.1. Red de reacción de citral y citronelal con sus diferentes reacciones en serie y paralelo. 
Se conoce que la molécula de citral cuenta con tres dobles enlaces, dos de ellos conjugados que tienen funcionalidad de grupo carbonilo $(\mathrm{C}=\mathrm{O})$ y grupo olefínico $(\mathrm{C}=\mathrm{C}$ en posiciones $\alpha$ y $\beta$ ), el tercer doble enlace se le conoce como aislado trisustituido y es un grupo olefínico $\mathrm{C}=\mathrm{C}$ (Figura 2.2). Dada la reactividad de cada una de las insaturaciones, se puede derivar una red de reacciones general a partir de citral como lo muestra la Figura 2.1

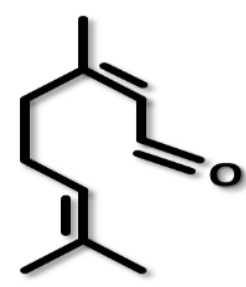

Figura 2.2. Molécula de aldehído $\alpha, \beta$-insaturado citral.

Por la presencia del oxígeno en el grupo carbonilo, la reactividad de la molécula de citral aumenta debido a que el enlace $\mathrm{C}=\mathrm{O}$ está polarizado gracias a la diferencia de electronegatividad entre el oxígeno y el carbono. Si dibujamos una estructura de resonancia (Figura 2.3) observamos que la carga positiva es alílica y entonces se crean dos sitios electrofílicos susceptibles de ser atacados por nucleófilos.

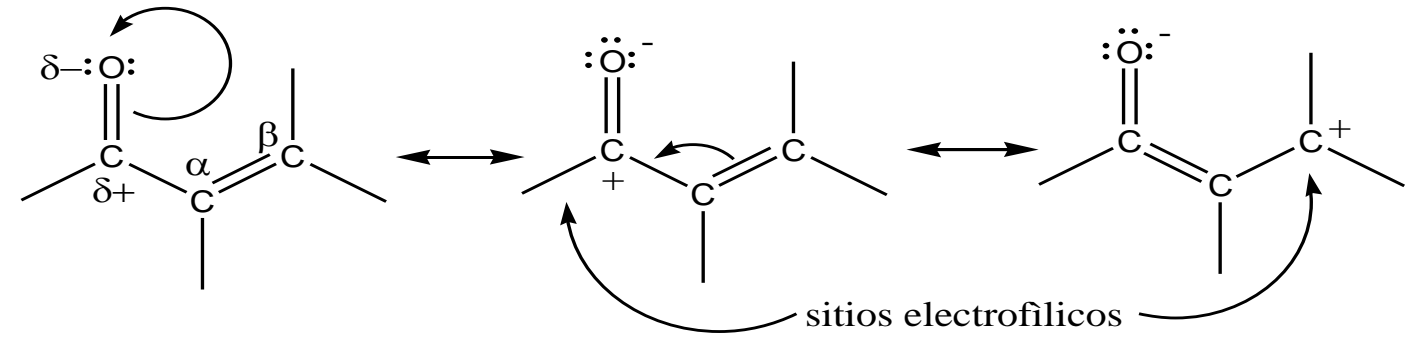

Figura 2.3. Estructura de resonancia para un compuesto $\alpha, \beta$-insaturado [4].

El citronelal (3,7-dimetil-6-octenal, Figura 2.4) es un monoterpeno formado por el metabolismo secundario de las plantas. Normalmente se obtiene como una mezcla no racémica de sus enantiómeros $(R)$ y $(S)$ por arrastre de vapor o por la extracción con disolventes de los aceites de las plantas Corymbia citriodora, Eucalyptus citriodora, Cymbopogon nardus y Java citronela. La producción anual de aceite de citronelal, el cual contiene el $40-50 \%$ de citronelal, es de alrededor de 2300 toneladas métricas [3]. Dentro de sus aplicaciones industriales, el mayor interés se encuentra en la síntesis de isopulegol, ya que a partir de este último se puede obtener mentol. 

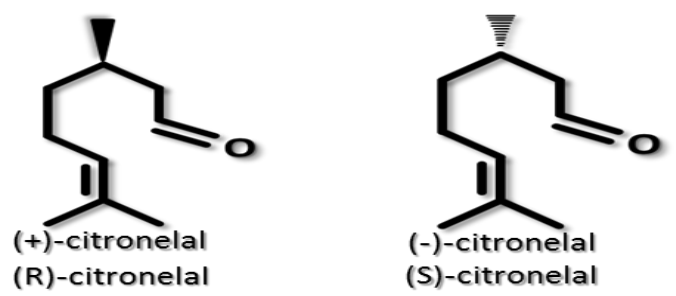

Figura 2.4. Estereoisómeros de citronelal

Uno de los retos de la catálisis, dentro de la química fina, está el emplear al citral para obtener mentol en una sola etapa, es decir, crear un sistema catalítico que permita hidrogenar de manera selectiva al citral para obtener citronelal, que el citronelal sufra una reacción de ciclización y producir isopulegol, para que este último sea hidrogenado y así obtener el mentol, todo este proceso en un solo paso. Cada etapa por separado, la hidrogenación de citral, ciclización de citronelal e hidrogenación de isopulegol tiene sus dificultades técnicas y de razonamiento. Por varios años se ha estudiado cada etapa a fondo con múltiples sistemas catalíticos y las siguientes secciones están enfocadas en mencionar las conclusiones, hipótesis y controversias más importantes que han surgido en torno a cada una de las etapas antes mencionadas y a la síntesis de mentol a partir de citral.

\subsection{Hidrogenación de citral y citronelal}

La hidrogenación de citral puede darse por diferentes rutas y producir tres diferentes compuestos dependiendo de cuál doble enlace es hidrogenado, como se muestra en la Figura 2.5. Las rutas $A$ y $B$ son las que son más factibles de llevarse a cabo debido a la reactividad de la molécula de citral como lo muestra la Figura 2.3. La Ruta A se lleva a cabo por la hidrogenación del doble enlace $\mathrm{C}=\mathrm{O}$ de citral que produce geraniol y nerol, que son alcoholes de alto valor agregado y útiles en la fabricación de fragancias por su aroma floral. En la literatura existen varios estudios enfocados a la producción de geraniol y nerol a partir de citral, donde se han utilizado catalizadores tales como $\mathrm{Co}, \mathrm{Ru}, \mathrm{Rh}, \mathrm{Pt}$ y catalizadores bimetálicos de PtSn y RuSn soportados en materiales como $\mathrm{TiO}_{2}, \mathrm{SiO}_{2}$, carbón, $\mathrm{Al}_{2} \mathrm{O}_{3}$ y óxidos mixtos de $\mathrm{SiO}_{2}-\mathrm{TiO}_{2}$ y $\mathrm{SiO}_{2}-\mathrm{ZrO}_{2}$ [3,6-9]. La Ruta $\mathrm{B}$ se lleva a cabo por la hidrogenación del doble enlace $\mathrm{C}=\mathrm{C}$ conjugado de citral que produce citronelal. Los estudios realizados para obtener citronelal a partir de citral emplean catalizadores de Ni o 
Pd soportados en $\mathrm{SiO}_{2}$ y $\mathrm{Al}_{2} \mathrm{O}_{3}$ [6,10-12]. La hidrogenación del doble enlace aislado $\mathrm{C}=\mathrm{C}$ se representa por la Ruta C que da como producto el 3,7-dimetil-2-octenal.

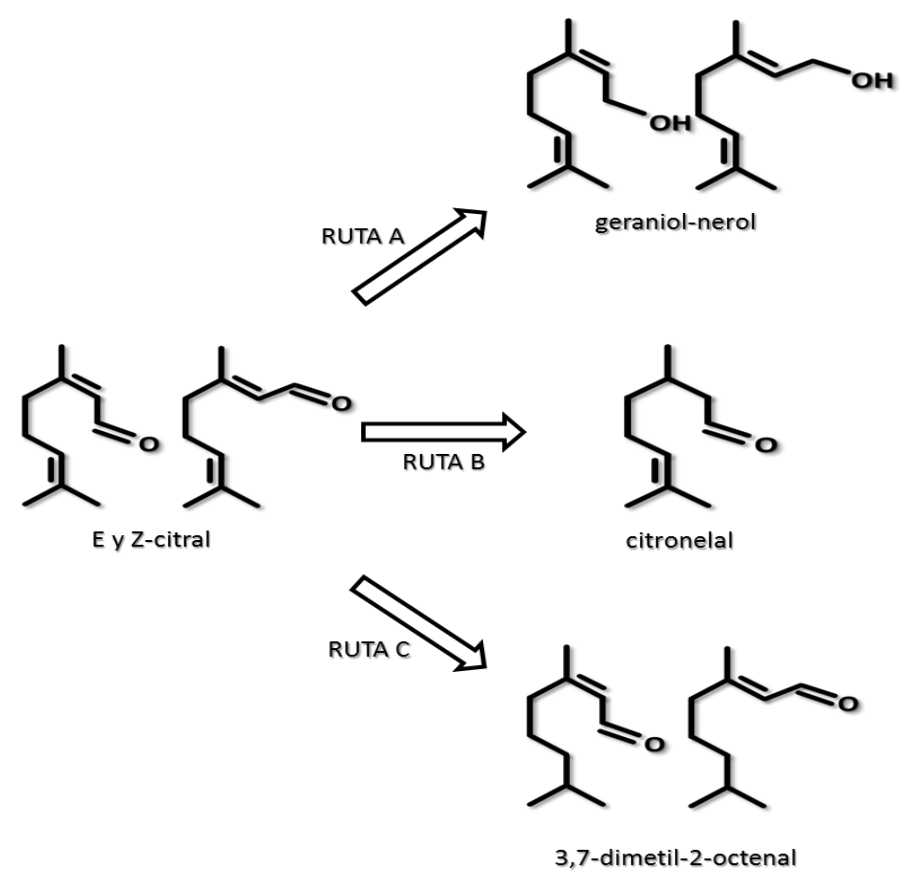

Figura 2.5. Esquema de hidrogenación de citral. RUTA A: hidrogenación de doble enlace $\mathrm{C}=\mathrm{O}$; RUTA B: hidrogenación de doble enlace $\mathrm{C}=\mathrm{C}$ conjugado, RUTA $\mathrm{C}$ : hidrogenación de doble enlace $\mathrm{C}=\mathrm{C}$ aislado.

Recientemente se han desarrollado diversos trabajos de investigación en la hidrogenación de citral en fase líquida empleando distintos catalizadores soportados en una gran variedad de óxidos metálicos. Una de las investigaciones más citadas es la desarrollada por Vannice y col. [10] en la hidrogenación de citral utilizando metales del grupo VIII de la tabla periódica como catalizadores soportados en $\mathrm{SiO}_{2}$. Los resultados de la actividad catalítica muestran que $\mathrm{Ni}$ y $\mathrm{Pd}$ son altamente selectivos hacia citronelal $(61$ y $69 \%$ de selectividad respectivamente, a $5 \%$ de conversión) y Pt es moderadamente selectivo hacia citronelal ( $50 \%$ de selectividad). El análisis de resultados y su discusión la realizan de manera cualitativa utilizando datos experimentales y resultados teóricos. De manera general muestran que existe una correlación del ancho de banda $d$ del metal activo con la selectividad. De manera detallada observan que el ancho de banda- $d$, que es un parámetro teórico que se utiliza para determinar el grado de interacción de la superficie catalítica con el adsorbato, tiene relación con la hidrogenación del doble enlace $\mathrm{C}=\mathrm{C}$ conjugado de citral y por lo tanto se ve reflejado en la selectividad hacia citronelal. En la Tabla 2.1 se muestran los resultados obtenidos por XPS del ancho de banda-d para distintos metales de transición. 
El Ni presenta el ancho de banda-d más estrecho y es el metal que muestra la mayor selectividad hacia citronelal al inicio de la reacción de hidrogenación. El Pd muestra un ancho de banda-d más amplio que $\mathrm{Ni}$ y aunque presenta una selectividad mayor hacia citronelal al inicio de la reacción, éste lleva reacciones de hidrogenación consecutivas con alta actividad catalítica. El Pt tiene un ancho de banda-d más amplio que Ni y Pd y muestra una baja selectividad hacia citronelal con una producción considerable de citronelol que es producto de la hidrogenación del doble enlace $\mathrm{C}=\mathrm{O}$. El Os presenta el mayor ancho de banda- $d$ y no produce compuestos de la hidrogenación del doble enlace $\mathrm{C}=\mathrm{C}$ de citral. Los autores concluyen que entre más estrecho sea el ancho de banda- $d$ menor es la interacción repulsiva de cuatro-electrones y mayor es la interacción del enlace $\mathrm{C}=\mathrm{C}$ con la superficie del metal. Esta conclusión está fundamentada por lo reportado por Delbeq y col. [13] en estudios de teoría de funcionales de densidad (DFT) donde muestran resultados con la molécula de crotonaldehído que tiene dobles enlaces $\mathrm{C}=\mathrm{C}$ y $\mathrm{C}=\mathrm{O}$ conjugados. Los resultados teóricos muestran un comportamiento de $\mathrm{Pd}$ y $\mathrm{Pt}$ con dichos dobles enlaces de crotonaldehído similar a lo que sucede con citral.

Tabla 2.1. Ancho de banda-d para metales del grupo VIII, obtenido de mediciones de XPS [14].

\begin{tabular}{c|c}
\hline Metal & Ancho de banda-d (eV) \\
\hline $\mathrm{Fe}$ & 4.2 \\
\hline $\mathrm{Co}$ & 4.0 \\
\hline $\mathrm{Ni}$ & 3.0 \\
\hline $\mathrm{Ru}$ & 4.9 \\
\hline $\mathrm{Rh}$ & 4.4 \\
\hline $\mathrm{Pd}$ & 4.1 \\
\hline $\mathrm{Os}$ & 6.5 \\
\hline $\mathrm{Ir}$ & 6.3 \\
\hline $\mathrm{Pt}$ & 5.8 \\
\hline
\end{tabular}

En un estudio previo sobre la hidrogenación en fase líquida de citral [6], se probaron catalizadores de Pt y Ni soportados en Silice Gel 7 (SG7, Aldrich), utilizando hexano como disolvente, donde se observó una variación en la distribución de productos debido al tipo de metal activo. El sistema de Ni/SG7 presenta una alta actividad de hidrogenación y una alta selectividad inicial hacia citronelal (Figura 2.6). Además, se puede observar una rápida conversión de citronelal hacia citronelol y 3,7-dimetil-1-octanol como reacciones 
consecutivas de hidrogenación, pero también se observa la formación de isopulegol e incluso mentol. Vannice y col. [10] mencionan que el catalizador de Ni soportado en sílice es muy difícil de reducir a pesar de ser sometido a temperaturas de $450^{\circ} \mathrm{C}$. En Ni/SG7, el catalizador se sometió a una reducción de $500^{\circ} \mathrm{C}$ y posiblemente a esta temperatura no se alcanzó a reducir el material en su totalidad y como consecuencia se formaron especies de $\mathrm{Ni}^{0}$ y especies de níquel cargadas positivamente $\mathrm{Ni}^{+}$. En la literatura existe evidencia de que especies soportadas de óxidos de metales de transición o especies cargadas positivamente, pueden comportarse como sitios ácidos tipo Lewis y por lo tanto ser funcionales en reacciones donde se requieren este tipo de sitios catalíticos. Por lo tanto, la formación de isopulegol en el sistema de Ni soportado en SG7 nos da un indicio de la presencia de sitios ácidos tipo Lewis que catalizan la reacción de ciclización de citronelal para la formación de isopulegol. En la hidrogenación en fase líquida de citronelal, Weismeijer y col. [15] utilizaron catalizadores de $\mathrm{Ru}$ soportado en $\mathrm{TiO}_{2}$ y $\mathrm{SiO}_{2}$ para la obtención de citronelol. Con el catalizador de $\mathrm{Ru} / \mathrm{SiO}_{2}$ observaron la formación de isopulegol y atribuyeron este resultado a la presencia de sitios incompletamente reducidos de rutenio $\left(\mathrm{RuO}_{\mathrm{x}}\right)$.
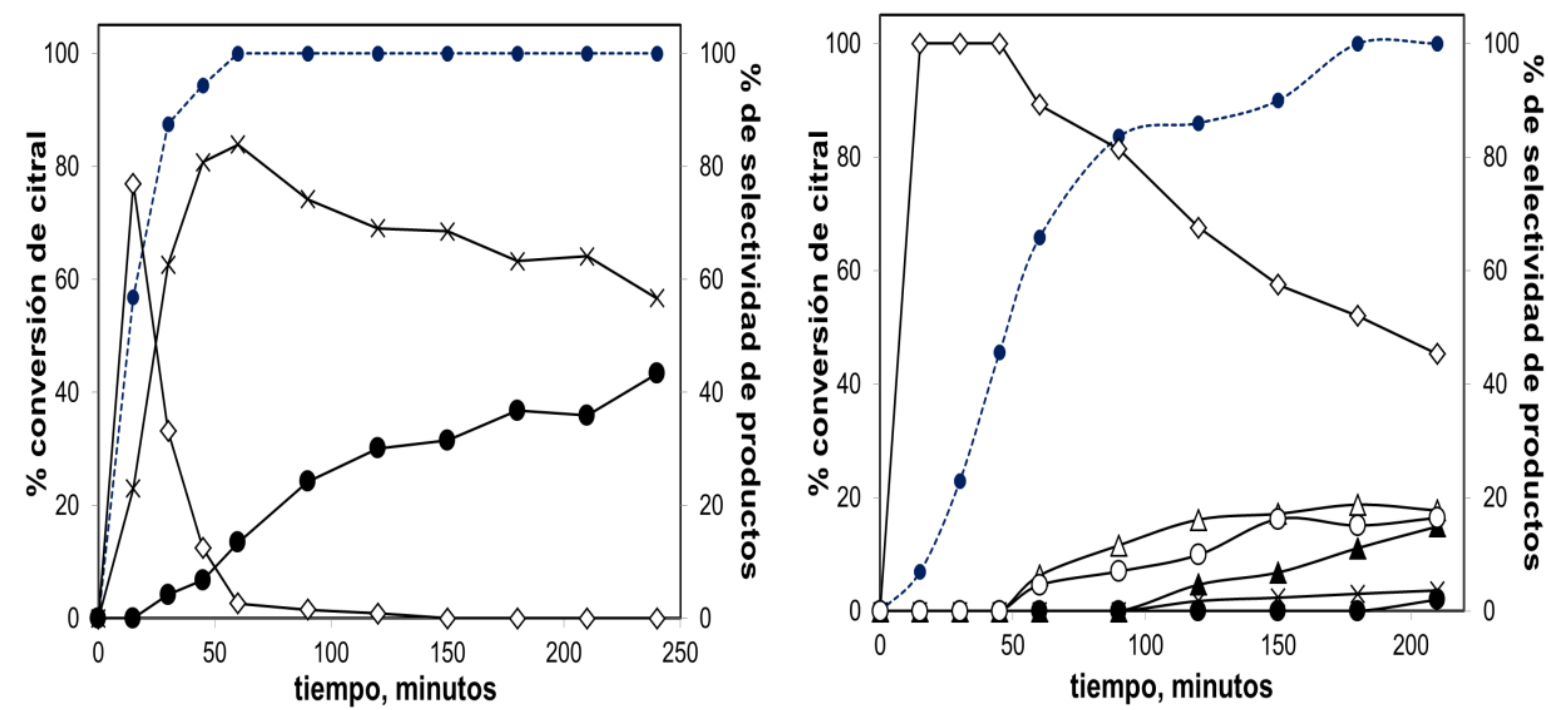

Figura 2.6. Hidrogenación de citral a $100{ }^{\circ} \mathrm{C}, 1.4 \mathrm{MPa}$ de $\mathrm{H}_{2}, 0.1 \mathrm{M}$ citral/ciclohexano, $0.5 \mathrm{~g}$ de catalizador. Izquierda: $1 \%$ Pt/SG7. Derecha: $3 \%$ Ni/SG7. • \% x citral; $\diamond$ CAL; O COL; DMOCTOL; $\triangle$ ISO; $\triangle$ MTOL; X DHCAL.

Murzin y col. [11] realizaron un estudio en la hidrogenación en fase líquida de citral con catalizadores de $\mathrm{Ru}$, Rh y Ni, en soportes de carbón activado, alúmina y sílice para la supresión de productos no deseados tales como 3,7-dimetil-1-octanol, dihidrocitronelal, 3,7dimetil-octenal y citronelal acetal. El estudio está enfocado al efecto del disolvente en la actividad y selectividad hacia citronelol, siendo la etapa limitante la actividad inicial de 
hidrogenación de citral hacia la formación de citronelal. Los disolventes utilizados fueron etanol, 2-propanol, 2-metil-2-propanol y 2-pentanol en donde concluyen que la polaridad del disolvente puede promover la reacción de acetalización de citronelal con el respectivo alcohol, produciendo citronelal acetal como compuesto no deseado. El catalizador de $\mathrm{Ni} / \mathrm{Al}_{2} \mathrm{O}_{3}$ inhibe la formación de acetales a ciertas condiciones de pretratamiento debido a tres posibles causas: a) El uso de un precursor de Ni libre de cloruros; b) el uso de alcoholes de cadenas ramificas y c) la promoción de spillover de $\mathrm{H}_{2}$ en la superficie de los centros activos causado por un pre-tratamiento de reducción a alta temperatura $\left(500^{\circ} \mathrm{C}\right)$.

En otro estudio, Murzin y col. [12] utilizan un catalizador de $\mathrm{Ni} / \mathrm{SiO}_{2}$ con $10 \%$ en peso de $\mathrm{Ni}$ soportado en etanol como solvente en la hidrogenación de citral, alcanzando una selectividad inicial de citronelal de $100 \%$ en 20 minutos de reacción, sin embargo, la desventaja que existe en este sistema de reacción es la formación de acetales conforme avanza la reacción, que cinéticamente son más favorables que los productos de hidrogenación consecutiva de citronelal (citronelol y dihidrocitronelal).

Un factor importante a tomar en cuenta, de acuerdo a lo anterior, es la elección del disolvente en la reacción de hidrogenación en fase líquida de citral, con la finalidad de suprimir la formación de productos no deseados, tales como citral acetal, citronelal acetal y dihidrocitronelal acetal, en el caso donde se utilizan alcoholes como solventes; y 3,7-dimetil2-octenal, dihidrocitronelal, geraniol-nerol, citronelol y 3,7-dimetil-1-octanol en el caso donde se requiere la formación de un componente especifico (citronelal) de las rutas de hidrogenación de citral y reacciones consecutivas. Para ello, Murzin y col. [11] determinaron que el empleo de alcoholes de cadena C4, C5 y C6 evitan la formación de acetales y Barrales [6] determinó que el uso de hexano como disolvente evita la formación de geraniolnerol, dihidrocitronelal y 3,7-dimetil-2-octenal cuando se utiliza un catalizador de $\mathrm{Ni} / \mathrm{SiO}_{2}$ en la hidrogenación en fase líquida de citral.

Por otro lado, la ruta de hidrogenación de citral se ve influenciada por el soporte catalítico. Las propiedades del soporte pueden modificar la actividad catalítica, la ruta de reacción de hidrogenación y puede también promover la formación de compuestos no deseados. Las reacciones que se pueden llevar a cabo en la superficie del soporte en la hidrogenación de citral son: acetalización, isomerización-ciclización, cracking, entre otras. Galvagno y col. [16] argumentan que la reacción de isomerización-ciclización de citronelal se lleva a cabo 
en sitios ácidos superficiales, sitios generados por la naturaleza del soporte, por reducción parcial de la fase activa, por precursores de la fase activa o por promotores de sitios ácidos.

De un estudio previo de la hidrogenación de citral, Barrales [6] encontró que la polarización de los reactivos, en el medio de reacción, es importante para determinar que ruta de reacción se llevará a cabo. Dicha polarización puede estar dada por la naturaleza del disolvente o por las especies metálicas presentes en la superficie catalítica. En la hidrogenación de citral con catalizadores de $\mathrm{Ni} / \mathrm{SiO}_{2}$, la formación de $85 \%$ de citronelal fue evidente, y la posterior conversión de citronelal hacia citronelol indica que existe una adsorción de la molécula de citronelal por el enlace $\mathrm{C}=\mathrm{O}$ para su posterior ciclización, hecho que puede ser atribuido a sitios ácidos de Lewis generados por la reducción parcial de $\mathrm{Ni}$, como lo determinó Galvagno y col. [16] para catalizadores de Ru; o por la polarización de la molécula de citronelal debido al solvente polar utilizado. Cuando se emplearon catalizadores de $\mathrm{PtSn} / \mathrm{SiO}_{2}$ se mostró que existe una transferencia de carga entre Pt y Sn generando sitios ácidos tipo Lewis, permitiendo altas selectividades hacia geraniol y nerol, citronelal y citronelol, rutas de reacción que implican la rápida adsorción del enlace $\mathrm{C}=\mathrm{O}$.

Con estos resultados se concluye que $\mathrm{Ni}$ como metal activo promueve una elevada selectividad hacia citronelal a partir de la hidrogenación de citral dada su funcionalidad para hidrogenar el enlace $\mathrm{C}=\mathrm{C}$ conjugado de citral. Por otro lado, el medio de reacción tiene una importante contribución en la distribución de productos, en este sentido, el hexano como solvente promueve la ruta de hidrogenación de citral favoreciendo la hidrogenación de los enlaces olefínicos $\mathrm{C}=\mathrm{C}$ y además promoviendo sólo reacciones en serie. Además son necesarios sitios ácidos de Lewis para llevar a cabo la coordinación molécula de citronelal vía el enlace $\mathrm{C}=\mathrm{O}$ y así generar el mecanismo necesario para llevar a cabo una posterior conversión de esta molécula. 


\subsection{Ciclización de citronelal}

La reactividad de citronelal le permite llevar a cabo dos principales reacciones: a) hidrogenación directa del doble enlace $\mathrm{C}=\mathrm{O}$ o del doble enlace aislado $\mathrm{C}=\mathrm{C}$; y b) ciclizaciónisomerización. La molécula de citronelal presenta un carbón estereogénico o quiral que deriva dos enantiómeros: (+)-citronelal y (-)-citronelal. En la hidrogenación directa se produce el alcohol insaturado citronelol o el aldehído saturado dihidrocitronelal; y en la ciclización se producen 4 diastereoisómeros de cada uno de los enantiómeros de citronelal como se muestra en la Figura 2.7.

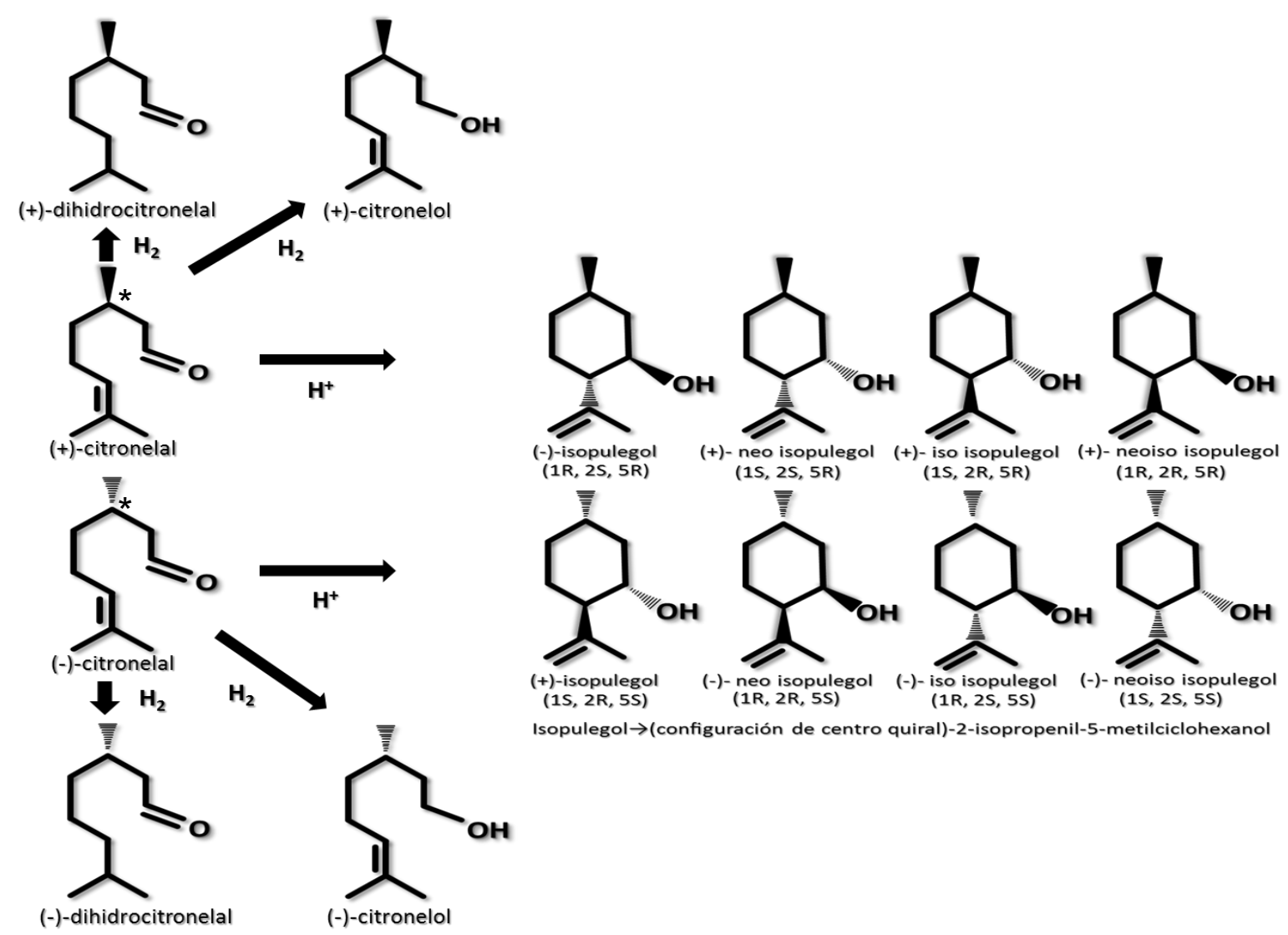

Figura 2.7. Red de reacción de hidrogenación y ciclización de citronelal. ( $\left.{ }^{*}\right)$ Centro estereogénico.

Para la obtención de mentol en una sola etapa ya sea desde citral o citronelal, la ciclización de citronelal es la etapa limitante para la obtención de altos rendimientos y selectividades hacia el isopulegol y de manera consecutiva para la obtención de mentol. La ciclización de citronelal se lleva a cabo mediante una reacción eno, la cual implica la adición de un 
compuesto que lleva un doble enlace (enófilo) a una olefina que posee un átomo de hidrógeno alílico. Ellos pueden ser térmicamente activados, pero como el enófilo debe ser deficiente de electrones, la complejación con un ácido Lewis aumenta la velocidad de reacción, permitiendo así llevar a cabo la reacción en condiciones más suaves. Por otro lado los ácidos Brønsted también pueden catalizar la reacción a través de la protonación del grupo carbonilo y de un nuevo reordenamiento para formar un carbocatión más estable [17] (Figura 2.8). Debido a que la molécula de citronelal cuenta con un grupo carbonilo eno y un hidrógeno alílico dentro de su misma estructura se dice que la reacción de ciclización es intramolecular carbonil-eno y puede ser catalizada por materiales con propiedades ácidas.

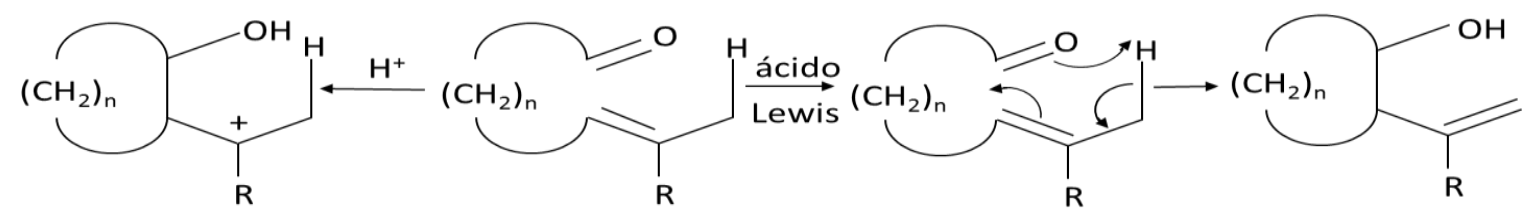

Figura 2.8. Esquema de la reacción eno en presencia de sitios ácidos Lewis y Brønsted.

La revisión de la literatura indica que aún no existe una conclusión concreta acerca del mecanismo por el cual se lleva a cabo la ciclización de citronelal. Varios autores indican que el mecanismo de protonación de citronelal, mediante sitios ácidos Brønsted, promueve una alta actividad catalítica y alta selectividad hacia isopulegol [18,19]. Otros autores tienen la postura de que los sitios ácidos Lewis son los que tienen una mejor función catalítica en la ciclización eno de citronelal [17,20,21]. Otra parte de las investigaciones realizadas en torno a la ciclización de citronelal argumentan que es necesaria una dualidad de sitios ácidos Brønsted y Lewis para llevar a cabo la ciclización de citronelal y que las características de cada tipo de sitio como la densidad y la fuerza tienen un efecto importante en la actividad y la selectividad, respectivamente [22,23].

El mecanismo de protonación en presencia de un catalizador ácido Brønsted se lleva a cabo a través de tres etapas consecutivas (Figura 2.9): protonación del grupo carbonilo del reactivo, reordenamiento intramolecular (ciclización carbonil-eno) para formar un carbocatión más estable y desprotonación para general isopulegol. Este tipo de mecanismos se dice que es por etapas. 


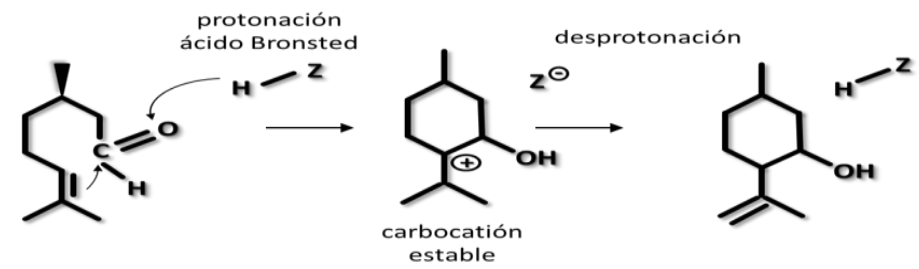

Figura 2.9. Esquema de ciclización de citronelal mediante un sitio ácido Brønsted.

Corma y col. [18] utilizaron zeolitas como catalizadores con acidez Brønsted en la ciclización de citronelal. Los resultados indicaron que la clinoptilolita, mordenita y faujasita son funcionales para la ciclización de citronelal y que la selectividad está en función del tamaño de los canales de la zeolita, ya que en el material con mayor tamaño de canal se presenta la reacción de eterificación de isopulegol. Murzin y col. [19] hicieron un estudio del efecto de la acidez Brønsted en materiales que contienen ambos sitios Lewis y Brønsted (H-MCM41, H-ZSM-5, H-Beta-11, sílice) para la ciclización de citronelal. Sus resultados mostraron que no hay una correlación de la actividad catalítica ni de la selectividad con la concentración de sitios Brønsted. Las diferencias en actividad catalítica de los materiales se la atribuyeron a limitaciones difusionales por el tamaño de los poros de las zeolitas. Contradictoriamente la baja actividad de sílice se la atribuyen a la ausencia de sitios Brønsted, y adicionalmente a la baja concentración de sitios ácidos Lewis. La distribución de productos para todos los materiales fue de 64:27:7:2\% para isopulegol, neo isopulegol, iso isopulegol y neo iso isopulegol, respectivamente. No se observó variación de la relación de isopulegoles con todos los catalizadores empleados, ni tampoco se encontró interconversión entre los estereoisómeros de isopulegol.

El mecanismo de ciclización en presencia de un catalizador ácido Lewis se lleva a cabo mediante una sola etapa de reordenamiento molecular (ciclización carbonil-eno) como lo muestra la Figura 2.8. Este tipo de mecanismo se dice que es concertado [24]. Ravasio y col. [17] emplearon catalizadores de $\mathrm{SiO}_{2}-\mathrm{TiO}_{2}, \mathrm{SiO}_{2}-\mathrm{Al}_{2} \mathrm{O}_{3}$ y $\mathrm{SiO}_{2}-\mathrm{ZrO}_{2}$ en la ciclización eno de citronelal y determinaron que la estereoselectividad hacia el estereoisómero (-)isopulegol se correlaciona con la fuerza de los sitios ácidos Lewis. $\mathrm{Al}^{+3}$ es más fuerte que $\mathrm{Ti}^{+4} \circ \mathrm{Zr}^{+4}$, debido a la formación de una carga efectiva más alta entre dichos cationes y $\mathrm{Si}$ como lo establece la hipótesis de Tanabe [25], y la selectividad hacia (-)-isopulegol fue de 70,62 y $62 \%$, respectivamente. Onaca y col. [20] utilizaron varios materiales mesoporosos de silicio (HMS, MCM-41), meso-alúmina y aluminosilicato (Al-HMS) en la ciclización de (+)citronelal y observaron muy bajo rendimiento para la obtención de (-)-isopulegol y para 
meso-alúmina no hubo actividad. Cuando le agregaron varias sales de zinc a los soportes $\left(\mathrm{ZnCl}_{2}, \mathrm{ZnBr}_{2}, \mathrm{Znl}_{2}, \mathrm{ZnF}_{2}\right)$, la actividad aumentó considerablemente y la selectividad hacia (-)-isopulegol permaneció prácticamente constante con un valor de 86\%. Milone y col. [21] utilizaron sílice comercial para soportar $\mathrm{ZnBr}_{2}$ y reportaron que la sílice es ligeramente activa para la ciclización de (+)-citronelal y la adición de $\mathrm{ZrBr}_{2}$ aumenta la actividad catalítica en un orden de magnitud. La selectividad observada para los materiales de $\mathrm{ZrBr} 2 / \mathrm{SiO}_{2}$ fue de $86 \%$ hacia (-)-isopulegol.

Por otro lado, el mecanismo de ciclización propuesto por Chuah y col. [22] y apoyado por Apesteguia y col. [23] muestra que para la reacción de isomerización-ciclización de citronelal es necesario primero la coordinación de la molécula a través del oxígeno del aldehído y el doble enlace rico en electrones hacia el sitio ácido Lewis. Este atrae al citronelal en una orientación favorable para cerrar el anillo a través de una reacción intramolecular carbonil-eno. En el estado de transición, la protonación del oxígeno ocurre vía el grupo hidroxil Brønsted junto con una sustracción del hidrógeno del grupo isopropil seguido por el cierre del anillo para formal isopulegol y posteriormente la protonación del carbocatión formado siguiendo el mecanismo de ciclización-eno. Para llevar a cabo dicho mecanismo es necesario la presencia de sitios ácidos Lewis fuertes para la adsorción y sitios ácidos Brønsted débiles como donadores de protones (Figura 2.10). De acuerdo a los autores anteriores este tipo de mecanismos se puede llevar a cabo en hidróxido de zirconio, zirconia fosfatada y Al-MCM-41 para obtener altas velocidades de reacción y altas selectividades hacia la mezcla de isopulegol.

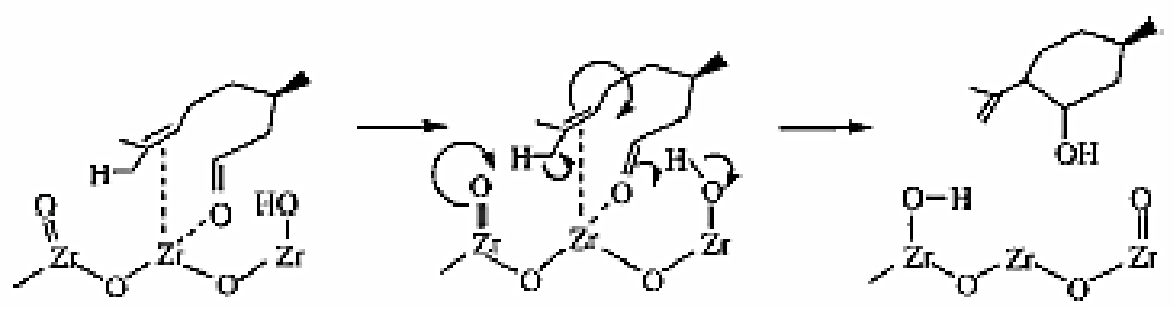

Figura 2.10. Mecanismo de ciclización ene de citronelal donde participan la dualidad de sitios ácidos Lewis y Brønsted [22].

Chuah y col. [22] utilizan catalizadores a base de zirconia y otros materiales ácidos como Amberlist y Nafion para la ciclización de citronelal. El método de preparación utilizado para la zirconia es el de precipitación de cloruro de zirconilo en amonio. Para mejorar las 
propiedades texturales de la zirconia utilizaron un método de digestión de los precursores que consta de varios días a reflujo. Durante la digestión de los precursores a pH 9, la sílice disuelta del recipiente que contiene la mezcla de síntesis, se incorpora a la red de la zirconia y de esta manera obtienen materiales con área superficial estable. De acuerdo con Tanabe y col. [25], la acidez se genera en óxidos binarios debido a un desbalance de carga cuando el componente óxido menor adopta el enlace de la matriz del óxido mayor. La sílice incorporada a la zirconia le otorga una mayor cantidad de sitios ácidos de Lewis. La presencia de sitios ácidos Brønsted en la zirconia tratada a reflujo se debe a los grupos hidroxilos adyacentes a los iones de zirconio descoordinados. Esta supuesta incorporación de la sílice a la matriz de zirconia en los materiales de Chuah y col. [22], le otorga propiedades catalíticas que le permiten aumentar la selectividad hacia isopulegol de $90 \%$ (98\% a $97 \%$ de conversión de citronelal) en comparación con otros materiales (Nafion, Amberlist: $20-76 \%$ de selectividad hacia isopulegoles). Como se puede observar, la incorporación de la sílice a la zirconia no está sistematizada en esta la metodología experimental realizada por Chuah y col., la incorporación de $\mathrm{Si}$ a la red de $\mathrm{ZrO}_{2}$ fue una consecuencia del tratamiento de digestión; además el modelo de acidez de óxidos mixtos de Tanabe no se puede establecer solo con resultados cinéticos, y es preciso utilizar técnicas de caracterización para confirmar estos resultados. En materiales de $\mathrm{ZrO}_{2}-\mathrm{PO}_{4}$ y $\mathrm{ZrO}_{2}-\mathrm{SO}_{4}$, que contienen ambos tipos de sitios Brønsted y Lewis, la actividad aumentó con respecto al material de zirconia. La conversión para estos materiales después de $1 \mathrm{hr}$ de reacción fue mayor a 95\% y la selectividad de isopulegol fue de 99\% para zirconia fosfatada y de $52 \%$ para zirconia sulfatada. La menor selectividad hacia isopulegoles de $\mathrm{ZrO}_{2}-\mathrm{SO}_{4}$ se le atribuye a la fuerza acida muy alta que promueve reacciones de craqueo, eterificación de isopulegol y deshidratación de citronelal.

A manera de resumen, a pesar de los beneficios que implica el empleo de sólidos catalíticos en la producción de mentol y su aplicación industrial, el mecanismo de reacción de ciclización de citronelal, como paso determinante, todavía está en debate. Como ya se mencionó, en el proceso Takasago se utiliza la disolución de un catalizador ácido de Lewis $\left(\mathrm{ZnBr}_{2}\right)$ otorgando alta estereoselectividad hacia (-)-isopulegol [1]. Esto indica que este tipo de sitios ácidos son los que promueven con eficacia la estereoselectividad, sin embargo, en catalizadores heterogéneos existe una hipótesis que indica que una dualidad de sitios ácidos Lewis y Brønsted son los que promueven la ciclización de citronelal con alta estereoselectividad hacia (-)-isopulegol. Cuando se utilizan catalizadores heterogéneos 
ácidos, varios autores proponen que los sitios ácidos de Lewis son los que promueven la reacción de ciclización mediante la coordinación de citronelal en los sitios activos donde se lleva a cabo el mecanismo de ciclización eno de citronelal. Otros autores proponen un mecanismo de reacción en donde solo intervienen sitios ácidos Brønsted y la ciclización se lleva a cabo mediante la protonación del grupo carbonilo de citronelal, después el cual forma el carbocatión estable vía re-arreglo intramolecular, y como última etapa se lleva a cabo la desprotonación para la formación de isopulegoles. Otros autores argumentan que una dualidad de sitios ácidos Lewis y Brønsted son los que intervienen en el mecanismo de reacción y que la fuerza y densidad de estos sitios son los que otorgan mejoras en la selectividad hacia isopulegol a partir de citronelal.

La mayoría de los autores mencionados anteriormente concluyen que existe un debate sobre las especies ácidas superficiales que intervienen en la reacción de ciclización de citronelal. Sin embargo, el uso de una gran gamma de catalizadores, con diferentes propiedades acidas, hace difícil el esclarecimiento de los fenómenos involucrados en la reacción de ciclización; y en la mayoría de los casos se dispersan los argumentos que mejor se adecuan a la representación del mecanismo de ciclización de citronelal.

\subsection{Síntesis de mentol en una sola etapa}

Existen escasos estudios acerca de la obtención de mentol a partir de citronelal [26-29] y a partir de citral en una sola etapa [21,28,29]. Específicamente Apesteguía y col. [23,30], Murzin y col. [31] han utilizado materiales catalíticos tales como: Pt, Pd, Ir, Ni, Co, Cu soportados en $\mathrm{ZnO} / \mathrm{SiO}_{2}, \mathrm{CsHPA}, \mathrm{SiO}_{2}-\mathrm{Al}_{2} \mathrm{O}_{3}, \mathrm{Al}-\mathrm{MCM}-41, \mathrm{H}-\mathrm{Y}$ logrando una alta actividad catalítica y alta selectividad hacia la mezcla de $( \pm)$-mentol.

En los reportes de obtención de mentol a partir de citronelal, el objetivo fue evaluar diferentes sistemas catalíticos y mostrar cual presenta la mayor selectividad hacia (-)isopulegol en la reacción de ciclización de citronelal, de acuerdo a las propiedades de los sólidos catalíticos. Tal es el caso de Galvagno y col. [29] que utilizan un catalizador de $\mathrm{Ru} / \mathrm{ZnBr}_{2} / \mathrm{SiO}_{2}$ con un porcentaje de $10-15 \%$ en peso de $\mathrm{ZnBr}_{2}$. Los resultados que reportan son de rendimientos $>85 \%$ de (-)-mentol y determinan que la elevada estereoselectividad de (-)-isopulegol se debe al pre-tratamiento de los catalizadores, que permite una pérdida de sitios ácidos Brønsted que no son selectivos a la formación de (-)-isopulegol. 
Chuah y col. [26] reportan resultados de la obtención de mentol a partir de citronelal con catalizadores de $\mathrm{Ni}$, Cu y Rh soportados en Zr-Beta y MCM-41, donde una variable importante es la variación de la cantidad de $\mathrm{Ni}$. De los resultados se puede observar que existe una pérdida de actividad en la ciclización de citronelal por el aumento en la cantidad de $\mathrm{Ni}$, atribuyendo esta consecuencia al bloqueo parcial de sitios ácidos por el metal activo. En este artículo no se presentan resultados de caracterización que correlacionen los resultados cinéticos con la fuerza y la naturaleza de los sitios ácidos.

Murzin y col. [31] utilizaron catalizadores de Pd, Ir, Ru y Ni soportados en H-MCM-41 y zeolita $\mathrm{H}-Y$ para la obtención de mentol a partir de citral en una sola etapa en fase líquida. Los resultados muestran una selectividad hacia mentoles de $44 \%$ a $80 \%$ de conversión con el catalizador Pd-H-MCM-41; el catalizador de Ni-H-MCM-41 muestra una selectividad de $54 \%$ a altas conversiones y en ambos catalizadores se observa una considerable producción de compuestos no deseados provenientes de la reacción de hidrogenólisis. Los catalizadores soportados en zeolita $\mathrm{H}-\mathrm{Y}$ no fueron selectivos hacia mentol.

Apesteguía y col. [23] presentan resultados favorables para la síntesis de mentol a partir de citral utilizando Ni como metal activo soportado en Al-MCM-41 con selectividad hacia los enantiomeros ( \pm )-mentol de $70 \%$ con rendimiento hacia mentoles mayor a $90 \%$. Al igual que Chuah y col. [31], Apesteguía y col. muestran que una dualidad de sitios ácidos Lewis fuertes y sitios Brønsted débiles (determinados por adsorción de piridina) promueven la ciclización de citronelal con alta selectividad hacia isopulegoles.

En los grupos de investigación de Apesteguia y col. y Chuah y col. se muestra la importancia de la obtención de los enantiómeros de mentol, pero específicamente no caracterizan la cantidad de (-)-mentol producida. Es importante saber la selectividad de (-)-mentol, ya que las variables como la cantidad de metal activo, tipo de soporte y fuerza y naturaleza de los sitios ácidos puede modificar su selectividad y por ello es importante cuantificarla.

De lo anterior se concluye que se pueden obtener catalizadores bifuncionales que lleven a la obtención de mentol a partir de citral en una sola etapa, con materiales que presenten una dualidad de sitios ácidos Lewis/Brønsted dispersando las fases activas involucradas, tomando en cuenta las propiedades de los sitios ácidos superficiales tales como la densidad, fuerza y naturaleza. También se puede concluir que las propiedades catalíticas 
del óxido de circonio promovidos con iones sulfato o fosfato presenta ser una buena opción para lograr los objetivos propuestos más adelante.

\subsection{Zirconia sulfatada en reacciones de isomerización-ciclización}

Existen diversos factores que determinan las propiedades catalíticas del óxido de circonio o zirconia como catalizador. Uno de esos factores es la baja área superficial específica de $\mathrm{ZrO}_{2}$, obtenida por diferentes métodos de preparación, que ha limitado su uso como catalizador a nivel industrial para reacciones que demandan alta área superficial específica y alta dispersión de la fase activa con propiedades estructurales, texturales y mecánicas específicas. Dentro de esos factores se debe tomar en cuenta la fase cristalina del óxido de circonio. El óxido de circonio puede presentar diferentes fases cristalinas tales como monoclínica, tetragonal y cúbica, dependiendo de factores como el método de preparación, $\mathrm{pH}$ y temperatura de síntesis. Se ha determinado por métodos experimentales [32-34] y teóricos por DFT [35] que la fase tetragonal de $\mathrm{ZrO}_{2}$ es la fase cristalina más activa catalíticamente cuando se promueve con iones sulfato. La adición de dopantes, como los iones sulfato, a la red cristalina de los soportes catalíticos como $\mathrm{TiO}_{2}, \mathrm{Fe}_{2} \mathrm{O}_{3}$ y $\mathrm{ZrO}_{2}$ les brinda una mayor estabilidad térmica, una mayor área superficial y una mejor dispersión de los sitios ácidos generados [36], siendo la inhibición del sinterizado el argumento en que se basa la mejora de las propiedades mencionadas por la adición de dopantes [37].

De acuerdo con Tanabe y col. [36], una estructura tipo II, la cual es la responsable de la generación de acidez fuerte, se identifica como un complejo sulfato que tiene dos dobles enlaces covalentes SO enlazado al catión metálico. La generación de sitios ácidos en la zirconia sulfatada se explica en términos de la tendencia a perder el carácter del doble enlace del ion sulfato coordinado, o dicho de otra manera, por la disminución del orden de enlace de SO por un cambio electrónico de una molécula básica adsorbida al complejo sulfato. Ko y col. [37] argumentan que el mecanismo de generación de sitios ácidos relaciona a las especies $\mathrm{SO}_{4}^{-2}$ con el carácter de doble enlace cercano al catión, que crea una región de densidad electrónica baja, induciendo a un grupo hidroxilo cercano a comportarse como un sitio acido de Brønsted.

Tanabe y col. [36] concluye que los óxidos metálicos tienen una acidez fuerte por la promoción de iones sulfato en sistemas catalíticos de $\mathrm{ZrO}_{2}, \mathrm{TiO}_{2}$ y $\mathrm{Fe}_{2} \mathrm{O}_{3}$ y el número de 
sitios ácidos obtenidos puede ser limitado por el área superficial de los óxidos, donde se tiene que considerar una reconstrucción de las especies activas en un soporte de alta área superficial específica.

Mediante el método de preparación de sol-gel se puede sintetizar zirconia sulfatada con alto grado de mezclado, formándose los denominados heteroenlaces M-O-M' que le otorgan propiedades óptimas a los sólidos y que pueden ser influenciadas y modificadas por la manipulación de los parámetros de síntesis. Los factores que deben ser considerados, como ya se mencionó anteriormente, son las propiedades estructurales-superficiales y las propiedades catalíticas de la zirconia. Son muy diversas las modificaciones que se han realizado en la síntesis de $\mathrm{ZrO}_{2}$ por el método de sol-gel, siendo las más determinantes la relación agua/alcóxido, tipo de catalizador de hidrólisis y condensación, temperatura y pH de síntesis, naturaleza de los alcóxidos y solvente [37,39,40]. Por otro lado el tratamiento pot-síntesis también demuestra ser determinante, desde el tiempo de añejamiento, pasando por la temperatura de secado y finalizando en la temperatura de calcinación y el ambiente en el cual ocurre esta [37]. Estas variables pueden ser modificadas dependiendo de las exigencias que se tengan para dicho material, tomando en consideración la distribución de tamaño de poro, área superficial, estructura cristalina, tipo y densidad de sitios ácidos generados.

Por otro lado existe la necesidad de acidez Brønsted para llevar a cabo la protonación en el mecanismo de ciclización-eno, por ello se han utilizado materiales catalíticos en donde se añade un promotor de acidez como son los fosfatos y los sulfatos que permiten aumentar la densidad y la fuerza de los sitios ácidos superficiales [22]. Comúnmente se han utilizado materiales sulfatados o fosfatados en reacciones de isomerización de olefinas en fase gas, en donde se ha utilizado el método de impregnación como el método de adición de los promotores de acidez. En reacciones en fase líquida se tiene la incertidumbre de que estos promotores, en lugar de formar parte de la matriz del soporte, se encuentren disueltos en el medio de reacción cumpliendo su función de donador de protones, pero sin ser realmente parte de un material catalítico heterogéneo [38]. Pero existen varias investigaciones en donde utilizan materiales como zirconias sulfatadas y fosfatadas en reacciones de isomerización de citronelal, reacciones de condensación aldólica y reacciones de transesterificación de triglicéridos sin presentar perdida de actividad con materiales 
reutilizados y de lo cual se puede decir que no existe disolución de las especies promotoras de acidez [39].

Akkari y col. [40] sintetizaron catalizadores de $\mathrm{SiO}_{2}-\mathrm{ZrO}_{2}-\mathrm{SO}_{4}$ variando la relación $\mathrm{Zr} / \mathrm{S}$ y muestran que esta variación tiene repercusión en las propiedades físico-químicas de los sólidos catalíticos. La sulfatación la llevaron a cabo en una sola etapa mediante el proceso sol-gel, es decir, utilizaron $\mathrm{H}_{2} \mathrm{SO}_{4}$ como agente sulfatante y como catalizador de hidrólisis y condensación, variando la relación $\mathrm{S} / \mathrm{Zr}$ de 0 a 1.2. Los resultados muestran que existe una distribución bimodal del diámetro de poro (3.5 y $10 \mathrm{~nm}$ ) para materiales con una relación de $\mathrm{S} / \mathrm{Zr}<0.4$ y la disminución de la cantidad de sulfatos en estas relaciones se atribuye a que los iones sulfato participan de manera importante en el proceso de hidrólisis y condensación del sol-gel. Para las relaciones de S/Zr mayores a 0.6, la distribución de tamaño de poro es unimodal y estrecha, sin embargo, el área superficial específica disminuye considerablemente, comparado con el área superficial de las relaciones de S/Zr menores a 0.4. Con respecto a la acidez, el aumento en la cantidad de sulfatos le otorga una mayor fuerza a los sitios ácidos Brønsted de los sólidos, sin embargo se observa que en el aumento de la temperatura a $200^{\circ} \mathrm{C}$ en la desorción de piridina se pierden estos sitios superficiales para bajas relaciones de S/Zr. La relación de S/Zr de 0.5 la presentan como la óptima para conservar las propiedades de alta área superficial específica, acidez Brønsted, porosidad regular, tamaño nanocristalino de zirconia sulfatada. Con respecto a los modelos teóricos y experimentales presentados para la estructura de zirconia sulfatada, se observa que en la relación de 0.5 se conserva el modelo propuesto por la mayoría de los investigadores para la ciclización de citronelal.

Por otro lado existe poca evidencia experimental acerca del efecto de la adición de un metal en sólidos de zirconia sulfatada. Comúnmente en la reacción de una sola etapa para la producción de mentol a partir de citral, la densidad, fuerza y tipo de sitios se determina para el material ácido sin la presencia del catalizador promotor de la hidrogenación. Gómez y col. [41] reportan que la adición de Ni en zirconia sulfatada tiene un efecto desfavorable en la fuerza ácida para la reacción de oligomerización de isobuteno. Ebitani y col. [42] obtuvieron el espectro de piridina adsorbida en $\mathrm{Pt} / \mathrm{ZrO}_{2}, \mathrm{ZrO}_{2}-\mathrm{SO}_{4}$ y $\mathrm{Pt} / \mathrm{ZrO}_{2}-\mathrm{SO}_{4}$ y este indica que los sitios ácidos superficiales de los catalizadores de Pt en estado metálico son de naturaleza Lewis y que el material de $\mathrm{ZrO}_{2}-\mathrm{SO}_{4}$ presenta sitios Brønsted. Estos autores 
concluyen, mediante los perfiles de desorción, que el catalizador de $\mathrm{Pt} / \mathrm{ZrO}_{2}-\mathrm{SO}_{4}$ presenta una acidez más fuerte que los demás catalizadores.

\subsection{El rol de las mezclas mecánicas de catalizadores}

Las propiedades catalíticas de los materiales permiten llevar a cabo de manera eficiente la conversión de ciertos componentes hacia una ruta específica, pero cuando la reacción requiere varias funcionalidades de los catalizadores, las propiedades de un material en ciertas ocasiones no son suficientes, por tal motivo se requiere modificar a los catalizadores con la adición de componentes que mejoren sus propiedades en un mismo material. La adición de componentes que funcionan como promotores no siempre resulta en un beneficio para las propiedades físico-químicas de un catalizador. Por ese motivo se crean distintos materiales con propiedades distintas para llevar a cabo una reacción que requiere de varias funciones catalíticas y se mezclan en el mismo sistema de reacción, con el objetivo de crear un efecto concertado que permita llevar a la reacción hacia una ruta específica. Estos materiales se conocen como mezclas mecánicas. Tal es el caso de la mezcla de carbón activado $+\mathrm{V}_{2} \mathrm{O}_{5}-\mathrm{TiO}_{2}$ que se utiliza para destruir dibenzo-p-dioxinas y dibenzofuranos policlorinados en fase gas. La adición de carbón activado mejora la actividad catalítica, aunque la variación de la relación entre los materiales tiene un ligero efecto [43]. En el caso de la síntesis de dimetil eter a partir de metanol, la adición de $\mathrm{AlF}_{3}$ a la zeolita HZSM-5, como mezcla mecánica, le permite aumentar su desempeño catalítico y la estabilidad. En la metanación de $\mathrm{CO}_{2}$, se conoce que el catalizador de $\mathrm{Pd} / \mathrm{Al}_{2} \mathrm{O}_{3}$ es un inerte a condiciones medias, pero la adición en una mezcla mecánica con $\mathrm{Rh} / \mathrm{Al}_{2} \mathrm{O}_{3}$ mejora notablemente la actividad en comparación con el material solo de $\mathrm{Rh} / \mathrm{Al}_{2} \mathrm{O}_{3}$ [44]. Para la hidrogenólisis de celulosa para producir sorbitol, el catalizador bifuncional de $\mathrm{Ru} / \mathrm{SiO}_{2}-\mathrm{SO}_{3} \mathrm{H}$ es más selectivo que la mezcla mecánica de $\mathrm{Ru} / \mathrm{SiO}_{2}+\mathrm{SiO}_{2}-\mathrm{SO}_{3} \mathrm{H}$. En el caso de la obtención de mentol a partir de citral con mezclas mecánicas de distintos catalizadores, solo se tiene conocimiento de un solo artículo publicado por Chuah y col. [26], el cual combina en una mezcla la funcionalidad acida de Zr-beta y la funcionalidad hidrogenante y ácida de Ni/MCM-41. Además utilizan un catalizador bifuncional de Ni/Zr-beta, el cual muestra una mayor actividad y selectividad que la mezcla mecánica. Los resultados sólo están en torno a la selectividad y no se cuenta con algún indicio que permita determinar cuáles son las propiedades específicas de los sistemas catalíticos que llevan a cabo de manera eficiente la obtención de mentol a partir de citral. 


\section{OBJETIVOS}

\subsection{Justificación de la investigación y Planteamiento de la hipótesis}

La motivación que se tiene en la presente investigación es: observar, analizar y determinar qué efectos tiene un sistema catalítico como la zirconia, cuando se le agrega cierta cantidad de sulfatos, en las reacciones de ciclización de citronelal y obtención de mentol a partir de citronelal y citral, además de contribuir al esclarecimiento de la controversia que existe acerca de la participación que tiene el tipo, la fuerza y la densidad de sitios ácidos Lewis y Brønsted en las reacciones ya mencionadas".

Como planteamiento del problema, de acuerdo a la revisión bibliográfica, se establece lo siguiente:

a) En la síntesis de mentol en una sola etapa a partir ya sea de citral o de citronelal, el paso limitante para obtener altas selectividades de mentol es la etapa de ciclización de citronelal. En este aspecto las propiedades de acidez de los materiales catalíticos juega un papel preponderante para la obtención de altos rendimientos hacia el estereoisómero deseado de isopulegol. Los materiales hasta ahora propuestos cuentan con diversas características ya sea por el tipo de acidez superficial, fuerza y densidad de sitios ácidos y no se ha establecido con claridad cuál es la contribución de cada una de las propiedades ácidas en la actividad catalítica.

b) Hasta ahora el método de preparación de catalizadores, el tipo de cationes utilizados en los óxidos metálicos, el tipo de iones utilizados como promotores de acidez, entre otras variables, le otorgan a los sólidos catalíticos características intrínsecas para llevar a cabo la reacción de ciclización de citronelal; no se ha propuesto un catalizador que mediante una metodología establecida como método de preparación se pueda modificar el tipo, la fuerza y la densidad de sitios para estudiar cual es el efecto de este material en la actividad catalítica y la selectividad en la reacción de ciclización de citronelal.

c) Con respecto a la selectividad, la reactividad de las insaturaciones de las moléculas de citral y citronelal hacen que sean muy sensibles a ciertas especificidades de los materiales catalíticos y por lo tanto pueden derivar múltiples componentes como 
productos no deseados cuando se tiene una ruta de reacción específica y más cuando se trata de reacciones en serie en una sola etapa.

De acuerdo al planteamiento del problema se plantean las siguientes preguntas de investigación científica:

a) ¿Es posible determinar cuáles son las propiedades ácidas específicas de los materiales catalíticos que pueden llevar a obtener altas selectividades de isopulegol en la reacción de ciclización de citronelal?

b) ¿Se puede desarrollar una metodología para obtener un material que pueda ser modificado en sus propiedades catalíticas mediante la variación de los parámetros de síntesis?

c) ¿Es posible establecer bajo qué condiciones de pre-tratamientos de los materiales y bajo qué condiciones de reacción se puede minimizar la formación de compuestos no deseados en la obtención de mentol a partir de citral o citronelal en una sola etapa?

Las preguntas deben responderse a partir de un estudio experimental, que permita valorar de forma directa los efectos que genere la modificación de ciertas variables de síntesis en las propiedades de los materiales catalíticos, con la finalidad de obtener altas selectividades en cada una de las reacciones planteadas, la ciclización de citronelal y la obtención de mentol a partir de citronelal y citral.

De acuerdo a todo lo dicho anteriormente, se propone evaluar el efecto que tiene la cantidad de sulfatos en las propiedades catalíticas ácidas de la zirconia sulfatada y evaluar el efecto que tienen dichas propiedades en la actividad catalítica evaluada en las reacciones de ciclización de citronelal y la obtención de mentol a partir de citronelal y citral. Siendo la cantidad de sulfatos la variable a modificar en la zirconia sulfatada, se plantea la síntesis de zirconia sulfatada mediante el método sol-gel utilizando $\mathrm{H}_{2} \mathrm{SO}_{4}$ como catalizador de hidrólisis y como agente sulfatante. Además se plantea la adición de Ni en los materiales catalíticos ya sea por impregnación o por adición in situ desde la síntesis sol-gel para llevar a cabo la obtención de mentol en una sola etapa y se plantea evaluar el efecto de la adición de Ni en las propiedades ácidas de la zirconia sulfatada. 


\section{Hipótesis:}

El método sol-gel permite modificar la relación molar S/Zr desde la síntesis para obtener diferentes propiedades ácidas de la zirconia sulfatada. Las propiedades ácidas de la zirconia sulfatada se pueden modificar de tal manera que se puede evaluar el efecto que tiene el tipo de sitio ácido, la fuerza y la densidad de sitios en la reacción de ciclización de citronelal y los distintos tipos de selectividad de isopulegol (selectividad, estereoselectividad y enantioselectividad). La adición de $\mathrm{Ni}$ a la zirconia sulfatada, sintetizada por el método sol-gel, permite llevar a cabo la obtención de mentol a partir de citronelal y citral en una sola etapa con altas conversiones y altos rendimientos hacia la mezcla de mentoles.

\section{Propuesta de investigación científica:}

El tema de investigación sustenta su importancia en el análisis de los efectos del tipo, densidad y fuerza de los sitios ácidos presentes en los materiales catalíticos sobre las constantes cinéticas de reacción de hidrogenación e isomerización-ciclización, logrando este propósito mediante la caracterización físico-química y catalítica de los materiales propuestos.

La caracterización de los sólidos catalíticos permitirá establecer que tipos de sitios de hidrogenación e isomerización-ciclización son los que influyen en la selectividad y la actividad catalítica, logrando así determinar las especies superficiales presentes y que llevan a cabo de manera eficaz las reacciones pertinentes y aportar luces congruentes sin caer en las controversias presentadas hasta hoy en día, que fueron presentadas en la revisión bibliográfica. 


\subsection{Objetivo general y objetivos particulares}

\section{Objetivo General}

Determinar el efecto de la relación molar S/Zr de la zirconia sulfatada en la ciclización de citronelal y en la obtención de mentol a partir de citronelal y citral.

\section{Objetivos Particulares}

a) Obtener materiales de zirconia sulfatada por el método sol-gel con distintas propiedades acidas superficiales variando la relación $\mathrm{S} / \mathrm{Zr}$ y evaluar el efecto que tiene la cantidad de sulfatos en las propiedades físico-químicas.

b) Evaluar las propiedades catalíticas de la zirconia sulfatada con distinta relación molar $\mathrm{S} / \mathrm{Zr}$, tales como el tipo, la fuerza y la densidad de sitios ácidos en la reacción de ciclización de citronelal.

c) Evaluar el efecto de la adición de $\mathrm{Ni}$, a los sistemas catalíticos donde intervienen las propiedades de la zirconia sulfatada, en la actividad catalítica en la reacción de ciclización de $( \pm)$-citronelal, obtención de mentol a partir de ( \pm )-citronelal y en la obtención de mentol a partir de citral.

d) Evaluar la actividad catalítica de sistemas catalíticos de distintas proporciones de mezclas mecánicas de $\mathrm{Ni} / \mathrm{SiO}_{2}$-zirconia sulfatada para la obtención de mentol a partir de citral en una sola etapa y establecer cuál es el balance adecuado de la relación de la mezcla mecánica para obtener alto rendimiento y selectividad de mentol.

e) Determinar, mediante un modelo cinético que describa adecuadamente la obtención de mentol a partir de citronelal y citral, los parámetros cinéticos y analizar el efecto de la proporción de la mezcla mecánica sobre las distintas reacciones involucradas en la obtención de mentol a partir de citral 


\section{METODOLOGÍA EXPERIMENTAL}

A lo largo de este capítulo se describirá la metodología para la síntesis de los materiales propuestos y las variables importantes a modificar, para obtener los sólidos catalíticos con las características necesarias para nuestro estudio. Además se describirán las técnicas de caracterización útiles para interpretar y relacionar los resultados cinéticos con las propiedades físico-químicas de los catalizadores.

\subsection{Preparación de zirconia sulfatada por el método sol-gel}

Se preparó zirconia sulfatada por el método sol gel mediante la hidrólisis y condensación de isopropóxido de zirconio (Aldrich), utilizando ácido sulfúrico (J. T. Baker) como catalizador de la etapa de hidrólisis y como agente sulfatante. El solvente utilizado fue 2propanol (J.T. Baker). Los componentes de síntesis cumplieron las siguientes relaciones molares: alcohol/alcóxido $=10, \mathrm{H}_{2} \mathrm{O}$ /alcóxido=8, y la relación ácido/alcóxido varió en las siguientes proporciones $\mathrm{S} / \mathrm{Zr}=0.1,0.2,0.5$ ( $\mathrm{ZrS} 1, \mathrm{ZrS2}$ y $\mathrm{ZrS3}$, respectivamente). El procedimiento de síntesis fue el siguiente de acuerdo al método de Ardizzone y col. [45]:

En un matraz de bola se agregó una cantidad de $60 \%$ del alcohol total calculado. Se añadió la cantidad específica de isopropóxido de zirconio manteniendo la mezcla en agitación vigorosa mediante un agitador magnético. El ácido sulfúrico se goteó en un periodo de tiempo de 15 minutos y posteriormente se mantuvo en agitación toda la mezcla por otros 30 minutos. El otro $40 \%$ de alcohol se mezcló con la cantidad determinada de agua desionizada y se goteó a la mezcla a una velocidad de 1 gota/segundo hasta la obtención del gel y después permaneció en añejamiento por 24 horas. El material se dejó secando a $100^{\circ} \mathrm{C}$ del cual se logró un polvo fino. Los materiales secos se sometieron a un proceso de calcinación a $450^{\circ} \mathrm{C}$ por 4 horas en una mufla con aire estático.

Los materiales fueron etiquetados como ZrS1, ZrS2 y ZrS3 correspondiendo el número a la relación molar $S / Z r$ de $0.1,0.22$ y 0.5, respectivamente.

Como referencia se sintetizó zirconia pura por el mismo procedimiento anteriormente descrito pero utilizando ácido nítrico (J. T. Baker) como catalizador de la etapa de hidrólisis. La temperatura de calcinación fue de $450^{\circ} \mathrm{C}$ por 4 horas en una mufla con aire estático. Este material se etiqueto como $\mathrm{ZrO}_{2}$. 


\subsection{Preparación de Ni-zirconia sulfatada por el método sol-gel}

De manera similar a la síntesis de la zirconia sulfatada ZrS2, se sintetizó con el mismo procedimiento el material de Ni-zirconia sulfatada. La variación con respecto al procedimiento anterior consistió en agregar in situ la cantidad necesaria de $\mathrm{Ni}\left(\mathrm{NO}_{3}\right)_{2} \cdot 6 \mathrm{H}_{2} \mathrm{O}$, para que el contenido fuera de $3 \%$ en peso de $\mathrm{Ni}$, previo a la adición del ácido sulfúrico. El proceso de secado también se llevó a cabo a $100^{\circ} \mathrm{C}$ y la calcinación se efectuó a $450^{\circ} \mathrm{C}$ por 4 horas en una mufla con aire estático. El material fue etiquetado como NiZrS2.

\subsection{Preparación de los catalizadores soportados}

Los catalizadores de Ni soportados sobre zirconia sulfatada y $\mathrm{SiO}_{2}$ gel $7\left(\mathrm{SiO}_{2}\right.$, J. T. Baker, área superficial específica $\mathrm{Sg}=640 \mathrm{~m}^{2} / \mathrm{g}$ ) se prepararon por la técnica de impregnación por mojado incipiente utilizando una solución de $\mathrm{Ni}\left(\mathrm{NO}_{3}\right)_{2} \cdot 6 \mathrm{H}_{2} \mathrm{O}$ para soportar un contenido nominal de $3 \%$ en peso de Ni. Los sólidos se dejaron reposar después de la impregnación por 24 horas para luego someterlos a calcinación de $450^{\circ} \mathrm{C}$ en zirconia sulfatada y $500^{\circ} \mathrm{C}$ en $\mathrm{SiO}_{2}$. Los materiales fueron etiquetados como $\mathrm{Ni} / \mathrm{ZrS} 2$ y NiO/SiO${ }_{2}$.

\subsection{Métodos de caracterización fisicoquímica de los catalizadores}

\subsubsection{Análisis termogravimétrico (ATG) y térmico diferencial (ATD)}

Los materiales post-síntesis (precursores de zirconia sulfatada y Ni-zirconia sulfatada) se caracterizaron por análisis termogravimétrico (ATG) y por análisis térmico diferencial (ATD) para observar el perfil térmico del proceso de calcinación. El estudio se llevó a cabo en un equipo de análisis térmico simultáneo STA 409 EP NETSZCH con un tamaño de muestra de $100 \mathrm{mg}$ en aire estático, a una velocidad de calentamiento de $10{ }^{\circ} \mathrm{C} / \mathrm{min}$ desde temperatura ambiente hasta $1000^{\circ} \mathrm{C}$. Esta técnica de caracterización permite observar la pérdida de peso de los materiales por la eliminación de agua y otros componentes de síntesis, así como la combustión de componentes orgánicos, la deshidroxilación de la superficie para formar el respectivo óxido de zirconio o la posible eliminación de sulfatos. Además se puede analizar la transformación cristalina del sólido con respecto al aumento de temperatura. 


\subsubsection{Propiedades texturales. Fisisorción de nitrógeno}

La porosidad, área superficial específica y diámetro promedio de poro para los materiales ZrS1, ZrS2, ZrS3 y NiZrS2 calcinados a $450^{\circ} \mathrm{C}$ se determinaron en un equipo Autosorb IQ (Quantachrome Instruments), mediante la obtención de las isotermas de adsorcióndesorción de $\mathrm{N}_{2}$ a la temperatura de nitrógeno líquido. Con esta información se determinó la influencia de los parámetros de síntesis en las propiedades físicas de los materiales, específicamente en la porosidad.

\subsubsection{Estructura cristalina. Difracción de rayos $X$ (DRX)}

La estructura cristalina de los materiales ZrS1, ZrS2, ZrS3 y NiZrS2 calcinados a $450^{\circ} \mathrm{C}$ se analizó por difracción de rayos $X$ de polvos, en un equipo Siemens D-500 con radiación de CuKa y un monocromador de grafito en el haz difractado. Las muestras se prepararon empaquetando el polvo en un soporte de vidrio. La intensidad se midió en un intervalo $2 \theta$ de $10^{\circ}$ y $100^{\circ}$ con un paso de $0.03^{\circ}$ para observar las fases cristalinas existentes después de calcinación y observar el efecto del contenido de sulfatos en los materiales.

\subsubsection{Termodesorción de piridina y espectroscopia de infrarrojo (FTIR-Py)}

Para determinar el tipo, la fuerza y la cantidad de sitios ácidos en la superficie de los materiales catalíticos $\mathrm{ZrS} 1, \mathrm{ZrS} 2, \mathrm{ZrS} 3, \mathrm{NiO} / \mathrm{SiO}_{2}, \mathrm{Ni} / \mathrm{ZrS} 2$ y $\mathrm{NiZrS2}$, se utilizó la espectroscopia de infrarrojo por transformada de Fourier (FTIR por sus siglas en inglés) en la adsorción-desorción de piridina (Py). El espectro de absorción de Py se obtuvo a diferentes temperaturas y se llevó a cabo en un espectrofotómetro NICOLET 560 Magna. Las muestras calcinadas a $450^{\circ} \mathrm{C}$ se comprimieron para formar pastillas de peso entre 15 y $20 \mathrm{mg}$ y fueron colocadas en un porta-muestras de vidrio para posteriormente montarlas en una celda de vidrio con ventanas de $\mathrm{CaF}_{2}$. Se realizó un pre-tratamiento a $400{ }^{\circ} \mathrm{C}$ a vacío para eliminar humedad. La piridina se adsorbió a $100^{\circ} \mathrm{C}$ y el exceso de piridina se eliminó mediante vacío. Una vez realizado lo anterior se procedió a hacer el barrido en la región de infrarrojo y observar las bandas en los números de onda característicos de la piridina adsorbida en sitios Lewis $\left(1450 \mathrm{~cm}^{-1}\right)$, sitios Brønsted $\left(1545 \mathrm{~cm}^{-1}\right)$ y Brønsted + Lewis (1490 $\left.\mathrm{cm}^{-1}\right)$. Los espectros se obtuvieron a $50,100,200,300$ y $400{ }^{\circ} \mathrm{C}$. 


\subsubsection{Cantidad de Ni. Absorción atómica (AA)}

La cantidad de níquel soportada en los materiales $\mathrm{NiO} / \mathrm{SiO} 2, \mathrm{Ni} / \mathrm{ZrS} 2$ y NiZrS2 se cuantificó mediante absorción atómica en un equipo SpectrAA 220 FS VARIAN. Los patrones utilizados para la curva de calibración fueron de 2100, 120 y 180 ppm de Ni. Previo al análisis, las muestras se sometieron a digestión en agua regia con una proporción en volumen de $\mathrm{HNO}_{3}$ y $\mathrm{HCl}$ de 50:50. Se agregaron $100 \mathrm{mg}$ de muestra en $100 \mathrm{ml}$ de agua regia y se sometió a calentamiento con agitación para evaporar la mezcla hasta la mitad del volumen. La disolución se filtró y se aforó en $100 \mathrm{ml}$ de agua desionizada.

\subsubsection{Cantidad de sitios activos hidrogenantes. Quimisorción de hidrógeno $\left(\mathrm{Q}-\mathrm{H}_{2}\right)$}

Para determinar la capacidad de quimisorción de $\mathrm{H}_{2}$ de los catalizadores de Ni/ZrS2 y $\mathrm{NiO} / \mathrm{SiO}_{2}$ se utilizó un método volumétrico de adsorción de $\mathrm{H}_{2}$ a diferentes presiones parciales para obtener las isotermas de $\mathrm{H}_{2}$ reversible, irreversible y total, determinando la cantidad de hidrógeno quimisorbido en la monocapa mediante la extrapolación a presión parcial cero de la isoterma irreversible. La quimisorción se llevó a cabo en un equipo Autosorb IQ de Quantrachrom a $100{ }^{\circ} \mathrm{C}$. Los materiales de $\mathrm{Ni} / \mathrm{ZrS} 2$ y NiO/SiO 2 se pretrataron in situ en flujo de $\mathrm{He}$ a $200{ }^{\circ} \mathrm{C}$ por $2 \mathrm{hrs}$ a vacío a fin de limpiar la superficie, después se disminuyó la temperatura a $100^{\circ} \mathrm{C}$ y se pasó un flujo de $\mathrm{H}_{2}$ por $1 \mathrm{hr}$ para después hacer una evacuación por $1 \mathrm{hr}$. Una vez pretratados los materiales, se comienza el análisis de quimisorción a diferentes presiones parciales de $\mathrm{H}_{2}$ y así determinar el número de sitios catalíticos con capacidad de quimisorción de $\mathrm{H}_{2}$ a $100{ }^{\circ} \mathrm{C}$ utilizando una relación $\mathrm{H} /$ sitio catalítico=1. Para normalizar los resultados se utilizaron los valores de la cantidad de $\mathrm{Ni}$ determinados por AA.

\subsection{Métodos de caracterización catalítica}

\subsubsection{Ciclización de citronelal}

La ciclización de citronelal (CAL) se realizó para hacer la evaluación catalítica de los sitios ácidos de los materiales a base de zirconia sulfatada ZrS1, ZrS2, ZrS3, NiZrS2. Por medio de esta prueba es posible evaluar el efecto de la cantidad, fuerza y tipo de sitios ácidos en la conversión de CAL y la distribución de productos. 
Las pruebas de actividad catalítica para la ciclización de citronelal se realizaron en un matraz de bola acoplado a un sistema de reflujo. Se adicionó una solución de citronelalciclohexano ( $2 \mathrm{ml}$ de CAL, $20 \mathrm{ml}$ ciclohexano CHEX) al matraz y el sistema se sometió a calentamiento hasta la temperatura de reflujo de ciclohexano y con agitación. Una vez alcanzada la temperatura de reflujo se adicionaron $50 \mathrm{mg}$ de catalizador previamente tratado en flujo de helio para eliminar humedad.

Pequeñas cantidades de los productos de reacción fueron retiradas regularmente y analizadas en un cromatógrafo de gases Agilent $6890 \mathrm{~N}$ acoplado a un espectrómetro de masas 5973Netowork, usando una columna capilar HP-5MS. Las muestras fueron identificadas comparando los espectros de masas de las muestras de reacción con los espectros de masas de la base de datos Wiley7n de MSD ChemStation.

La conversión de citronelal ( $\left.\mathrm{X}_{\mathrm{CAL}}\right)$ se determinó de la siguiente manera:

$$
X_{C A L}=\frac{\left(C_{C A L}^{0}-C_{C A L}^{t}\right)}{C_{C A L}^{0}}
$$

$C_{C A L}^{0}=$ concentración inicial de citronelal

$C_{C A L}^{t}=$ concentración de citronelal al tiempo $\mathrm{t}$

La selectividad del producto $i, S_{i}$ (concentración del componente $i /$ concentración total de productos)

$$
S_{i}=\frac{C_{i}}{\sum_{\text {productos }} C_{i}}
$$




\subsubsection{Obtención de mentol a partir de ( \pm )-citronelal}

Para determinar la bifuncionalidad hidrogenante y ácida de los sistemas catalíticos de $\mathrm{Ni}$ zirconia sulfatada sin reducir, Ni/ZrS2 y NiZrS2, se llevó a cabo la obtención de mentol a partir de citronelal en fase líquida en un reactor Parr modelo 4843 de $450 \mathrm{ml}$ con inyección de $1.4 \mathrm{MPa}$ de $\mathrm{H}_{2}$, a $100{ }^{\circ} \mathrm{C}$ de temperatura de reacción con agitación de $1000 \mathrm{rpm}$. El reactor se cargó con una disolución de $130 \mathrm{ml}$ de concentración $0.1 \mathrm{M}$ de citronelal/ciclohexano (CAL/CHEX) (( \pm )-citronelal, Aldrich 95\%; hexano, Aldrich $98 \%$ ) y 500 mg de catalizador con pretratamiento ex situ a $300{ }^{\circ} \mathrm{C}$ con flujo de He. Los materiales probados fueron Ni/ZrS2 y NiZrS2. Cabe mencionar que los materiales no fueron sometidos a reducción previa a la reacción. Los productos retirados de la reacción se analizaron en un sistema de análisis Agilent $6890 \mathrm{~N}$ que consta de cromatógrafo de gases acoplado en línea a un espectrómetro de masas, usando una columna capilar HP-5MS. La enantioselectividad de mentoles se analizó con una columna quiral a-Dex Supelco. La conversión de citronelal y la selectividad se establecieron como se indica en la sección 4.5.1.

La selectividad de $( \pm)$-mentol $\left(S_{( \pm) M T O L}\right)$ se calculó mediante la siguiente ecuación:

$$
S_{( \pm) M T O L}=\frac{C_{( \pm) M T O L}}{\sum C_{\text {mentoles }}}
$$

La enantioselectividad de (-)-mentol se determinó mediante la siguiente expresión:

$$
S_{(-) M T O L}=\frac{C_{(-) M T O L}}{C_{(-) M T O L}+C_{(+) M T O L}}
$$

Donde $C_{( \pm) M T о L}$ y $C_{(-) M T O L}$ son las concentraciones del par enantiomérico de mentol y la enantioselectividad del (-)-mentol

\subsubsection{Obtención de mentol a partir de citral}

En la obtención de mentol mediante catalizadores heterogéneos a partir de citral se planteó la ruta hidrogenación-ciclización-hidrogenación, donde la hidrogenación está en función de un solo material, en este caso de Ni soportado; y la ciclización en función de la zirconia 
sulfatada, ambos materiales con sus características establecidas previamente para llevar una ruta selectiva hacia un alto rendimiento de mentol.

Bajo las mismas condiciones de reacción dadas en la sección 4.5.2, se sometieron a evaluación mezclas mecánicas de $\mathrm{Ni} / \mathrm{SiO}_{2}$ y $\mathrm{ZrS} 2$ con las siguientes proporciones de porcentaje en peso 90:10, 80:20 y 60:40, partiendo en este caso de una disolución de citral/hexano (citral, Aldrich 95\%; hexano, Aldrich 98\%) de $0.1 \mathrm{M}$. Los catalizadores fueron pre-tratados por separado mediante el siguiente procedimiento:

a) $\mathrm{Ni} / \mathrm{SiO}_{2}$ se sometió a un flujo de $\mathrm{H}_{2}$ de $50 \mathrm{~cm}^{3} /$ min en un reactor tubular de vidrio a una temperatura de $500{ }^{\circ} \mathrm{C}$ para la reducción de $\mathrm{Ni}$.

b) ZrS2 se sometió a un flujo de He de $50 \mathrm{~cm}^{3} / \mathrm{min}$ en un reactor tubular de vidrio para eliminar humedad.

Ambos catalizadores se cargaron al reactor en las diferentes proporciones en peso indicadas arriba para cumplir un peso total de catalizador de 500 mg.

La conversión de citral $\left(X_{\text {citral }}\right)$ se determinó con la siguiente ecuación:

$$
X_{\text {citral }}=\frac{\left(C_{\text {citral }}^{0}-C_{\text {citral }}^{t}\right)}{C_{\text {citral }}^{0}}
$$

$C_{\text {citral }}^{0}=$ concentración inicial de citral

$C_{\text {citral }}^{t}=$ concentración de citral al tiempo $\mathrm{t}$

La selectividad de productos se determinó de la siguiente manera:

$$
S_{i}=\frac{C_{i}(t)}{\sum C_{\text {productos }}}
$$

$S_{i}=$ Selectividad del producto $i$

$C_{i}(t)=$ Concentración del producto $i$ que depende del tiempo 


\section{RESULTADOS Y DISCUSIÓN DE CARACTERIZACIÓN FISICOQUÍMICA DE MATERIALES CATALÍTICOS}

\subsection{Análisis termogravimétrico (ATG) y térmico diferencial (ATD)}

En la Figuras 5.1 y 5.3 se muestran los perfiles de ATG-ATD de las muestras $\mathrm{ZrO}_{2}, \mathrm{ZrS} 1$, ZrS2, ZrS3 y NiZrS2, preparados por el método sol-gel. En la evolución térmica para todos los materiales se observa que en intervalo de $\mathrm{T}_{\mathrm{amb}}-900{ }^{\circ} \mathrm{C}$ existe una pérdida de peso de entre $30 \%$ y $40 \%$. Para los materiales de $\mathrm{ZrO}_{2}, \mathrm{ZrS} 1, \mathrm{ZrS} 2, \mathrm{ZrS3}$ y NiZrS2 se observan los siguientes eventos termoquímicos en el intervalo de $\mathrm{T}_{\text {amb }}$ y $400^{\circ} \mathrm{C}$ : a) En el intervalo $\mathrm{T}_{\text {amb- }}$ $180^{\circ} \mathrm{C}$ hay una pérdida de peso considerable atribuida a la evaporación de agua libre y de alcohol de síntesis; además de la formación de agua por hidroxilación, lo cual coincide con la señal endotérmica con un máximo alrededor de $150{ }^{\circ} \mathrm{C}$ [39]; b) la pérdida de peso entre $200{ }^{\circ} \mathrm{C}$ y $400{ }^{\circ} \mathrm{C}$ se atribuye a la deshidroxilación del material y a la pérdida de masa por la combustión de los precursores orgánicos de la zirconia, la cual corresponde a una señal exotérmica a $280^{\circ} \mathrm{C}$ [39]. Para el material de NiZrS2 existe una señal a $250{ }^{\circ} \mathrm{C}$ que se puede atribuir a la descomposición de los nitratos para dar paso a la formación de NiO de acuerdo a la siguiente reacción:

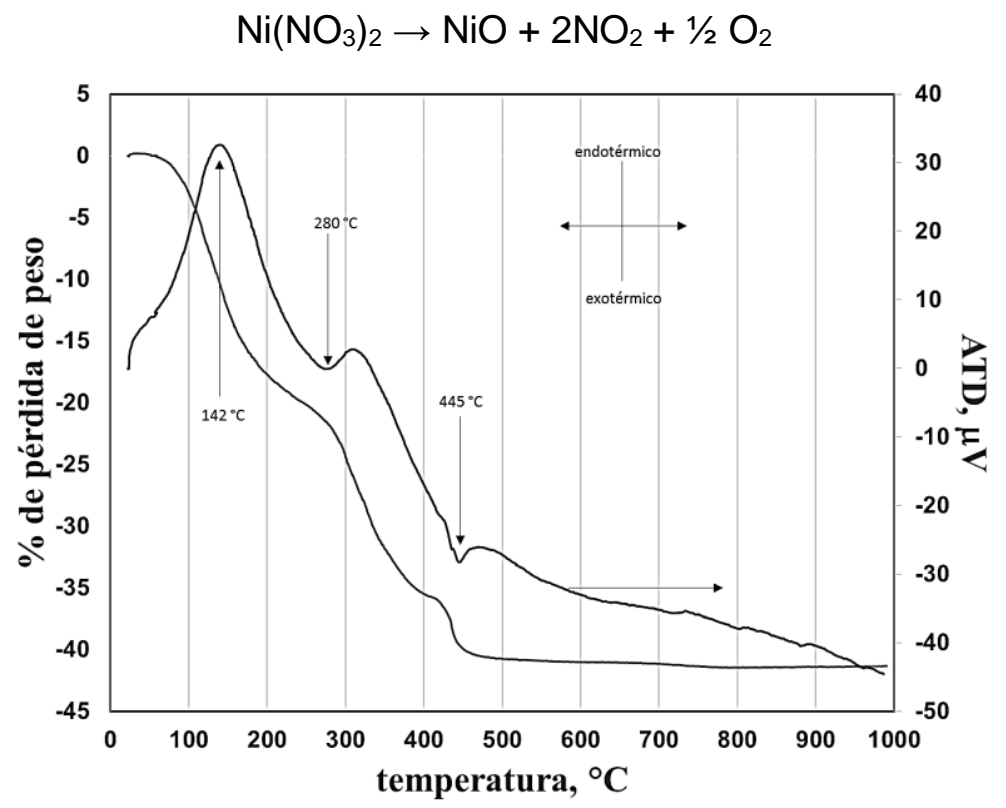

Figura 5.1. Curvas de ATG y ATD para precursor de zirconia sol-gel, $\mathrm{ZrO}_{2}$. 
a)

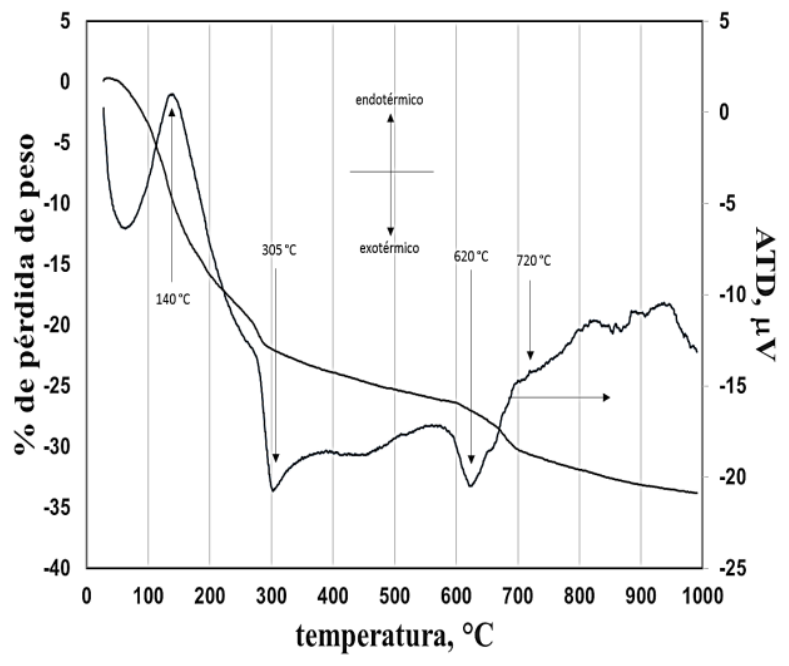

c)

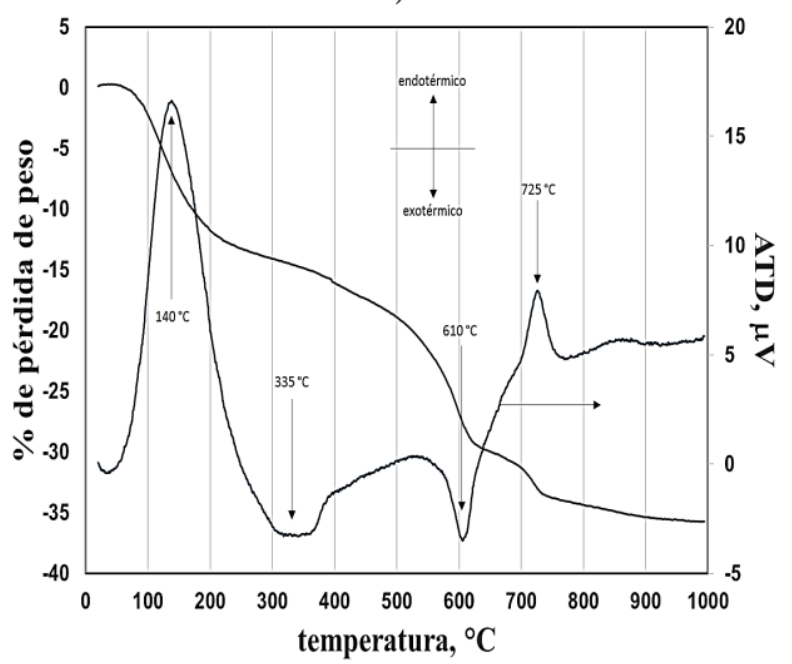

b)

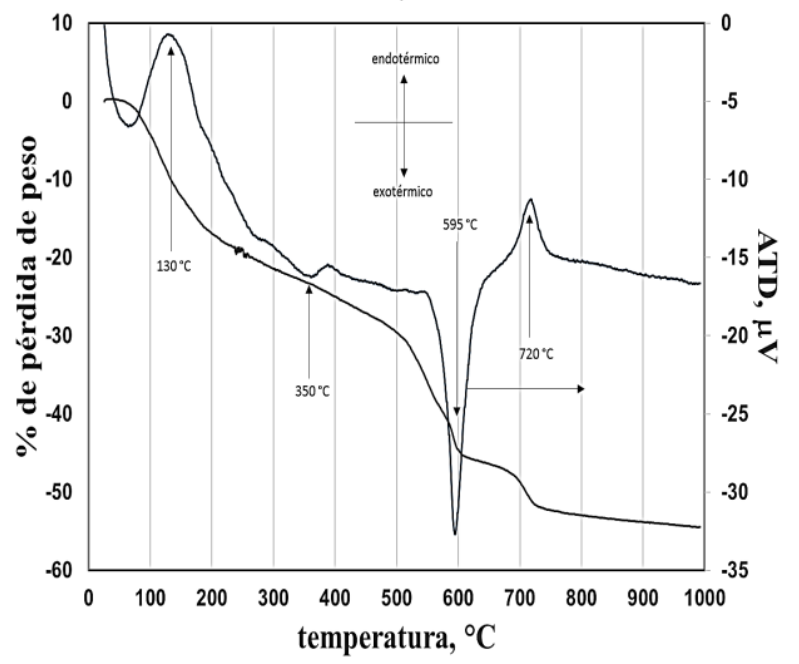

d)

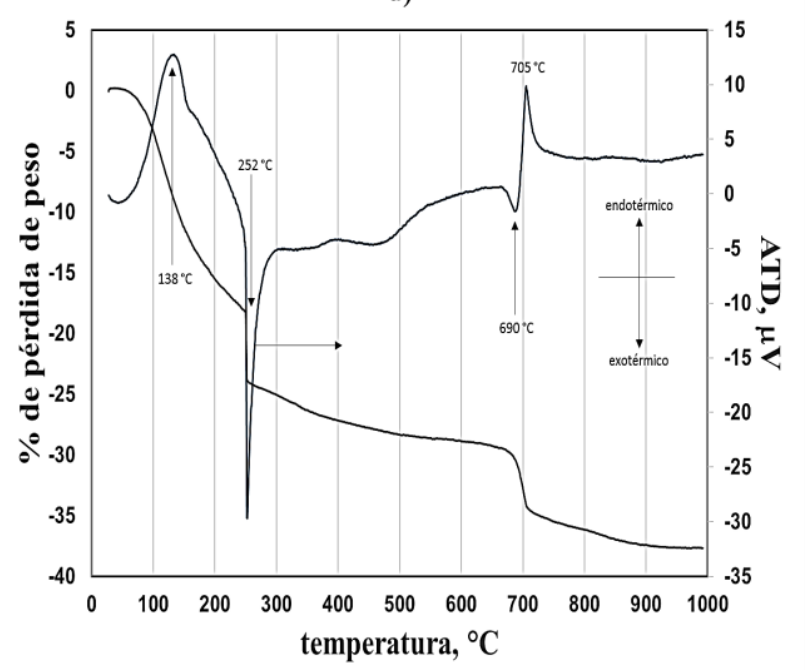

Figura 5.2. Curvas de ATG y ATD para precursor de zirconia sulfatada con variación en la relación $S / Z r$ y NiZrS. a) ZrS1; b) ZrS2; c) ZrS3 y d) NiZrS2

Para $\mathrm{ZrO}_{2}$, la Figura 5.1 muestra una señal de pérdida de peso a $450{ }^{\circ} \mathrm{C}$, la cual se atribuye a la pérdida de $\mathrm{H}_{2} \mathrm{O}$ en el proceso de cristalización de $\mathrm{Zr}(\mathrm{OH})_{4}$ [41], esta señal está acompañada por una señal exotérmica a $450^{\circ} \mathrm{C}$ atribuida a la cristalización de la zirconia de acuerdo al siguiente proceso:

$$
2 \mathrm{Zr}(\mathrm{OH})_{4} \rightarrow \mathrm{ZrO}_{2} \text { (tetragonal) }+\mathrm{ZrO}_{2}(\text { monoclínica })+4 \mathrm{H}_{2} \mathrm{O}
$$

Para los materiales que contienen sulfatos ZrS1, ZrS2, ZrS3 y NiZrS2, la disminución de peso debido a la pérdida de sulfatos y la señal exotérmica debido a la cristalización de la 
zirconia se desplaza hasta los $600{ }^{\circ} \mathrm{C}$, esto se debe a que los iones sulfatos retardan el proceso de cristalización de la zirconia debido a que éstos desplazan a iones hidroxilos desde la síntesis sol-gel de acuerdo a la reacción (3).

A temperatura $<500^{\circ} \mathrm{C}$

$$
\left(\mathrm{SO}_{4}^{-2}-\mathrm{ZrO}_{2}-(\mathrm{OH})_{2} \cdot\left(\mathrm{H}_{2} \mathrm{O}\right)_{x} \rightarrow\left(\mathrm{SO}_{4}^{-2}\right)-\mathrm{ZrO}_{2}+(\mathrm{x}+1) \mathrm{H}_{2} \mathrm{O}\right.
$$

Dichos sulfatos enlazados a la zirconia le dan mayor estabilidad a la estructura amorfa por ser más resistentes a la temperatura que los iones hidroxilos, tal como lo sugieren Srinivasan y col. [46].

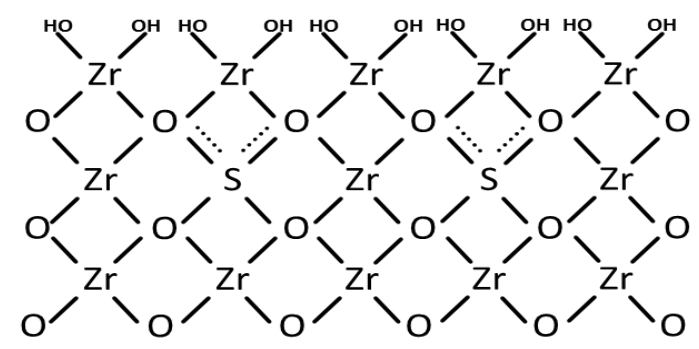

(a)

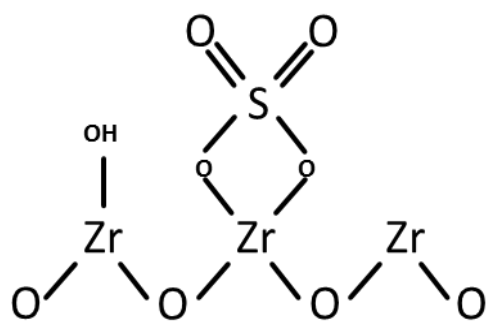

(b)

Figura 5.3. a) estructura de $\left(\mathrm{SO}_{4}^{-2}\right)-\mathrm{ZrO}_{2}$ amorfa y b) estructura de zirconia con sulfatos superficiales.

Tal como se observa en la Figura 5.2, las muestras de ZrS con diferente relación S/Zr presentan una señal exotérmica alrededor de los $600^{\circ} \mathrm{C}$ acompañada de una señal de pérdida de peso. Dicha señal se asocia a la perdida de iones sulfatos y a la cristalización de la zirconia en las fases tetragonal y monoclínica. Ko y col. [47] muestran una representación esquemática posible de la zirconia amorfa con contenido de sulfatos en la estructura, como se muestra en la Figura 5.3. Dichos autores proponen la existencia de sulfatos atrapados desde la síntesis en la estructura del precursor de zirconia, como se propone en (3) y como se observa en la Figura 5.3a. Los sulfatos migran a la superficie a una temperatura mayor de $500{ }^{\circ} \mathrm{C}$ y tienen una transición de sulfatos bulk a sulfatos superficiales, con cierta pérdida de peso por descomposición de los sulfatos superficiales. Como se muestra en la Figura 5.2 para ZrS1, ZrS2, y ZrS3, después de la pérdida de peso atribuida a la deshidroxilacion, existe una evolución en la pérdida de peso y en la señal exotérmica hasta llegar a la señal de cristalización $\left(\sim 600^{\circ} \mathrm{C}\right)$. Esto puede deberse a que una parte de los sulfatos migran a la superficie y otros siguen atrapados en la estructura del 
material que le permiten mantener su condición de amorfo. Una vez que llegan a cierta concentración, la zirconia pasa a ser cristalina, con especies enlazadas como se muestra en la Figura 5.3b. Después de este evento termoquímico, se presenta una pérdida de peso adicional acompañada de una señal endotérmica alrededor de los $700{ }^{\circ} \mathrm{C}$ por la descomposición de los sulfatos en otras especies $\mathrm{SO}_{x}$ de acuerdo a las siguientes reacciones:

$$
\begin{aligned}
& \mathrm{SO}_{4}^{-2}-\mathrm{ZrO}_{2} \rightarrow \mathrm{ZrO}_{2}(\mathrm{Oa})+\mathrm{SO}_{3} \\
& \mathrm{SO}_{3} \rightarrow \mathrm{SO}_{2}(\text { ó SO})+\mathrm{O}\left(\mathrm{ó} \mathrm{O}_{2}\right)
\end{aligned}
$$

Para el material de NiZrS2 la señal exotérmica, atribuida a la cristalización de la zirconia amorfa, se retarda hasta alrededor de los $690^{\circ} \mathrm{C}$, esto indica que de igual forma que los iones sulfato se encuentran en la red de la zirconia para los materiales ZrS1, ZrS2 y ZrS3, el níquel se encuentra presente en la red de la zirconia y retarda la cristalización de la fase amorfa incluso a temperatura más alta. La pérdida de sulfatos para el material de NiZrS2 se presenta de igual manera a los materiales de ZrS alrededor de los $700^{\circ} \mathrm{C}$. 


\subsection{Propiedades texturales. Fisisorción de nitrógeno}

En la Figura 5.4 se observan las isotermas de adsorción de nitrógeno para los catalizadores ZrS1, ZrS2, ZrS3 y NiZrS2. De acuerdo a la IUPAC [48] estas isotermas se clasifican como Tipo IV que se asocian a materiales mesoporosos con histéresis tipo $\mathrm{H} 1$ que se asocia a poros de forma cilíndrica abiertos o cerrados.
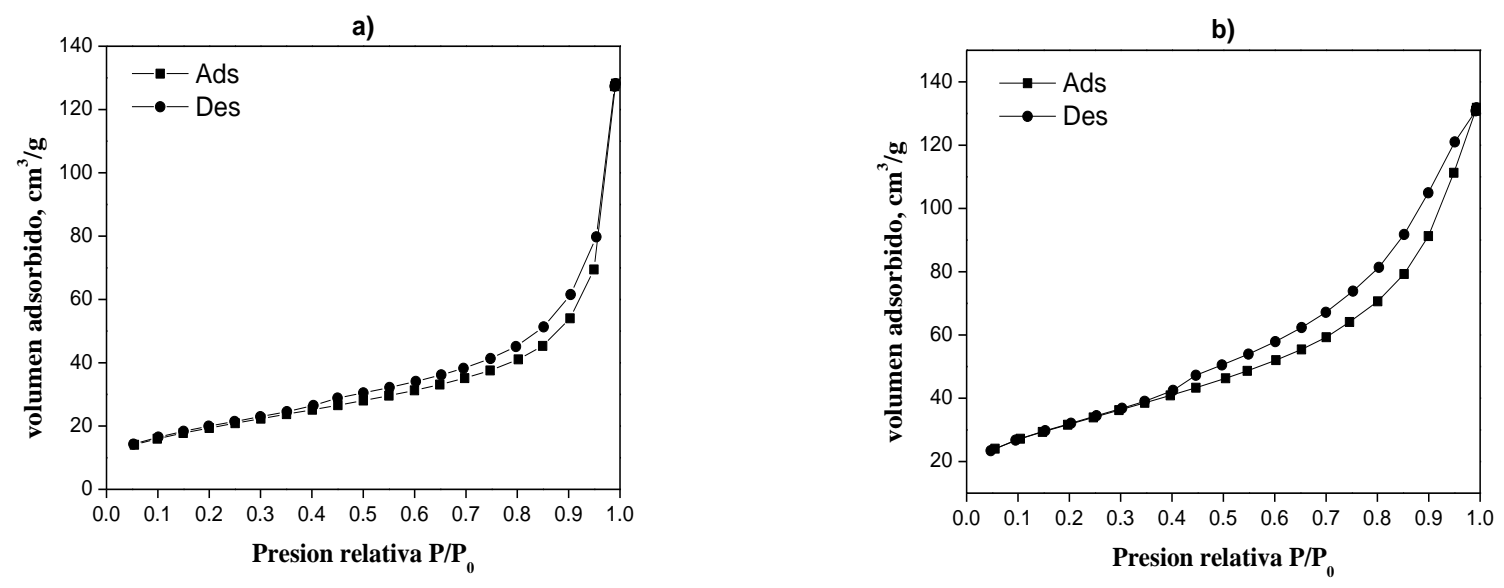

c)
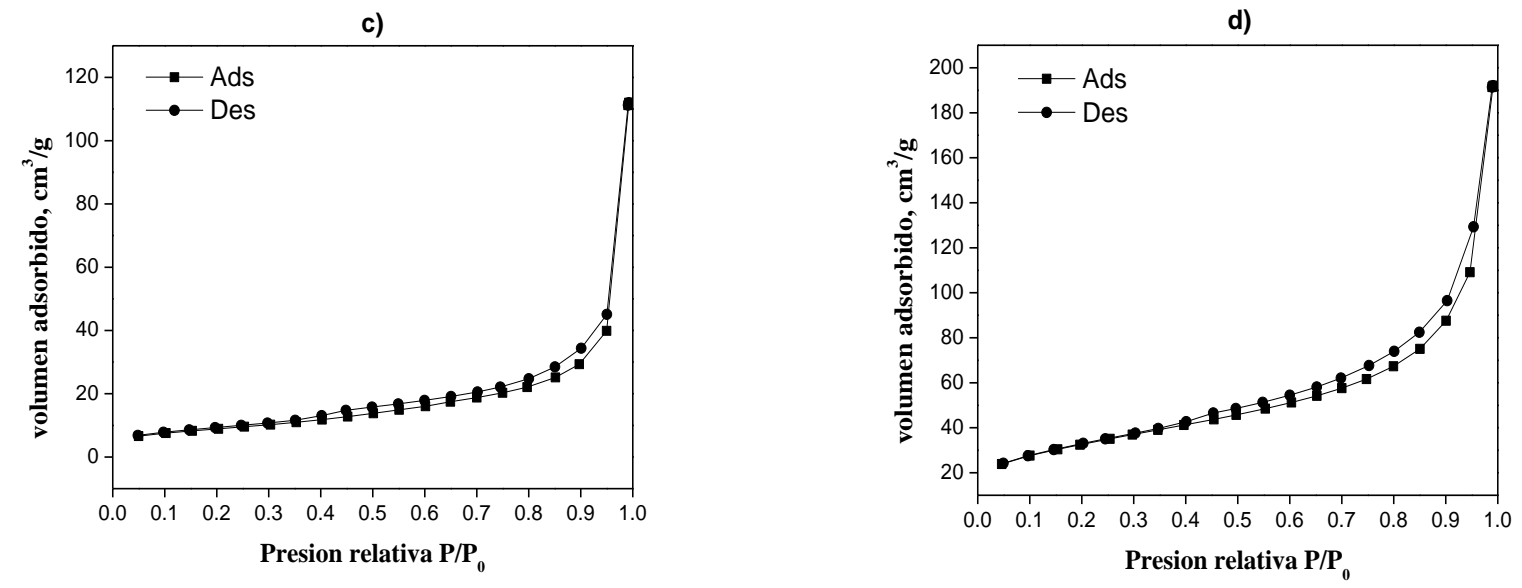

Figura 5.4. Isotermas de adsorción de nitrógeno para a) ZrS1, b) ZrS2, c) ZrS3 y d) NiZrS2.

En la Tabla 5.1 se reportan los resultados de área BET y volumen de poros para los materiales de ZrS1, ZrS2, ZrS3 y NiZrS2. Los resultados muestran que el material ZrS2 presenta una mayor área superficial y un mayor volumen de poro que sus similares ZrS1 y ZrS3. Esta diferencia en el área superficial específica se explica a continuación. En la síntesis sol-gel, la hidrólisis de los alcóxidos de zirconio es muy rápida y la velocidad de condensación puede ser influenciada por la concentración de un ácido [49]. Si no se añade ácido o la concentración es muy baja, la precipitación ocurre de manera inmediata. Los 
precipitados usualmente no poseen una estructura porosa y área superficial específica deseable. En cierto intervalo de concentración de ácido, rápidamente se puede observar la formación de un gel que contiene un precipitado polimérico duro. Con un incremento en la cantidad de ácido, el tiempo de gelación aumenta progresivamente y se forma un alcogel claro y suave. Si la concentración de ácido es demasiado elevada, la condensación puede ser incluso suprimida [50]. Gonzalez y col. [51] mencionan que la hidrólisis es de primer orden con respecto a la concentración de agua y se ve favorecida en condiciones ácidas. Entonces el material es el resultado de una reacción coloidal en lugar de una reacción de polimerización. A altas concentraciones de ácido, la reacción de condensación ocurre antes de que la hidrólisis se complete, por lo tanto se obtienen materiales que no forman grandes cadenas poliméricas y como resultados final se obtienen sólidos de baja área superficial. En este trabajo, la variación del $\mathrm{H}_{2} \mathrm{SO}_{4}$ como catalizador de hidrólisis y agente sulfatante dentro de la síntesis sol-gel tuvo un efecto importante en el aspecto físico del alcogel al final de la síntesis. Como se mencionó en la Sección 4.1 para la síntesis de zirconio sulfatada, el procedimiento de síntesis sol-gel consistió en el goteo de una solución alcohol-agua para efectuar la reacción de hidrólisis. Para la relación $S / Z r$ de 0.1 y 0.2 , la solución se agregó completamente y después de un periodo no mayor a 1 minuto después de la última gota se formó un alcogel claro y turgente. Para la relación S/Zr de 0.5 , no se terminó de gotear la solución alcohol-agua cuando el material formó un precipitado opaco y duro. Esto indica que la concentración de ácido, que corresponde a las relaciones $\mathrm{S} / \mathrm{Zr}$ de 0.1 y 0.2 , está dentro de un intervalo donde se tiene un control adecuado de la velocidad de hidrólisis con respecto a la velocidad de condensación, permitiendo a los materiales de ZrS1 y ZrS2 tener las mayores áreas superficiales específicas.

Para el caso del material NiZrS2, la adición del catión de Ni desde la síntesis sol-gel le permite tener un área superficial específica comparable al material ZrS2, mientras que en el volumen de poro y el diámetro promedio de poro si se observa una diferencia del $30 \%$, aumentando estas dos propiedades al incluir el $\mathrm{Ni}$ a la red de la zirconia sulfatada. 
Tabla 5.1. Propiedades texturales de materiales ZrS1, ZrS2, ZrS3 y NiZrS2. Efecto de la variación de la relación $\mathrm{S} / \mathrm{Zr}$.

\begin{tabular}{|c|c|c|c|c|}
\hline Catalizador & $\begin{array}{c}\text { Relación } \\
\text { molar }^{a} \\
\text { S/Zr }\end{array}$ & $\begin{array}{c}\text { Área específica } \\
\text { BET } \\
\left(\mathrm{m}^{2} / \mathrm{g}\right)\end{array}$ & $\begin{array}{c}\text { Volumen de } \\
\text { poro } \\
\left(\mathrm{cm}^{3} / \mathrm{g}\right)\end{array}$ & $\begin{array}{c}\text { Diámetro } \\
\text { promedio de } \\
\text { poro }(\AA)\end{array}$ \\
\hline ZrS1 & 0.10 & 70 & 0.198 & 56 \\
\hline ZrS2 & 0.22 & 113 & 0.204 & 36 \\
\hline ZrS3 & 0.50 & 58 & 0.153 & 52 \\
\hline NiZrS2 & 0.10 & 115 & 0.297 & 51 \\
\hline
\end{tabular}

${ }^{a}$ Relación molar de síntesis sol-gel ácido/alcóxido de Zr

\subsection{Estructura cristalina de los materiales. Difracción de rayos $X$ (DRX)}

En la Figura 5.4 se muestran los difractogramas de los catalizadores ZrO2, ZrS2, ZrS3 y NiZrS2 calcinados a $450{ }^{\circ} \mathrm{C}$. El difractograma obtenido para $\mathrm{ZrO}_{2}$ tratado a $450{ }^{\circ} \mathrm{C}$, mostrado como blanco, indica una muestra completamente cristalina y con estructura tetragonal, lo cual muestra que la síntesis sol-gel permite obtener un material con $100 \%$ de estructura tetragonal a $450{ }^{\circ} \mathrm{C}$ de calcinación. Lo anterior complementa lo discutido en los resultados de ATG y ATD, donde se expuso que la señal endotérmica a $450{ }^{\circ} \mathrm{C}$ corresponde a la transición de zirconia amorfa a zirconia cristalina con fases tetragonal y monoclínica. En varias investigaciones se expone que en la transformación de la zirconia amorfa a cristalina por tratamiento térmico se tiene un material policristalino con una mezcla de fases tetragonal y monoclínica, y que los factores que intervienen en la composición de las fases son el método de preparación y el tratamiento post síntesis [45-47,52]. Los resultados mostrados en la Figura 5.4a confirman que la síntesis sol-gel permite obtener un material de zirconia monocristalina de fase tetragonal a $450^{\circ} \mathrm{C}$ de calcinación, tal como lo reportaron Ko y col. [47] para la síntesis de zirconia con el mismo método de preparación.

Los difractogramas de la Figura 5.4b muestran una estructura amorfa o microcristalina para las muestras ZrS2, ZrS3 y NiZrS2 calcinados a $450{ }^{\circ} \mathrm{C}$. Por consiguiente, la sulfatación inhibe la sinterización de zirconia y retarda la formación de fases cristalinas típicas de zirconia pura (tetragonal, cúbica y monoclínica) después de un tratamiento de calcinación de $450^{\circ} \mathrm{C}$, como se discutió en los resultados de ATG-ATD. Esto se puede observar desde las curvas de ATD de las Figuras 5.1 y 5.2. Norman y col. [52] proponen que en zirconia sulfatada, la presencia de puentes de iones sulfato tiene tres efectos. El primero es la 
estabilidad térmica de sulfato sobre puentes hidroxilo. La presencia de especies $\mathrm{SO}_{4}{ }^{-2}$, las cuales no se pierden hasta exceder la temperatura de $600{ }^{\circ} \mathrm{C}$, retrasa la formación de algunos enlaces oxo, retardando el sinterizado, y así estabilizando el área superficial específica. El segundo efecto es que la sustitución de $\mathrm{SO}_{4}^{-2}$ por $\mathrm{OH}^{-}$incrementa la separación de Zr-Zr de 3.3-3.7 Å para puentes hidroxilo a 3.5-4.3 $\AA$ para puentes sulfato. Por lo tanto, la cristalización del óxido de zirconio en estas circunstancias se retrasa. El tercer efecto está relacionado con los procesos de difusión debido a la rigidez impartida a la estructura por los puentes de iones sulfato.

a)

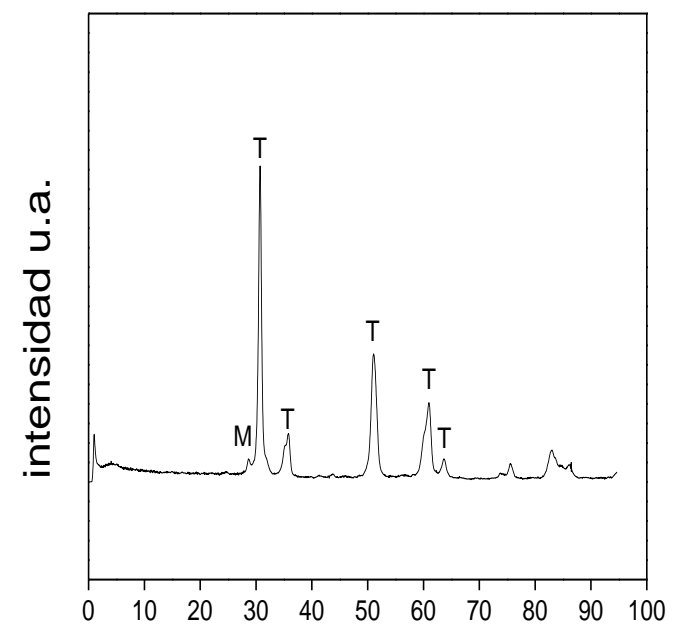

$2 \theta$ b)

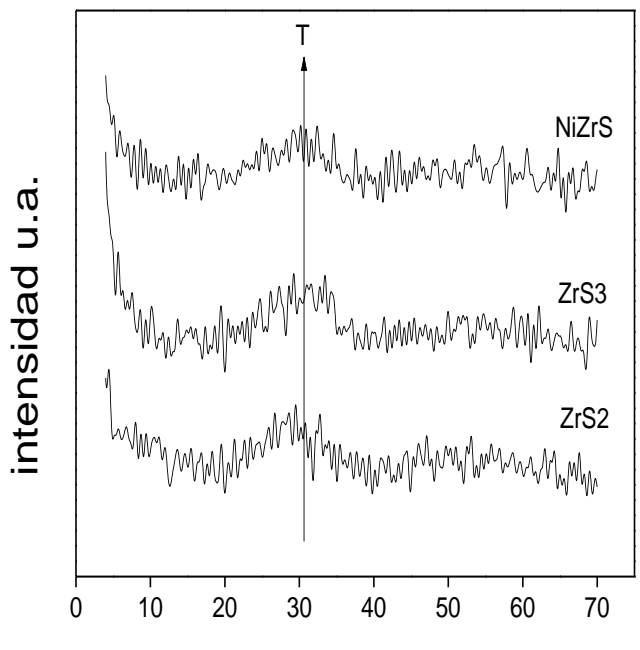

$2 \theta$

Figura 5.4 Patrón de difracción de rayos $\mathrm{X}$ de los materiales calcinados a $450{ }^{\circ} \mathrm{C}$ : (a) $\mathrm{ZrO}_{2}$ y (b) $\mathrm{ZrS2}$, ZrS3 y NiZrS 


\subsection{Cantidad de sulfatos}

La Tabla 5.2 muestra la cantidad de sulfatos $\left(\mathrm{SO}_{4}{ }^{-2}\right)$ presentes en el material como porcentaje teórico considerando las diferentes relaciones molares $\mathrm{S} / \mathrm{Zr}$; la cantidad porcentual de pérdida de masa durante el análisis térmico y la densidad de sulfatos superficiales por $\mathrm{nm}^{2}$ considerando el porcentaje de pérdida de masa determinado por ATG. Los resultados obtenidos por ATG se obtuvieron considerando que después de los $600^{\circ} \mathrm{C}$ existe una pérdida de peso únicamente asociada a la pérdida de sulfatos de la superficie como se estableció en la Sección 5.1. De acuerdo a la densidad superficial, el catalizador de ZrS3 contiene mayor cantidad de sulfatos por unidad de superficie debido a su baja área superficial específica. Los catalizadores de ZrS1 y ZrS2 contienen una cantidad de sulfatos muy parecida, siendo mayor el área superficial específica de ZrS2. Esto indica que la distribución de sulfatos es mayor para el material de ZrS2. El material de NiZrS2 contiene una cantidad ligeramente mayor en densidad superficial y área superficial que el material ZrS2, siendo que estos dos contienen la misma relación molar S/Zr de síntesis, lo cual indica que la presencia de $\mathrm{Ni}$ ayuda a la distribución de los iones sulfato en la superficie.

Tabla 5.2 Cantidad de iones sulfato teórica y determinada por análisis termogravimétrico (ATG)

\begin{tabular}{c|c|c|c}
\hline Catalizador & \% en peso $\mathrm{SO}_{4}^{-2}$ teórico & \% en peso $\mathrm{SO}_{4}{ }^{-2}$ real $^{\mathbf{a}}$ & $\begin{array}{c}\text { Densidad superficial } \\
\mathbf{S O}_{4}^{-2} / \mathbf{n m}^{\mathbf{2}}\end{array}$ \\
\hline ZrS1 & 7.2 & 4.7 & 4.2 \\
\hline ZrS2 & 14.6 & 5.8 & 3.2 \\
\hline ZrS3 & 28.0 & 17.1 & 56.4 \\
\hline NiZrS2 & 14.6 & 8.8 & 4.3 \\
\hline
\end{tabular}

a Determinado por análisis térmico ATG. 


\subsection{Termodesorción de piridina y espectroscopia de infrarrojo (FTIR-Py)}

El espectro de infrarrojo de la Figura 5.5 muestra 4 bandas IR de ZrS2 a 1340, 1150, 1050 y $960 \mathrm{~cm}^{-1}$ en la región de frecuencia de estiramiento de SO. Las primeras dos bandas son asignadas a las frecuencias de estiramiento asimétricas y las últimas dos bandas a las frecuencias simétricas de $\mathrm{O}=\mathrm{S}=\mathrm{O}$ y $\mathrm{O}-\mathrm{S}-\mathrm{O}$, respectivamente [53]. En el espectro de IR cuando se expone el material a la piridina muestra un desplazamiento de las bandas a menores longitudes de onda y conforme se aumenta la temperatura de desorción, las bandas de IR toman progresivamente las longitudes de onda de la zirconia sulfatada. Esto indica que la piridina esta interaccionando con la superficie de la zirconia sulfatada en sitios ácidos generados por la presencia de los sulfatos.

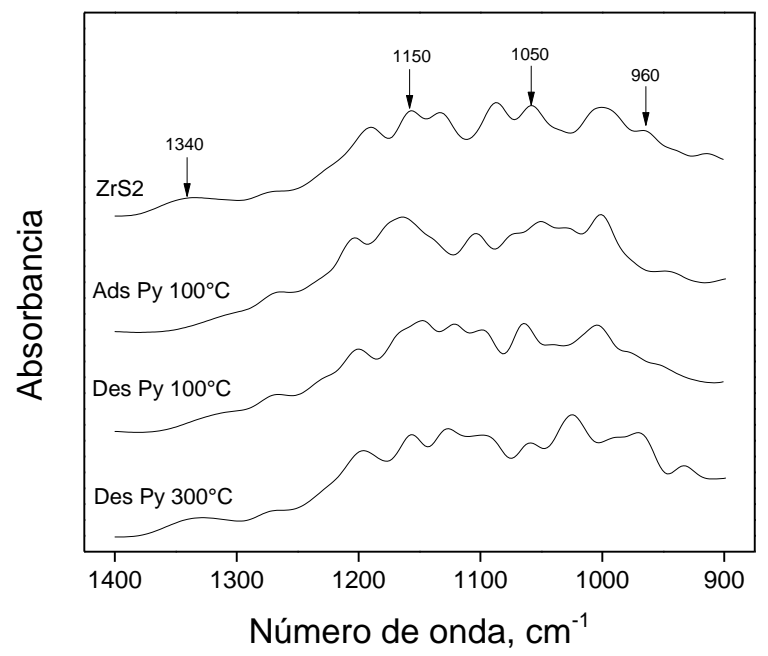

Figura 5.5. Espectro de IR de ZrS2 antes y después de la adsorción de piridina. Ads Py $100{ }^{\circ} \mathrm{C}$ : espectro IR al adsorber piridina; Des Py $100^{\circ} \mathrm{C}$ y $300^{\circ} \mathrm{C}$ : espectro IR a la temperatura de evacuación especificada.

La estructura para zirconia sulfatada, discutida en la Sección 5.1, Figura 5.3, se propone de igual manera con los resultados observados de IR para la adsorción de piridina y las bandas de IR mencionadas anteriormente para SO son observadas de igual manera por Tanabe y col. [53] para un catalizador de $\mathrm{ZrO}_{2}$ sulfatada. La estructura propuesta como una especie ácida se observa a continuación. 
<smiles>[Z7]OS(=O)(=O)O[Z7](=[Z7])O</smiles>

(a)

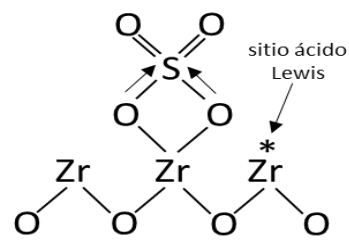

(b)

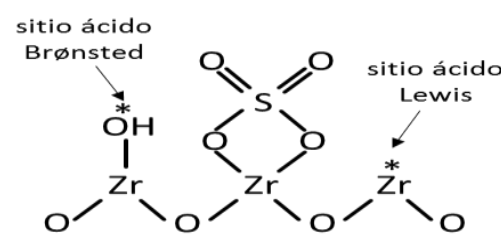

(c)

Figura 5.6. (a) estructura de una especie ácida en la zirconia sulfatada. (b) formación de sitio acido tipo Lewis. (c) formación de sitios ácidos Lewis y Bronsted.

La estructura representada en la Figura 5.6 se puede describir como una especie ácida Lewis debido a que el grupo sulfato crea un efecto inductivo electrónico por la presencia de los dos enlaces $\mathrm{S}=\mathrm{O}$. La formación de sitios ácidos Brønsted superficiales se debe al mismo efecto inductivo causado por los dos enlaces $\mathrm{S}=\mathrm{O}$ sobre especies $-\mathrm{OH}$ presentes en la superficie de la zirconia, donde el protón del grupo hidroxilo enlazado a un átomo de $\mathrm{Zr}$ se ve fortalecido por la presencia del grupo sulfato adyacente como se representa en la Figura 5.6c. Esta estructura se ha presentado en zirconia sulfatada obtenida por el método sol gel propuesto por Ko y col. [47]. La Figura 5.7 muestra el espectro de IR de la muestra ZrS2 en la región de 4000-3000 $\mathrm{cm}^{-1}$ característica del estiramiento del grupo funcional O-H [53].

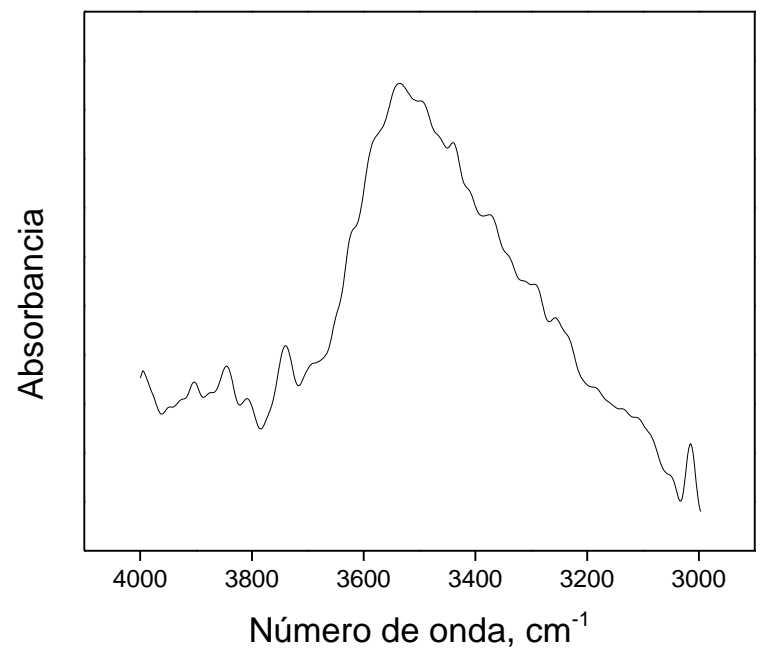

Figura 5.7. Espectro de IR de ZrS2 en la región de estiramiento de O-H.

Es importante mencionar que el tratamiento previo a la adsorción de piridina, sobre la muestra para el análisis FTIR, es de suma importancia, ya que se ha demostrado que la presencia de humedad y la evacuación de la muestra a diferentes temperaturas puede convertir reversiblemente los sitios ácidos Brønsted y Lewis [54], por tal motivo las muestras fueron sometidas a un riguroso pre-tratamiento térmico a vacío y a una temperatura de 
adsorción de piridina a $100{ }^{\circ} \mathrm{C}$ para asegurar que la presencia de agua no interfiera en la confiabilidad de los resultados.

La Figura 5.8 muestra los espectros de FTIR de la termodesorción de piridina para las muestras ZrS1, ZrS2 y ZrS3. Los resultados muestran la presencia de sitios ácidos Brønsted a $1540 \mathrm{~cm}^{-1}$, sitios ácidos Lewis a $1440 \mathrm{~cm}^{-1}$ y de acidez total (Lewis + Brønsted) a $1490 \mathrm{~cm}^{-1}$ [55]. Los espectros muestran una disminución de la acidez total con el incremento de la temperatura en el intervalo de $50-400{ }^{\circ} \mathrm{C}$, aunque se observa aun la presencia de sitios ácidos Brønsted y Lewis a alta temperatura considerando que tienen acidez fuerte. La cuantificación de la cantidad de sitios $\left(\mu \mathrm{mol} / \mathrm{g}_{\mathrm{cat}}\right)$ se realizó mediante la integración de las señales en las longitudes de onda correspondientes a sitios ácidos Lewis, Brønsted y totales y utilizando los coeficientes de extinción molar determinados por Emeis [56], haciendo la suposición de que estos coeficientes de extinción no dependen del tipo de catalizador. La Tabla 5.4 muestra la cantidad de sitios relacionada directamente con la cantidad de piridina adsorbida para los materiales de ZrS1, ZrS2 y ZrS3. En los resultados se observa que el material ZrS1 muestra una mayor cantidad de sitios Lewis en comparación con ZrS2 y ZrS3, que presentan mayor cantidad de sitios Brønsted. En la literatura se ha determinado que la zirconia $\left(\mathrm{ZrO}_{2}\right)$ presente únicamente sitios ácidos Lewis debido a que a altas temperaturas de calcinación se generan vacancias aniónicas formadas por especies catiónicas insaturadas de $\mathrm{Zr}^{4+}$ que actúan como receptoras de pares de electrones, es decir, como ácidos Lewis [57]. Por otro lado, conforme se agregan iones sulfatos al material se le otorga cierta acidez Brønsted, la cantidad de este tipo de sitios, relativo a la cantidad de sitios ácidos Lewis, depende de la relación S/Zr [57]. 
a)

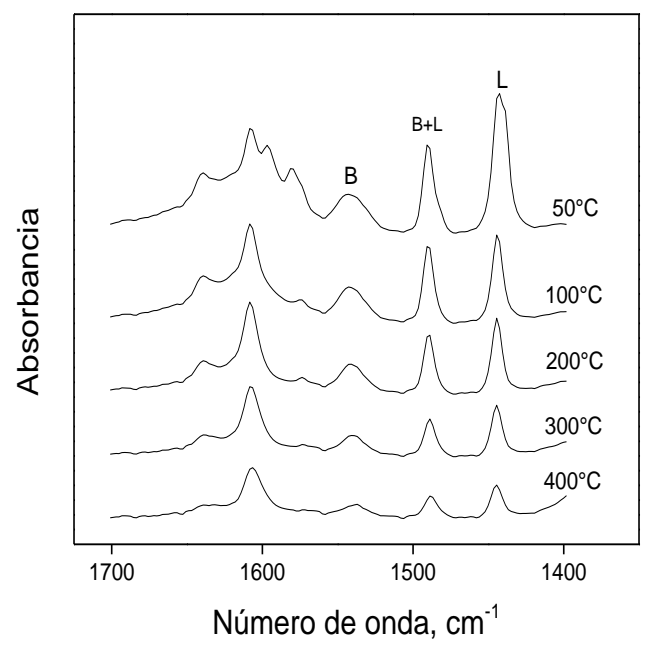

b)

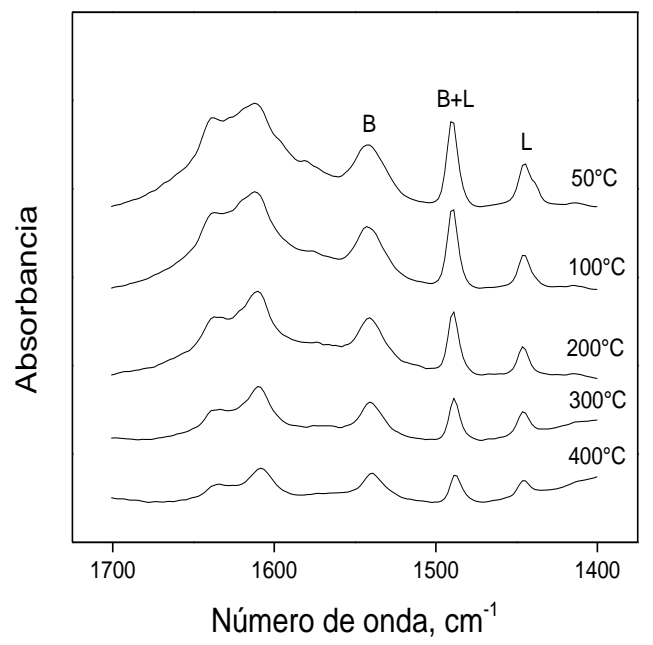

c)

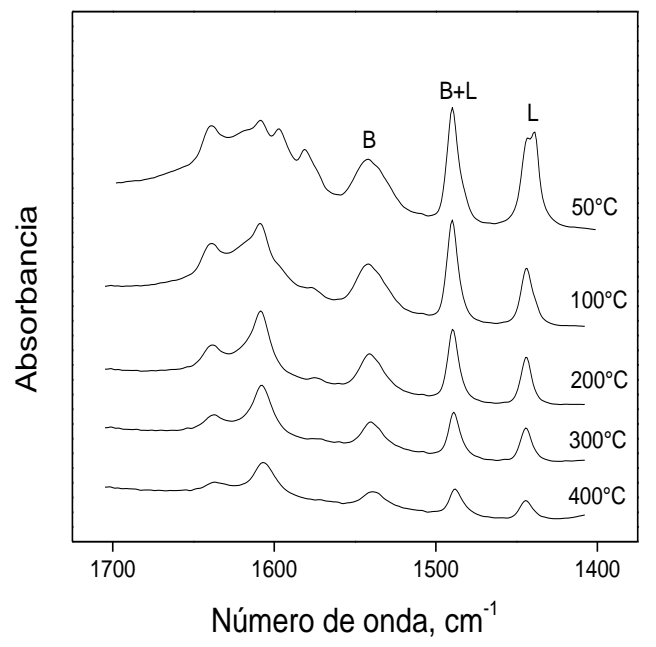

Figura 5.8. Espectro de IR de piridina en a) ZrS1, b) ZrS2 y c) ZrS3, después de evacuación a 50, 100, 200, 300 y $400^{\circ} \mathrm{C}$. L: $1440 \mathrm{~cm}^{-1}, 1610 \mathrm{~cm}^{-1}$; B: $1540 \mathrm{~cm}^{-1}$; B+L: $1490 \mathrm{~cm}^{-1}$.

Por otro lado, la Tabla 5.4 muestra la cantidad total de sulfatos determinada por ATG y la cantidad total de sulfatos determinada por adsorción de piridina, considerando que todos los sulfatos participan en la generación de sitios ácidos Lewis y Brønsted. La diferencia en las dos cantidades indica que no todos los sulfatos se encuentran en la superficie del material o que no todos los sulfatos interactúan con otras especies superficiales para generar sitios ácidos Lewis o Brønsted como se muestra en la Figuras 5.6. 
Tabla 5.4. Resultados de termodesorción de piridina a $100{ }^{\circ} \mathrm{C}$ de temperatura de evacuación.

\begin{tabular}{|c|c|c|c|c|c|c|c|c|}
\hline \multirow{3}{*}{ catalizador } & \multicolumn{8}{|c|}{ Cantidad de piridina adsorbida } \\
\hline & \multicolumn{2}{|c|}{ Brønsted $1540 \mathrm{~cm}^{-1}$} & \multicolumn{2}{|c|}{ Lewis $1440 \mathrm{~cm}^{-1}$} & \multirow{2}{*}{ Totales $^{a}$} & \multirow{2}{*}{$\begin{array}{c}\text { Totales } \\
\mathrm{SO}_{4}^{-2} / \mathrm{nm}^{2}\end{array}$} & \multirow{2}{*}{$\begin{array}{l}\text { Totales }^{\mathbf{b}} \\
\mathrm{SO}_{4}^{-2} / \mathrm{nm}^{2}\end{array}$} & \multirow{2}{*}{$L / B^{c}$} \\
\hline & $\mu \mathrm{mol} / \mathrm{g}_{\mathrm{cat}}$ & $\mu \mathrm{mol} / \mathrm{m}^{2}$ & $\mu \mathrm{mol} / \mathrm{g}_{\text {cat }}$ & $\mu \mathrm{mol} / \mathrm{m}^{2}$ & & & & \\
\hline $\mathrm{ZrS1}$ & 90 & 1.28 & 124 & 1.77 & 214 & 1.83 & 4.21 & 1.3 \\
\hline $\mathrm{ZrS2}$ & 114 & 1.0 & 40 & 0.35 & 154 & 0.81 & 3.22 & 0.3 \\
\hline ZrS3 & 151 & 7.94 & 96 & 5.05 & 247 & 7.82 & 56.43 & 0.6 \\
\hline $\mathrm{Ni} / \mathrm{ZrS2}$ & 34 & n.d & 61 & n.d & 95 & n.d & n.d & 1.8 \\
\hline NiZrS2 & 14 & 0.12 & 16 & 0.13 & 30 & 0.15 & 4.36 & 1.1 \\
\hline $\mathrm{NiO} / \mathrm{SiO}_{2}$ & 0 & 0 & 61 & 0.1 & 61 & 0.06 & n.d & 1 \\
\hline
\end{tabular}

aEn base a la cantidad de piridina adsorbida $/ \mathrm{g}_{\text {cat. }}$.

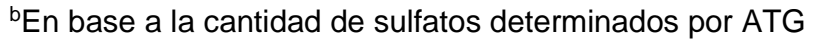

En la Figura 5.9 se observa la cantidad de piridina adsorbida con respecto a la masa de catalizador y al área superficial. El catalizador ZrS1 tiene una mayor cantidad de sitios ácidos Lewis por $\mathrm{m}^{2}$. Al aumentar la cantidad de sulfatos en la zirconia, la cantidad de sitios ácidos Brønsted predomina. Para el material de ZrS3 la diferencia de sitios Lewis y Brønsted con respecto a los catalizadores ZrS1 y ZrS2 es significativa y mantiene la mayor cantidad de sitios Brønsted con respecto a los sitios Lewis.

a)

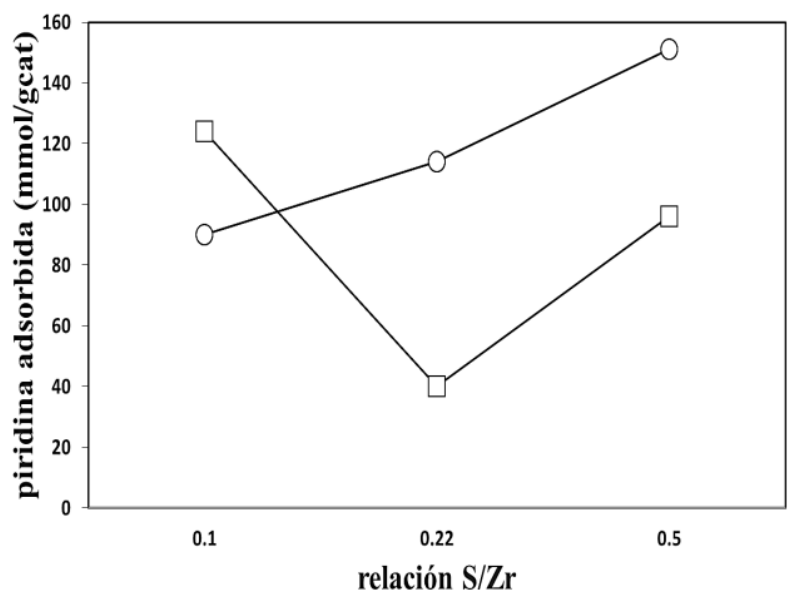

OBronsted $\square$-Lewis b)

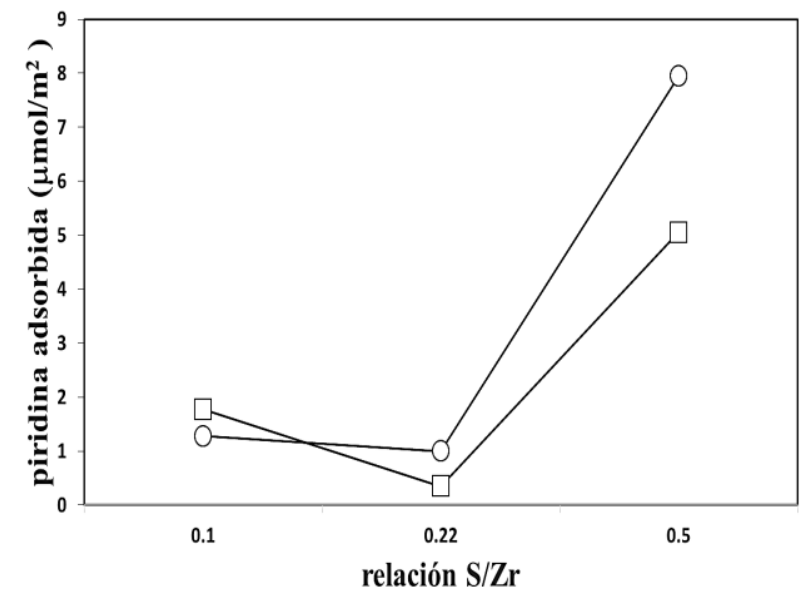

OBronsted 마ewis

Figura 5.9. Variación de la cantidad de sitios ácidos Lewis $\left(1440 \mathrm{~cm}^{-1}\right)$ y Brønsted $\left(1540 \mathrm{~cm}^{-1}\right)$ en función de la relación de $\mathrm{S} / \mathrm{Zr}$ para una temperatura de evacuación de piridina de $100^{\circ} \mathrm{C}$, a) por gramo de catalizador y b) por $\mathrm{m}^{2}$ de catalizador.

En la Figura 5.10 se muestra la variación de la cantidad de piridina adsorbida con respecto a la temperatura de evacuación para los materiales de ZrS1, ZrS2 y ZrS3. Los resultados 
muestran la fuerza ácida de los materiales, ya que la capacidad específica de los catalizadores se relaciona con la cantidad de piridina adsorbida a determinada temperatura. Debido a esto se puede asociar acidez fuerte Lewis y Brønsted a los materiales de ZrS1, ZrS2 y ZrS3, siendo el material de ZrS2 el que presenta mayor cantidad de sitios Brønsted fuertes en relación a la cantidad de sitios Lewis.

a)

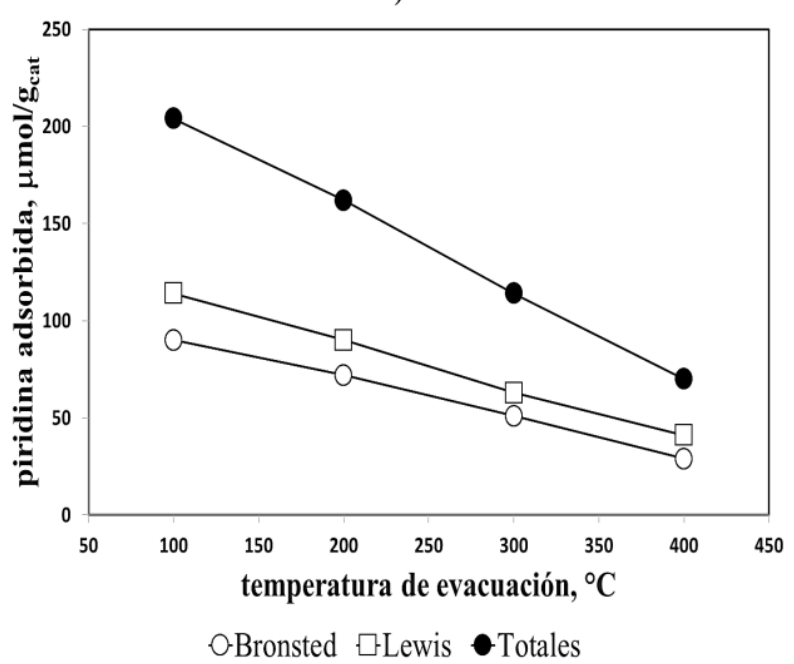

b)

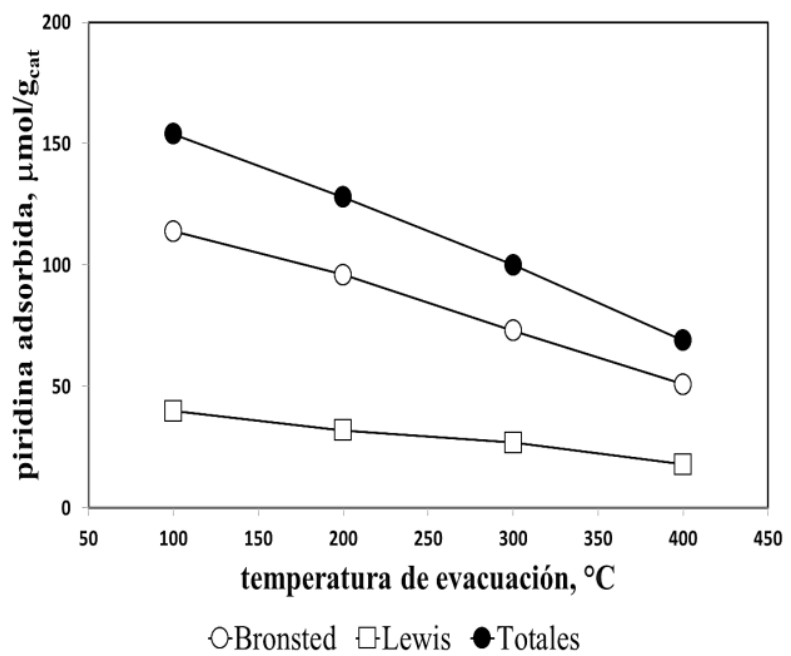

c)

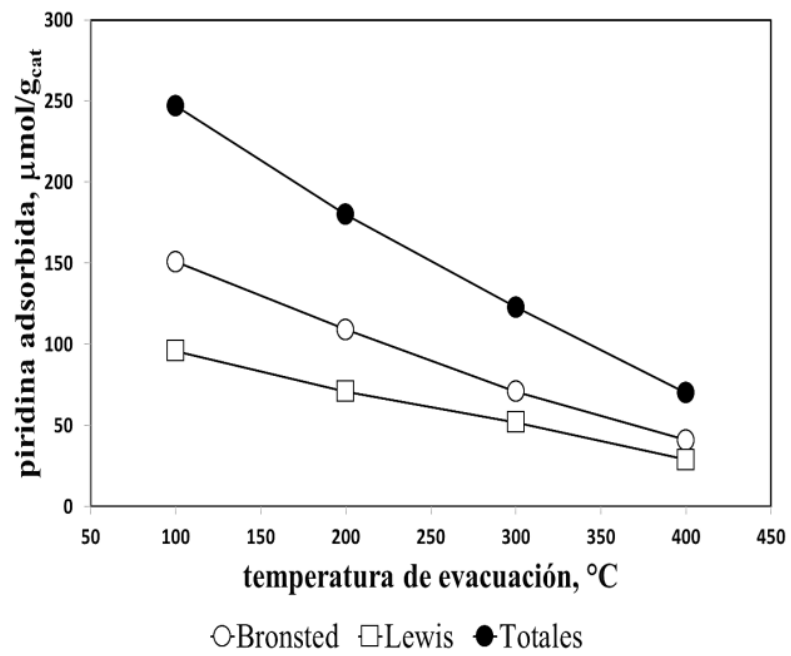

Figura 5.10. Variación de la cantidad de sitios ácidos Lewis, Brønsted y totales en función de la temperatura de evacuación de piridina para a) ZrS1, b) ZrS2 y c) ZrS3.

En la Figura 5.11 se muestran los resultados de la cantidad de piridina adsorbida para los catalizadores de $\mathrm{Ni} / \mathrm{ZrS} 2, \mathrm{NiZrS} 2$ y $\mathrm{NiO} / \mathrm{SiO}_{2}$. Los catalizadores de $\mathrm{Ni} / \mathrm{ZrS} 2$ y $\mathrm{NiZrS} 2$ presentan sitios ácidos Brønsted a $1540 \mathrm{~cm}^{-1}$, sitios ácidos Lewis a $1440 \mathrm{~cm}^{-1}$ y de acidez total (Lewis+Brønsted) a $1490 \mathrm{~cm}^{-1}$ [53], mientras que el catalizador de $\mathrm{NiO} / \mathrm{SiO} 2$ solo 
presenta sitios ácidos Lewis. De acuerdo a lo observado en la Figura 5.11 y a lo establecido con los catalizadores sin $\mathrm{Ni}$, la cantidad de sitios ácidos Lewis aumenta debido a la adición de $\mathrm{Ni}$ a la zirconia sulfatada como especies oxidadas NiOx superficial y que actúa como sitio ácido de Lewis. De manera similar a lo reportado por Weismeijer y col. [15] con catalizadores de $\mathrm{RuO} / \mathrm{TiO}_{2}$, las especies de $\mathrm{NiOx}$ pueden actuar como sitios ácidos Lewis debido a la polarización de la densidad electrónica de Ni por la presencia de O, creándose una especie de tipo $\mathrm{Ni}^{\delta+}-\mathrm{O}^{\delta-}$, con una deficiencia de electrones alrededor del átomo de $\mathrm{Ni}$ que actúa como sitio ácido de Lewis. Lo anterior es evidente en el catalizador de $\mathrm{NiO} / \mathrm{SiO}_{2}$ ya que el soporte de $\mathrm{SiO}_{2}$ no presenta ningún tipo de interacción con la piridina, pero una vez que se soporta Ni se observan señales de acidez tipo Lewis para temperatura de 50 y $100{ }^{\circ} \mathrm{C}$. Con respecto a la fuerza de los sitios ácidos, los materiales de Ni/ZrS2 y NiZrS2 presentan acidez de fuerza media con cierta cantidad de piridina adsorbida a $300{ }^{\circ} \mathrm{C}$ en sitios Lewis. La acidez Brønsted se puede considerar como de fuerza débil ya que a $200{ }^{\circ} \mathrm{C}$ presentan una disminución considerable con respecto a los catalizadores sin $\mathrm{Ni}$. El catalizador de $\mathrm{NiO} / \mathrm{SiO}_{2}$ presenta acidez débil mostrando solo una pequeña cantidad de sitios Lewis a $100^{\circ} \mathrm{C}$. 
a)

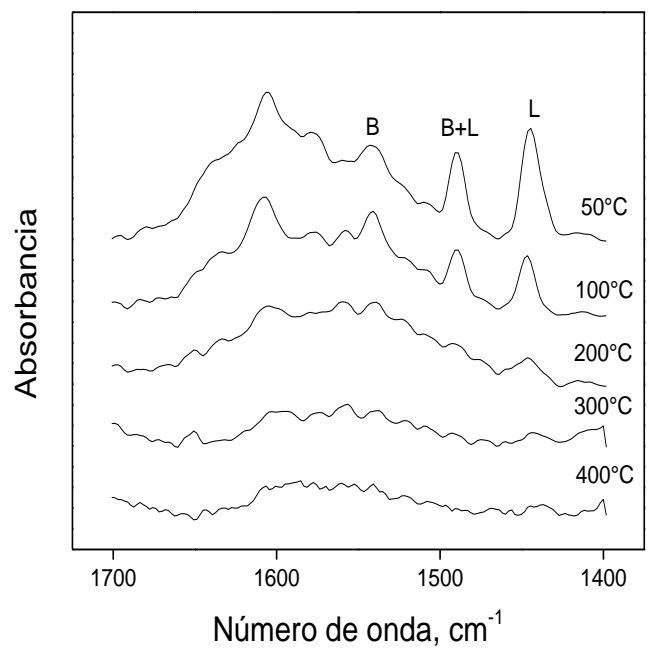

b)

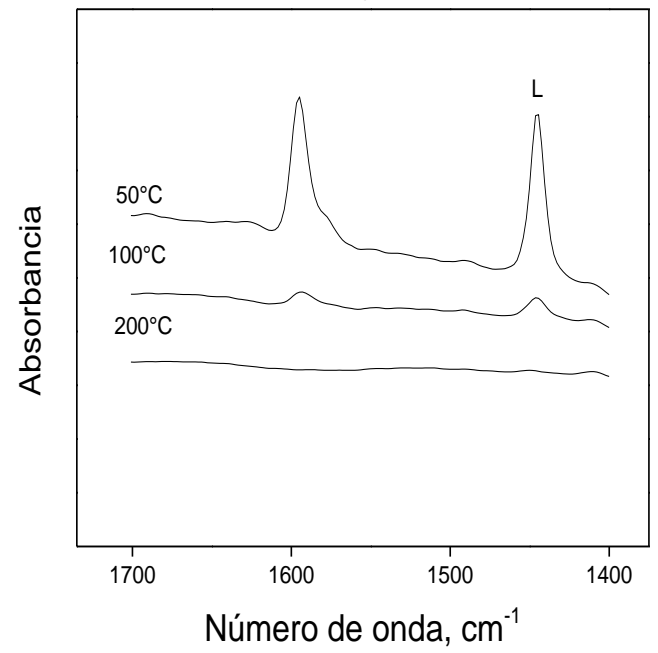

c)

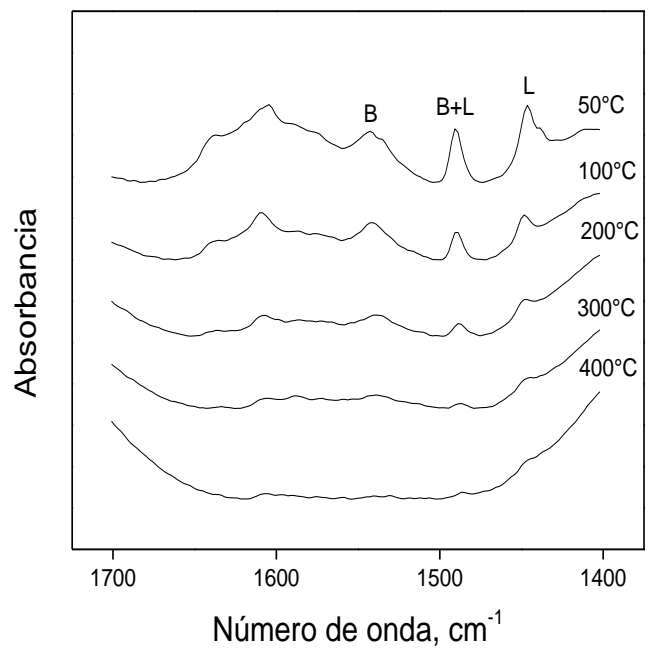

Figura 5.11 Espectro de IR de piridina en a) NiZrS2 y c) Ni/ZrS2 después de evacuación a 50, 100, 200, 300 y $40{ }^{\circ} \mathrm{C}$; y de b) $\mathrm{NiO} / \mathrm{SiO}_{2}$ a temperatura de evacuación de 50, 100 y $200{ }^{\circ} \mathrm{C}$. L: $1440 \mathrm{~cm}^{-1}, 1610 \mathrm{~cm}^{-1}$; B: 1540 $\mathrm{cm}^{-1} ; \mathrm{B}+\mathrm{L}: 1490 \mathrm{~cm}^{-1}$. 


\subsection{Cantidad de Ni. Absorción Atómica}

La disolución de níquel en mezcla de ácidos y mediante absorción atómica se pudo cuantificar la cantidad real de $\mathrm{Ni}$ en los materiales catalíticos. De manera analítica esta técnica puede dar resultados confiables dentro de un margen de error considerable, ya que los diferentes pasos en la realización de la técnica pueden ir propagando el error experimental. La Tabla 5.5 muestra la cantidad de níquel teórica determinada para la síntesis y la cantidad real de Ni determinada por AA para los materiales de Ni/SiO2, Ni/ZrS2 y NiZrS2. Las diferencias en los resultados teóricos y reales se atribuyen al error experimental.

Tabla 5.5 Cantidad de Ni determinada por absorción atómica

\begin{tabular}{c|c|c}
\hline Catalizador & $\begin{array}{c}\text { \% en peso } \mathbf{N i} \\
\text { teórico }\end{array}$ & $\begin{array}{c}\text { \% en peso } \mathbf{~ N i} \\
\text { real }^{\mathbf{a}}\end{array}$ \\
\hline $\mathrm{Ni} / \mathrm{SiO}_{2}$ & 3 & 1.9 \\
\hline $\mathrm{Ni} / \mathrm{ZrS} 2$ & 3 & 2.6 \\
\hline $\mathrm{NiZrS2}$ & 3 & 2.8 \\
\hline
\end{tabular}

aDeterminado por Absorción Atómica

\subsection{Cantidad de sitios activos hidrogenantes. Quimisorción de hidrógeno (Q- $\left.\mathrm{H}_{2}\right)$}

Las isotermas de quimisorción reversible, irreversible y total de $\mathrm{H}_{2}$ para los catalizadores de $\mathrm{Ni} / Z r S 2, \mathrm{NiZrS} 2$ y Ni/SiO 2 se muestran en la Figura 5.9, donde se puede observar que en el material de $\mathrm{Ni} / \mathrm{SiO}_{2}$ reducido a $400^{\circ} \mathrm{C}$ existe una cierta cantidad de $\mathrm{H}_{2}$ quimisorbido en la monocapa que permite determinar una dispersión de 7.5\%. Los materiales de $\mathrm{NiO} / \mathrm{SiO}_{2}$, $\mathrm{Ni} / Z r S 2$ y NiZrS2 se sometieron, previo al análisis, a un tratamiento a $100^{\circ} \mathrm{C}$ en flujo de $\mathrm{H}_{2}$ ya que a estas condiciones son a las que se encuentra en el medio de reacción cuando se llevan a cabo las pruebas de hidrogenación. Dichos materiales muestran las tres isotermas de igual manera que el catalizador de $\mathrm{Ni}$ reducido, pero además presentan una capacidad de quimisorción de $\mathrm{H}_{2}$ más baja como se reporta en la Tabla 5.6. Esto indica que existe cierta cantidad de sitios capaces de quimisorber hidrógeno aunque el Ni no se encuentre en estado metálico. 
a)

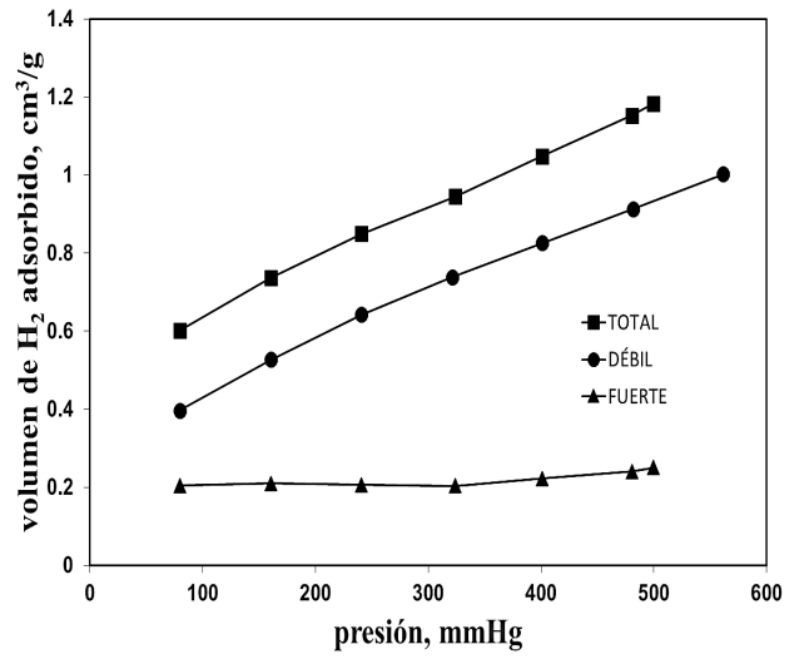

c)

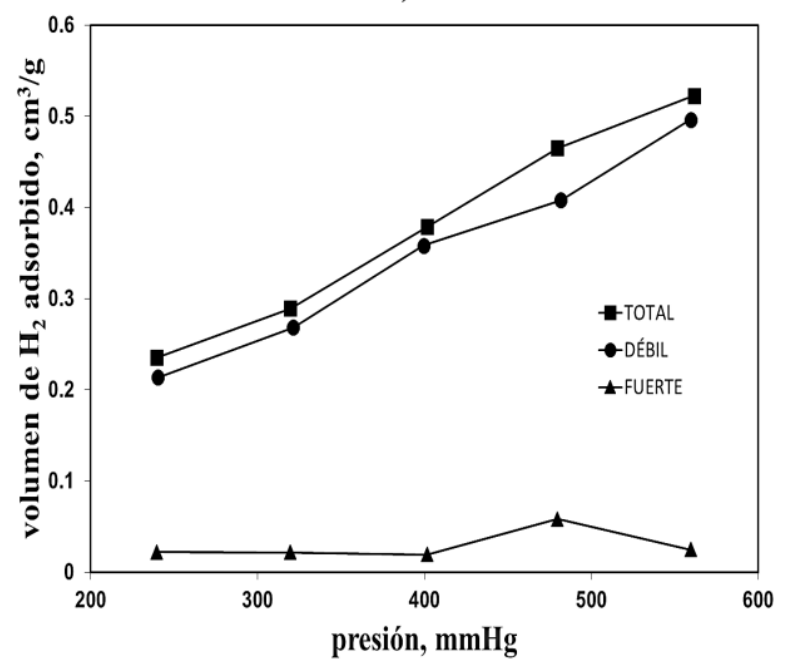

b)

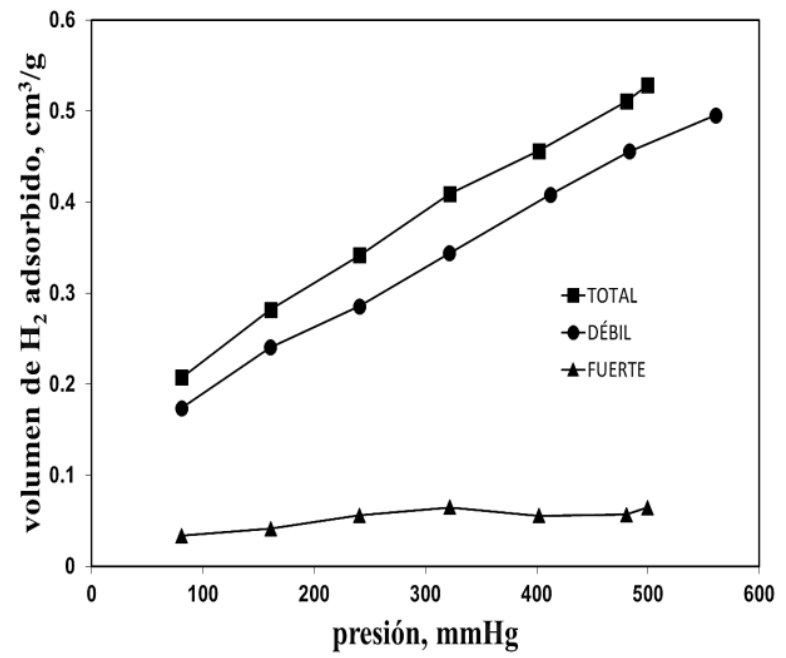

d)

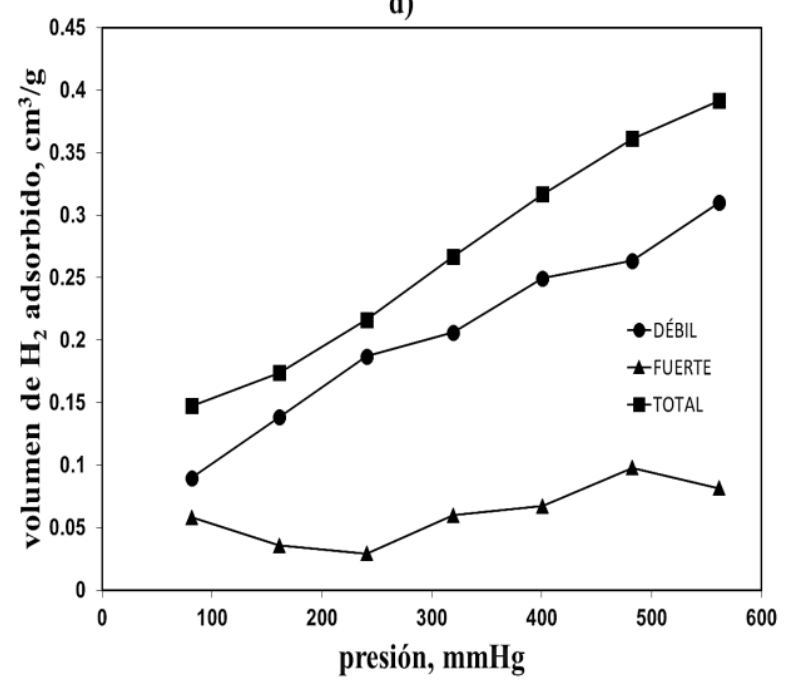

Figura 5.9. Isotermas de quimisorción de $\mathrm{H}_{2}$ determinadas por el método volumétrico para catalizadores de $\mathrm{Ni}$ soportado en $\mathrm{SiO}_{2}$ y ZrS2. a) $\mathrm{Ni} / \mathrm{SiO}_{2}$ reducido a $400^{\circ} \mathrm{C}$; b) $\mathrm{Ni} / \mathrm{SiO}_{2}$ sin reducir; c) $\mathrm{Ni} / \mathrm{ZrS} 2$ y d) $\mathrm{NiZrS} 2$ sin reducir.

Tabla 5.6. Resultados de quimisorción de $\mathrm{H}_{2}$ en catalizadores de Ni soportado determinados por el método volumétrico.

\begin{tabular}{c|c|c}
\hline catalizador & tratamiento & $\mathrm{Hm}\left(\boldsymbol{\mu m o l} / \mathbf{g}_{\text {cat }}\right)$ \\
\hline $\mathrm{Ni} / \mathrm{SiO}_{2}$ & Reducción a $400^{\circ} \mathrm{C}$ & 96 \\
\hline $\mathrm{Ni} / \mathrm{SiO}_{2}$ & Flujo de $\mathrm{H}_{2}$ a $100^{\circ} \mathrm{C}$ & 40 \\
\hline $\mathrm{Ni} / \mathrm{ZrS} 2$ & Flujo de $\mathrm{H}_{2}$ a $100^{\circ} \mathrm{C}$ & 22 \\
\hline $\mathrm{NiZrS}$ & Flujo de $\mathrm{H}_{2}$ a $100^{\circ} \mathrm{C}$ & 20 \\
\hline
\end{tabular}




\section{RESULTADOS Y DISCUSIÓN DE LA ACTIVIDAD CATALÍTICA}

\section{A. Ciclización de citronelal}

En esta sección se presentan los resultados de la actividad catalítica en la ciclización de citronelal de los materiales de zirconia sulfata sintetizados por el método sol-gel. Se muestran los resultados de conversión de citronelal, selectividad y estereoselectividad de isopulegol en función de la cantidad de sulfato presente en la zirconia. Por otro lado se determina el efecto de la adición de níquel en la actividad catalítica.

En la Figura 6.1 se observa la evolución del porcentaje de conversión de citronelal (CAL) en función del tiempo con los materiales ZrS1, ZrS2 y ZrS3. Se puede observar que se alcanza una conversión de 85\% en 180 min con ZrS1, mientras que con ZrS2 y ZrS3 alcanza una conversión total en los primeros instantes de la reacción. No existe una relación entre el comportamiento de la actividad catalítica de los materiales y la cantidad de sitios ácidos totales obtenidos por termodesorción de piridina (Sección 5.5) donde se observa que ZrS1 tiene mayor cantidad de sitios ácidos superficiales que ZrS2 (Tabla 5.4. ZrS1: 214 $\mu \mathrm{mol} / \mathrm{g}_{\text {cat }} ; Z \mathrm{rS2}: 154 \mu \mathrm{mol} / \mathrm{g}_{\text {cat }}$. La actividad está relacionada con la cantidad de sitios ácidos Brønsted, ya que los materiales ZrS2 y ZrS3 presentan la mayor cantidad de este tipo de sitios (Tabla 5.4. ZrS1: $90 \mu \mathrm{mol} / \mathrm{g}_{\text {cat }}$; ZrS2: $114 \mu \mathrm{mol} / \mathrm{g}_{\text {cat }}$; ZrS3: $151 \mu \mathrm{mol} / \mathrm{g}_{\text {cat }}$ ); y aunque la diferencia entre sitios Lewis y Brønsted es pequeña, si logra tener un efecto sustancial en la actividad catalítica. En la Figura 6.1 no se observa una diferencia en actividad ni una evolución representativa de la actividad con respecto al tiempo para los materiales ZrS2 y ZrS3, por lo tanto se realizaron otras pruebas de actividad de ciclización de CAL con una cantidad de catalizador $50 \%$ menor a las pruebas iniciales, éstas se presentan en la Figura 6.2. De los resultados mostrados en la Figura 6.2 se obtuvo la velocidad de reacción inicial para la ciclización de CAL $\left(R_{0, C A L}\right)$ y se presentan en la Tabla 6.1. Se puede observar que con ZrS1 se tiene la menor actividad y que la actividad de ZrS2 y ZrS3 es mayor y comparables. Esto permite concluir que una mayor cantidad de sitios ácidos Brønsted de los materiales ZrS2 y ZrS3, con respecto a los sitios Lewis, le permite tener mayor actividad catalítica. 
a)

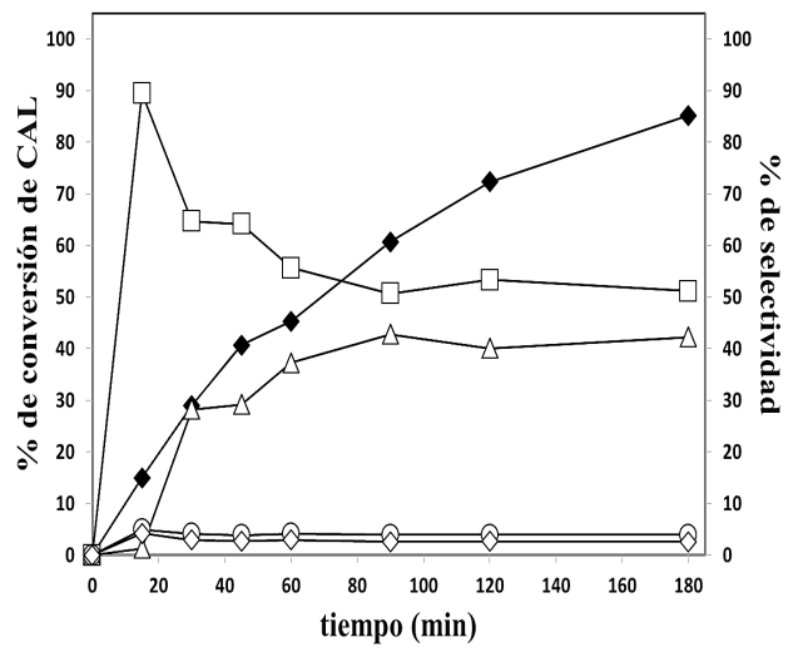

b)

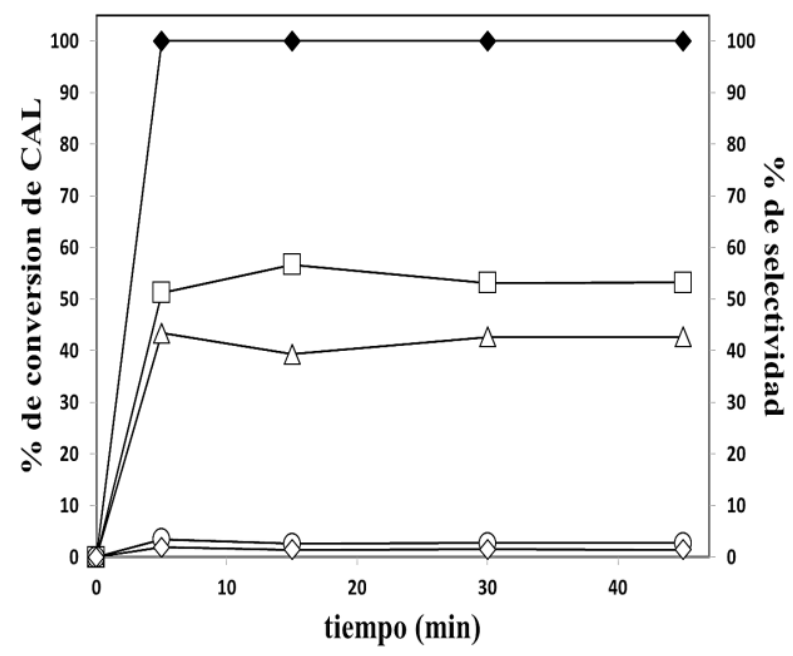

c)

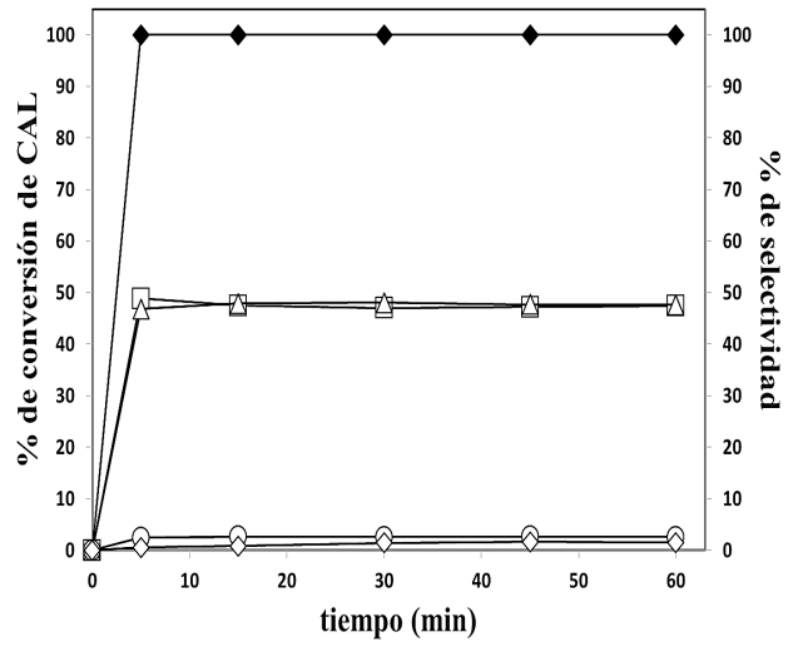

Figura 6.1. Porcentaje de conversión de citronelal y de selectividad de estereoisómeros de isopulegol como función del tiempo con catalizadores a) ZrS1,b) ZrS2 y c) ZrS3 en la ciclización de citronelal (CAL) a T de reflujo de ciclohexano $\left(70{ }^{\circ} \mathrm{C}\right)$ y $0.36 \mathrm{M} \mathrm{CAL} / \mathrm{CHEX}, 50 \mathrm{mg}$ de catalizador. $\bullet$ conversión de CAL; $\square$ isopulegol; $\triangle$ neo isopulegol; $\bigcirc$ neo-iso isopulegol; $\diamond$ iso-isopulegol.

De estudios de teoría de funcionales de densidad se ha propuesto que la ciclización eno se lleva a cabo en sitios Lewis por medio de un mecanismo por etapas, mientras que en sitios Brønsted la ciclización eno se lleva cabo por un mecanismo concertado. Cuando se lleva a cabo la reacción de ciclización por medio de un mecanismo por etapas la actividad catalítica es menor con respecto a un mecanismo concertado [58]. Esto no explica del todo la diferencia de actividad de los catalizadores de ZrS1, ZrS2 y ZrS3 en la ciclización de citronelal, pero la presencia de un protón en la superficie de materiales con acidez Brønsted incrementa de manera considerable la actividad catalítica [18]. De los resultados de FTIR 
de piridina también se determinó que el material de ZrS1 tiene una acidez Lewis débil comparada con los materiales ZrS2 y ZrS3 y esto puede ser la causa de la menor actividad catalítica, ya que en un mecanismo por etapas, la primera etapa a considerar es la coordinación de la molécula en un sitio acido de naturaleza Lewis fuerte para llevar a cabo la primera etapa de manera eficaz y después llevar a cabo la ciclización eno [17]. Otra evidencia que apoya lo anterior es la actividad presentada por el material de $\mathrm{Ni} / \mathrm{SiO}_{2}$ que muestra una baja actividad de ciclización de citronelal y los resultados de adsorción de piridina muestran que solo existen sitios ácidos Lewis debido a la presencia de NiOx y de fuerza ácida débil.
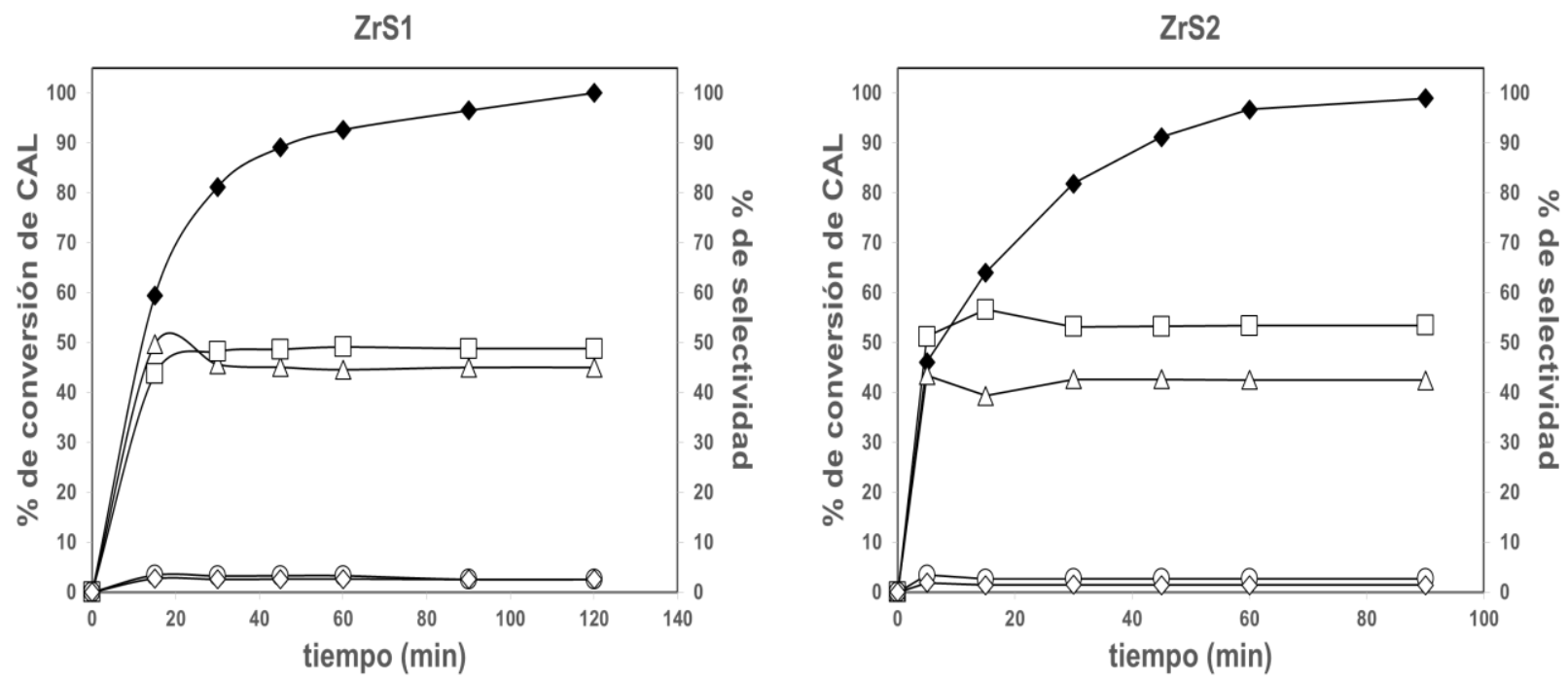

ZrS3

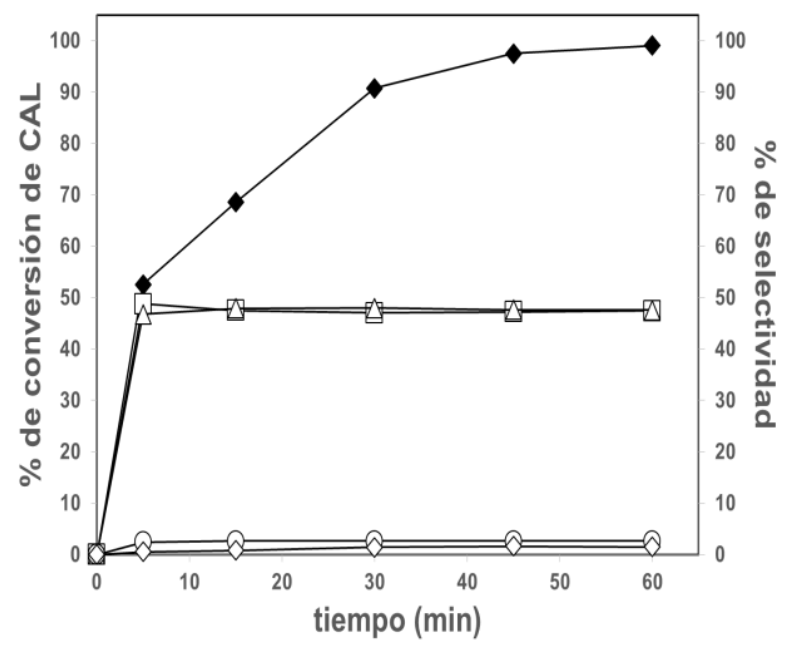

Figura 6.2. Porcentaje de conversión de citronelal y de selectividad de estereoisómeros de isopulegol como función del tiempo con catalizadores ZrS1, ZrS2 y ZrS3 en la ciclización de citronelal (CAL) a T de reflujo de ciclohexano $\left(70^{\circ} \mathrm{C}\right)$ y $0.36 \mathrm{M} \mathrm{CAL} / \mathrm{CHEX}, 25 \mathrm{mg}$ de catalizador. $\bullet$ conversión de CAL; $\square$ isopulegol; $\triangle$ neo isopulegol; $\bigcirc$ neo-iso isopulegol; $\diamond$ iso-isopulegol. 
Tabla 6.1. Resultados de conversión de citronelal (CAL) en la reacción de ciclización, \% selectividad de mezcla de isopulegol y \% estereoselectividad de isopulegoles al final de la reacción.

\begin{tabular}{|c|c|c|c|c|c|c|c|}
\hline \multirow{2}{*}{ catalizador } & \multirow{2}{*}{$\begin{array}{c}\text { Tiempo } \\
\text { (X⿳A口) }\end{array}$} & \multirow{2}{*}{$\begin{array}{c}\text { \%Selectividad } \\
\text { isopulegol }\end{array}$} & \multirow{2}{*}{$\begin{array}{c}R_{0, C A L X 10^{3}} \\
\left(\mathrm{~mol} / \mathrm{g}_{\mathrm{cat}} \cdot \mathrm{min}\right)\end{array}$} & \multicolumn{4}{|c|}{$\%$ estereoselectividad } \\
\hline & & & & $\mathbf{A}$ & B & $\mathbf{C}$ & D \\
\hline ZrS1 & $180 \min (85 \%)$ & 100 & 5 & 52 & 42 & 4 & 2 \\
\hline ZrS2 & $15 \min (100 \%)$ & 100 & 20 & 53 & 42 & 3 & 2 \\
\hline ZrS3 & $15 \min (100 \%)$ & 100 & 23 & 47 & 47 & 4 & 2 \\
\hline
\end{tabular}

Con respecto a la selectividad, en la Figura 6.1 y 6.2 se observa que solo existen productos de la ciclización de CAL ( $100 \%$ de selectividad hacia la mezcla de isopulegoles) y no existe la formación de otro tipo de compuestos derivados de reacciones no deseadas como la deshidratación y eterificación de citronelal. El efecto del tipo de acidez Brønsted o Lewis no se ve reflejado en los resultados obtenidos con los materiales ZrS1, ZrS2 y ZrS3, ya que como se discutió anteriormente, dichos materiales tienen una relación Brønsted/Lewis diferentes y una selectividad de $100 \%$ hacia la mezcla de isopulegoles se presenta en $\mathrm{ZrS1}$, ZrS2 y ZrS3, esto indica que la ciclización de CAL puede llevarse a cabo en ZrS sin importar la relación de sitios ácidos Lewis/Brønsted y presentando únicamente la mezcla de los cuatro pares enantiómeros de isopulegol.

Adicionalmente, Chuah y col. [22] reportan la formación de grandes cantidades de compuestos de deshidratación y eterificación de citronelal en la reacción de fase líquida con catalizadores de $\mathrm{ZrO}_{2}-\mathrm{SO}_{4}$ cuando la adición de los sulfatos es por impregnación y la zirconia es sintetizada por precipitación, lo cual contrasta con los resultados aquí reportados con la zirconia sulfatada sintetizada por sol-gel, por lo tanto se puede inferir que el tipo de acidez no tiene un efecto en la selectividad de la mezcla de isopulegoles y que el método de preparación por su parte si tiene un efecto importante en la selectividad de isopulegoles en la ciclización de CAL.

Por otra parte, en la Figura 6.1 y 6.2 se puede observar que existe una variación en la distribución de estereoisómeros o pares enantioméricos ( \pm )-isopulegol y ( \pm )-neo-isopulegol con los materiales ZrS1, ZrS2 y ZrS3, los demás estereoisómeros prácticamente permanecen sin cambio en cualquier caso. El material ZrS1 (mayor cantidad de sitios ácidos Lewis) muestra una mayor selectividad hacia ( \pm )-isopulegol al inicio de la reacción y 
conforme avanza la reacción, la formación de ( \pm )-isopulegol disminuye mientras que el ( \pm )neo-isopulegol aumenta. Cuando se realizó la ciclización de CAL con una cantidad menor de catalizador, los resultados de la Figura 6.2 muestran que al inicio de la reacción la selectividad de los estereoisomeros $( \pm)$-isopulegol y $( \pm)$-neo-isopulegol son parecidas y se mantiene hasta completar la conversión total de CAL. Este comportamiento puede deberse a que ocurrió una conversión de sitios ácidos Lewis a sitios ácidos Brønsted por la presencia de humedad en el medio de reacción. La conversión reversible de sitios Lewis y Brønsted esta reportada en varias investigaciones de zirconia sulfatada [54] y consiste en que los sitios ácidos Lewis pueden convertirse en sitios Brønsted por la presencia de agua en la superficie de la zirconia sulfatada, mientras que la eliminación de agua de la superficie por tratamiento térmico puede regenerar la superficie y recuperar los sitios Lewis (ver Figura 6.3). En el material ZrS2 (mayor cantidad de sitios ácidos Brønsted), la formación inicial de $( \pm)$-isopulegol se mantiene durante toda la reacción y mantiene la proporción entre los demás estereoisómeros a lo largo de toda la reacción, hasta completar el 100\% de conversión de CAL. En el material ZrS3 (mayor cantidad de sitios ácidos Brønsted), la selectividad de $( \pm)$-isopulegol y $( \pm)$-neo isopulegol es prácticamente la misma hasta alcanzar la conversión total de CAL, por lo tanto se puede decir que la estereoselectividad de $( \pm)$-isopulegol disminuye. Por el comportamiento observado con los tres catalizadores ZrS1, ZrS2 y ZrS3 se puede concluir que una mayor cantidad de sitios ácidos Lewis con respecto a los Brønsted promueve una mayor selectividad hacia el $( \pm)$-isopulegol y conforme aumenta la cantidad de sitios ácidos Brønsted la selectividad de ( \pm )-isopulegol disminuye y la de ( \pm )-neo-isopulegol aumenta. Este resultado confirma a lo que Corma y col. [16] reportan, ya que en su investigación con catalizadores con acidez Brønsted observaron que conforme aumenta la cantidad de sitios ácidos Brønsted la estereoselectividad de $( \pm)$-isopulegol disminuye.

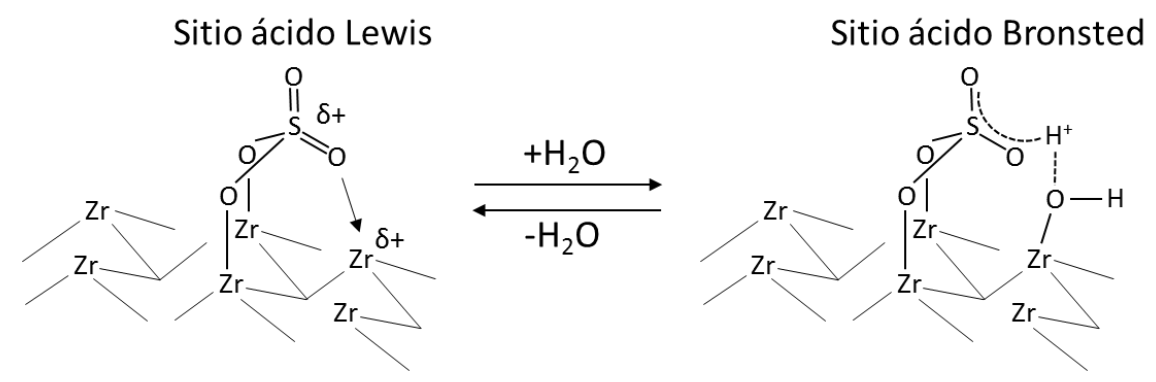

Figura 6.3. Estructura de sitio acido Lewis (izquierda) y sitio ácido Brønsted (derecha) en zirconia sulfatada. 
En la Figura 6.4 se observa el comportamiento de la actividad catalítica del material ZrS2 impregnado con Ni y el material NiZrS2. Los resultados muestran evidentemente que ZrS2 disminuye su actividad cuando se impregna $\mathrm{Ni}$. De acuerdo a lo discutido para los catalizadores de ZrSx, la mayor cantidad de sitios ácidos Lewis con respecto a los sitios Brønsted provoca que exista menor actividad por tratarse de un mecanismo de ciclización eno por etapas. La relación L/B, determinada con los resultados de FTIR de piridina, muestra que los catalizadores de ZrS1, Ni/ZrS2 y NiZrS2 tienen valor mayor a 1 y menor actividad catalítica con respecto a los materiales ZrS2 y ZrS3 que presentan un valor de L/B menor a 1, que implica mayor cantidad de sitios ácidos Brønsted y mayor actividad catalítica. Un resultado similar se muestra en el material NiZrS2 con respecto a la actividad catalítica, donde se pude decir que la incorporación de Ni ya sea por impregnación o por adición in situ en la síntesis sol-gel tiene el mismo efecto sobre la actividad catalítica discutido anteriormente.

a)

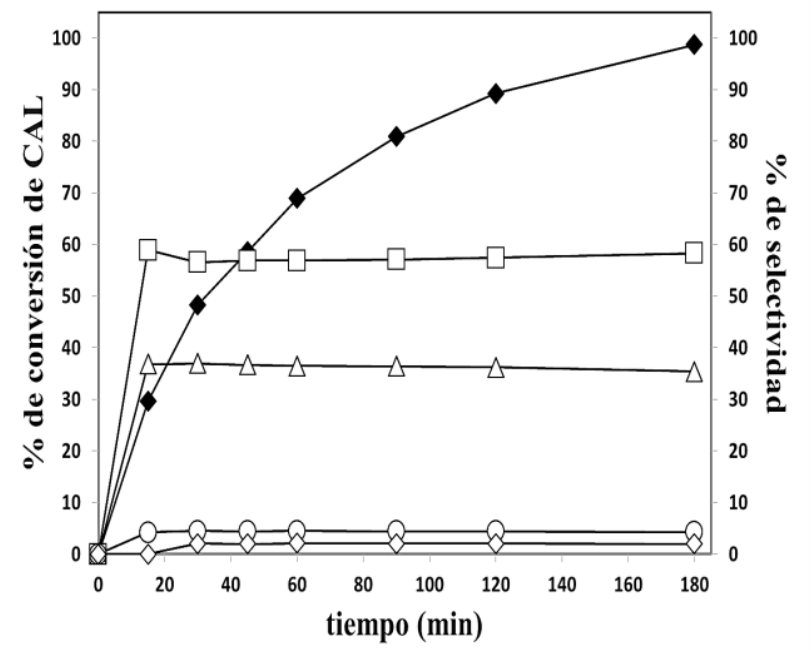

b)

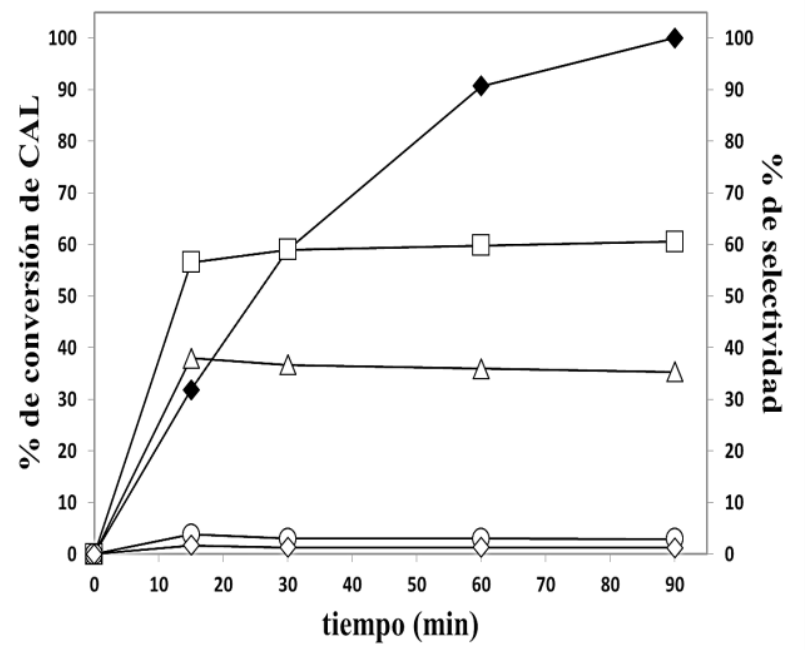

Figura 6.4. Porcentaje de conversión de citronelal y de selectividad de estereoisómeros de isopulegol como función del tiempo con catalizadores a) Ni/ZrS2 y b) NiZrS2 en la ciclización de CAL a T de reflujo de hexano $\left(70{ }^{\circ} \mathrm{C}\right)$ y $0.36 \mathrm{M} \mathrm{CAL} / \mathrm{CHEX}, 25 \mathrm{mg}$ de catalizador. $\bullet$ conversión de CAL; $\square$ isopulegol; $\triangle$ neo isopulegol; $\bigcirc$ neo-iso isopulegol; $\diamond$ iso-isopulegol.

De igual manera que el material de ZrS1, los catalizadores Ni/ZrS2 y NiZrS2 presentan el efecto de la mayor cantidad de sitios ácidos Lewis que se observa en la estereoselectividad donde ambos catalizadores muestran una selectividad de $60 \%$ hacia $( \pm)$-isopulegol y $35 \%$ hacia $( \pm)$-neo-isopulegol. El efecto de la acidez Lewis sobre la estereoselectividad se hace más notable en estos catalizadores que presentan una relación L/B mayor a 1 como ya se 
había discutido anteriormente para los catalizadores de ZrSx. Galvagno y col. [21] y Corma y col. [16] observan el efecto sobre la selectividad de ( \pm )-isopulegol del tipo de acidez Lewis y Brønsted respectivamente. De lo obtenido con ZrSx, Ni/ZrS2 y NiZrS2 se corrobora lo que han reportado los autores mencionados anteriormente pero no se tiene evidencia de lo que ocurre en los mecanismos de reacción que permita esclarecer la función de cada tipo de ácido, ya sea Lewis o Brønsted, en la estereoselectividad. Las explicaciones teóricas acerca de los mecanismos por etapas y concertado hasta el momento no hacen distinción en la forma en que uno u otro estereoisómero puedan obtenerse en función del tipo de acidez.

\section{B. Obtención de mentol a partir de citronelal}

En la Figura 6.5 se muestran los resultados de actividad catalítica de los materiales $\mathrm{NiO} / \mathrm{SiO}_{2}, \mathrm{Ni} / Z r S 2$ y NiZrS2 en la obtención de mentol a partir de citronelal (CAL), donde se observan que los únicos compuestos son isopulegol y mentol, productos de la ciclización de CAL y de la hidrogenación de isopulegol respectivamente. Las condiciones de operación fueron a $100{ }^{\circ} \mathrm{C}, 1.4 \mathrm{MPa}$ de $\mathrm{H}_{2}, 500 \mathrm{mg}$ de catalizador y $0.1 \mathrm{M}$ de CAL/CHEX. Como se mencionó en la metodología experimental, los tres materiales utilizados tuvieron un tratamiento post-síntesis a $450^{\circ} \mathrm{C}$ para su calcinación y previo a la reacción, los materiales se sometieron a un flujo de He para la eliminación de humedad y no se sometieron a tratamiento de reducción de Ni. De acuerdo a lo observado en la Figura 6.5, el catalizador de $\mathrm{NiO} / \mathrm{SiO}_{2}$ presenta baja actividad catalítica, con solo $55 \%$ de conversión después de 120 minutos de reacción. Los resultados de adsorción de piridina muestran que $\mathrm{NiO} / \mathrm{SiO}_{2}$ solo contiene acidez tipo Lewis y como se discutió en el apartado A de esta sección, cuando existe una mayor cantidad de sitios Lewis que sitios Brønsted la actividad es baja comparada con los catalizadores que muestran una mayor cantidad de sitios ácidos Brønsted. En este caso, el catalizador $\mathrm{NiO} / \mathrm{SiO}_{2}$, que solo muestra acidez Lewis, se esperaba que tuviera una baja actividad catalítica. Los catalizadores de Ni/ZrS2 y NiZrS2, de acuerdo a los resultados de FTIR de piridina, contienen ambos tipos de sitios Brønsted y Lewis que los hace más activos en la reacción de ciclización de CAL. Estos resultados complementan a lo discutido anteriormente para la ciclización de CAL con catalizadores de ZrSx en relación con la proporción de sitios ácidos Brønsted y Lewis, donde los materiales con una mayor cantidad de sitios ácidos Brønsted en relación con los sitios ácidos Lewis presentan un aumento considerable en la actividad catalítica. En este caso se observa que la presencia de sitios ácidos Brønsted en Ni/ZrS2 y NiZrS2 aumenta la actividad catalítica 
en la ciclización de CAL y que no es necesario que exista una mayor cantidad de sitios Brønsted con respecto a su similar Lewis.

a)

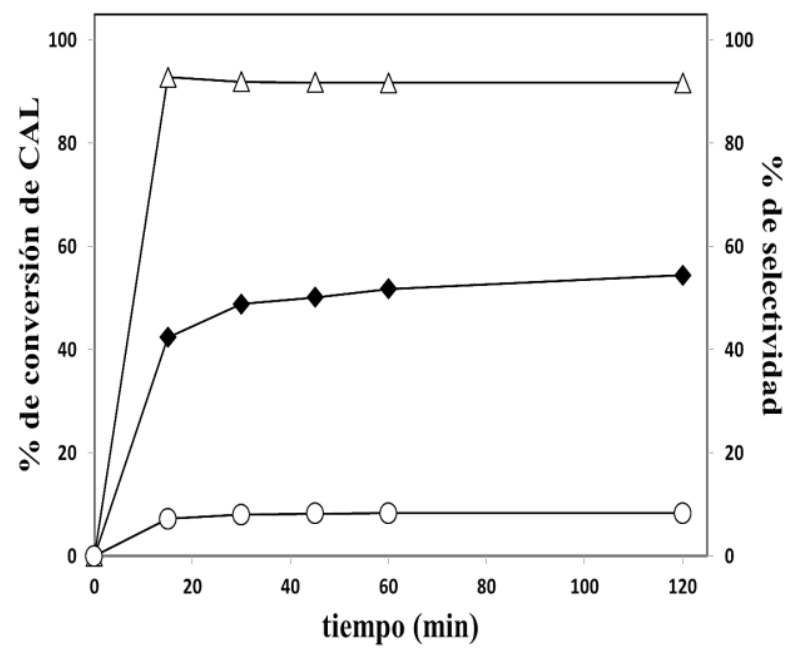

b)

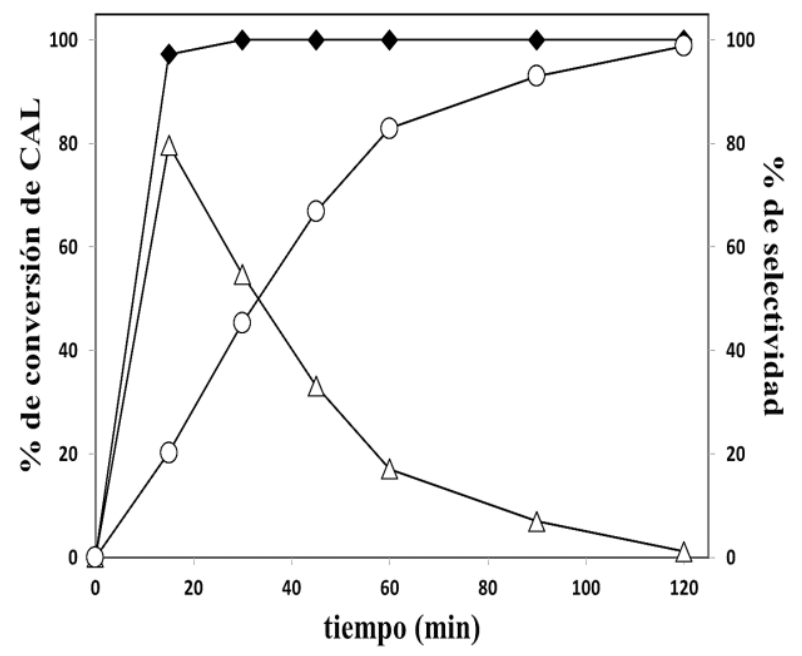

c)

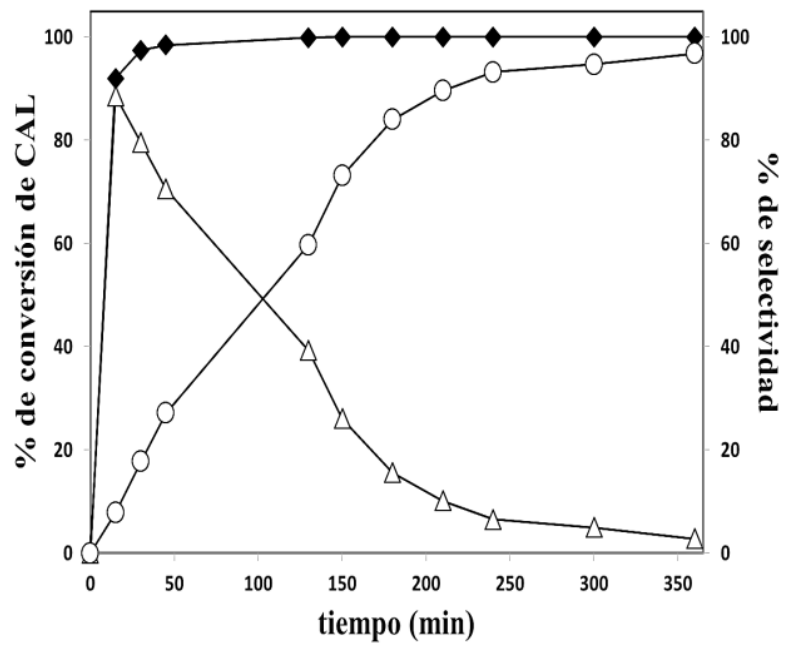

Figura 6.5. Porcentaje de conversión de citronelal y de selectividad de isopulegol y mentol como función del tiempo con catalizadores a) $\mathrm{NiO} / \mathrm{SiO}_{2}$, b) Ni/ZrS2 y c) NiZrS2 en la obtención de mentol a partir de CAL a 100 ${ }^{\circ} \mathrm{C}, 1.4 \mathrm{MPa}$ de $\mathrm{H}_{2}, 500 \mathrm{mg}$ de catalizador, $0.1 \mathrm{M} \mathrm{CAL} / \mathrm{CHEX}$. conversión de CAL; $\triangle$ isopulegol; $\bigcirc$ mentol.

La Tabla 6.2 muestra los resultados de actividad inicial para la reacción de ciclización (Rco) e hidrogenación de isopulegol ( $\left.\mathbf{R}_{\mathbf{1 0}}\right)$; además se muestran los resultados de la frecuencia de recambio (TOF por sus siglas en inglés) obtenido con la cantidad de sitios hidrogenantes y sitios ácidos. El catalizador de Ni/ZrS2 muestra la mayor actividad catalítica para la ciclización de CAL e hidrogenación de isopulegol, lo cual indica que existe un efecto del método de incorporación de $\mathrm{Ni}$ en el catalizador sobre la actividad catalítica posiblemente 
debido a la dispersión de Ni. Dados los resultados podemos inferir que el catalizador de $\mathrm{Ni} / Z r S 2$, donde el Ni fue incorporado por impregnación por mojado incipiente, nos permite obtener un material más disperso y con partículas de $\mathrm{NiO}$ expuestas sobre la superficie de la ZrS2; mientras que el catalizador de NiZrS2 obtenido por la incorporación de Ni desde la síntesis sol-gel puede contener tanto partículas de $\mathrm{Ni}$ en la superficie como en el bulk de la zirconia sulfatada, dando como resultado una disminución en la cantidad de sitios activos disponibles y como consecuencia una disminución de la actividad. Los resultados de adsorción de piridina muestran que el material de NiZrS2 contiene una cantidad menor de sitios ácidos totales (Brønsted + Lewis) que el material de Ni/ZrS2 y a esto se le atribuye la menor actividad catalítica en la ciclización de CAL.

Tabla 6.2. Resultados de velocidad de reacción inicial de citronelal ( $\left.\mathbf{R}_{\mathbf{c o}}\right)$ e isopulegol ( $\left.\mathbf{R}_{\mathbf{1 0}}\right)$ de frecuencia de recambio (TOF) para las reacciones de ciclización de CAL e hidrogenación de isopulegol en la obtención de mentol a partir de citral.

\begin{tabular}{|c|c|c|c|c|}
\hline Catalizador & $\begin{array}{c}R_{c 0} \times 10^{6} \\
\left(\mathrm{~mol} / \mathbf{g}_{\text {cat }} \cdot \mathbf{s}\right)\end{array}$ & $\begin{array}{l}\text { TOF }_{c 0} \\
\left(\mathbf{s}^{-1}\right)\end{array}$ & $\begin{array}{c}R_{10} \times 10^{6} \\
\left(\mathrm{~mol} / \mathrm{g}_{\mathrm{cat}} \cdot \mathrm{s}\right)\end{array}$ & $\begin{array}{l}\text { TOF }_{10} \\
\left(s^{-1}\right)\end{array}$ \\
\hline $\mathrm{Ni} / \mathrm{ZrS} 2$ & 6.40 & 0.2135 & 12.06 & 0.2010 \\
\hline NiZrS2 & 3.78 & 0.0398 & 8.71 & 0.1452 \\
\hline
\end{tabular}

La distribución de productos para los tres catalizadores $\mathrm{NiO} / \mathrm{SiO}_{2}, \mathrm{Ni} / \mathrm{ZrS} 2$ y NiZrS2 solo comprende de los estereoisómeros de isopulegol y mentol (Figura 6.5). El isopulegol se origina de la ciclización de citronelal y no se observa algún otro componente proveniente de CAL tales como citronelol y 3,7-dimetil-1-octanal, que son productos de la hidrogenación de CAL o compuestos provenientes del craqueo, deshidratación o eterificación de citronelal, como lo reporta Chuah y col. [22] para la actividad de la zirconia sulfatada, por lo tanto la selectividad en la reacción de ciclización de CAL es de 100\% hacia la mezcla de estereoisómeros de isopulegol con los catalizadores $\mathrm{NiO} / \mathrm{SiO}_{2}, \mathrm{Ni} / \mathrm{ZrS} 2$ y NiZrS2. Este resultado es de suma importancia, ya que el $\mathrm{Ni}$ en estos catalizadores no se encuentran en estado metálico por no haberse sometido a un proceso de reducción previo a la reacción y se encuentra como especie $\mathrm{NiO}$. Esta especie de $\mathrm{Ni}$ no es capaz de hidrogenar los dobles enlaces $\mathrm{C}=\mathrm{O}$ y $\mathrm{C}=\mathrm{C}$ aislado de citronelal, pero si tiene la capacidad de hidrogenar el doble enlace $\mathrm{C}=\mathrm{C}$ de isopulegol y así formar el mentol, por lo que la especie $\mathrm{NiO}$ en $\mathrm{SiO}_{2}$ y $\mathrm{ZrS}$ se vuelve muy selectiva en la reacción de hidrogenación en fase líquida de CAL. En un trabajo previo [6] se llevó a cabo la hidrogenación en fase líquida de citral con un catalizador de $\mathrm{Ni} / \mathrm{SiO}_{2}$ reducido a $450^{\circ} \mathrm{C}$. Los resultados mostraron que citronelal se produce selectivamente $(90 \%$ de selectividad) a partir de citral y se presentaron hidrogenaciones 
consecutivas de citronelal para producir citronelol hasta llegar al alcohol saturado 3,7dimetil-1-octanol por hidrogenación consecutiva. También se llevó a cabo la ciclización de citronelal como reacción paralela a la hidrogenación y se obtuvo una baja producción de isopulegol y mentol. Esto permitió establecer que después del pretratamiento a $450^{\circ} \mathrm{C}$, no se completó la reducción de toda la cantidad de Ni soportada y que permanecieron especies de $\mathrm{NiO}$ sin reducir, que fungieron como sitios ácidos de Lewis y que fueron capaces de llevar a cabo la ciclización de citronelal para producir isopulegol en baja concentración. Resultados similares fueron reportados por Weismeijer y col. [15] con catalizadores de $\mathrm{Ru} / \mathrm{TiO}_{2}$, donde observaron que solo la fase metálica puede llevar a cabo la hidrogenación de citronelal y que una especie no reducida de RuOx cataliza la reacción de ciclización para producir isopulegol. Por otro lado, Chuah y col. [26] mostraron que $\mathrm{Ni}^{0}$ soportado en $\mathrm{MCM}$ 41 no es funcional para la ciclización de citronelal y que en presencia de $\mathrm{H}_{2}$ en el medio de reacción solo obtuvieron compuestos de hidrogenación de citronelal como citronelol y 3,7dimetil-octanal. Dado lo anterior podemos concluir que la presencia de níquel como especie $\mathrm{NiO}$ cataliza la reacción de ciclización de citronelal para producir isopulegol como especie acida de Lewis, ya que los resultados de FTIR de adsorción de piridina muestran que el material de $\mathrm{NiO} / \mathrm{SiO}_{2}$ sin reducir contiene acidez Lewis débil (ver Sección 5.5). Por otro lado, la producción de mentol indica que existen sitios en el material de $\mathrm{NiO} / \mathrm{SiO}_{2}$ que catalizan la reacción de hidrogenación de isopulegol. Los resultados de quimisorción de hidrógeno en $\mathrm{NiO} / \mathrm{SiO}_{2}$ muestran que este material tiene la capacidad de quimisorber $\mathrm{H}_{2}$ en la superficie y los resultados cinéticos muestran que esa capacidad solo es funcional para llevar a cabo la hidrogenación del doble enlace aislado $\mathrm{C}=\mathrm{C}$ de isopulegol y que no tiene la especificidad para realizar la hidrogenación directa de citronelal para producir el alcohol insaturado (hidrogenación de $\mathrm{C}=\mathrm{O}$ ) $\mathrm{O}$ el aldehído saturado (hidrogenación de $\mathrm{C}=\mathrm{C}$ conjugado). Para respaldar lo anteriormente discutido se llevó a cabo la hidrogenación de (-)-isopulegol en el catalizador de Ni/ZrS2 sin reducir y se observó que existe una conversión de $80 \%$ después de 300 minutos de reacción como se observa en la Figura 6.6. 


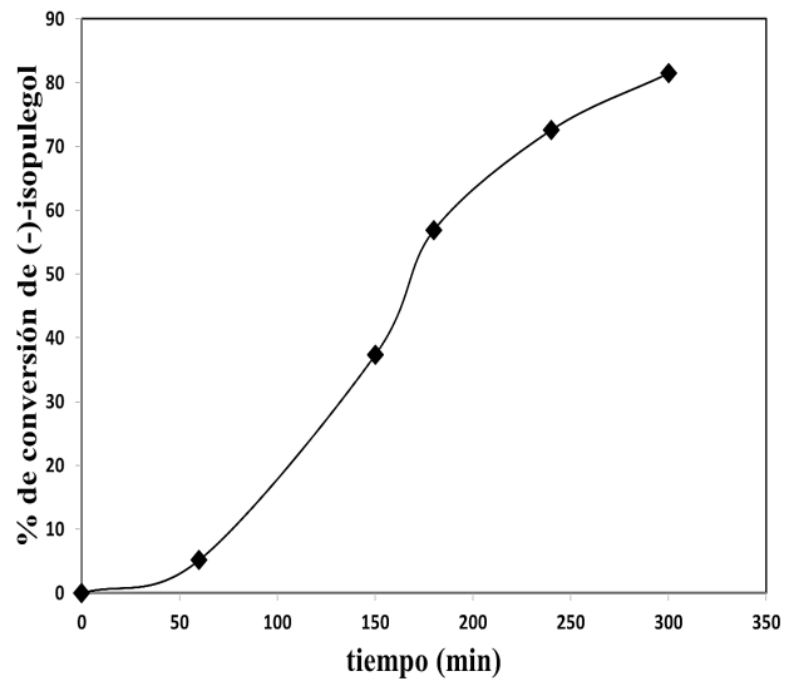

Figura 6.6. Porcentaje de conversión de isopulegol con catalizadores de Ni/ZrS2 a $100 \stackrel{\circ}{\mathrm{C}}, 1.4 \mathrm{MPa}$ de $\mathrm{H}_{2}, 500$ $\mathrm{mg}$ de catalizador, $0.1 \mathrm{M}$ CAL/CHEX.

Con respecto a la distribución de productos, la selectividad de los pares enantioméricos de mentol corresponde a lo que se obtiene con los isopulegoles en la reacción de ciclización de citronelal con ZrS2, es decir la estereoselectividad de ( \pm )-isopulegol es igual a la estereoselectividad de $( \pm)$-mentol, ya que no existe interconversión entre los estereoisómeros de mentol. Esto ya se ha reportado en otro tipo de sistemas catalíticos cuando se obtiene mentol a partir de citral o citronelal [19,31]. Por lo tanto con los sistemas catalíticos de Ni/ZrS2 y NiZrS2 se tiene una eficiencia atómica de 100\% hacia la obtención de mentol a partir de citronelal.

\section{Obtención de mentol a partir de citral}

Se presentan los resultados de la evaluación catalítica de las mezclas mecánicas de $\mathrm{Ni} / \mathrm{SiO}_{2}+\mathrm{ZrS} 2$ variando la relación en peso entre ambos materiales. Se determina la conversión de citral y se cuantifica la selectividad de productos. Además se presentan resultados de análisis cinético observado para determinar la actividad de cada una de las funciones de los sitios hidrogenantes y ácidos con respecto a la cantidad en peso de cada una de las partes. En el anexo se presenta el mecanismo cinético propuesto.

Previo a las pruebas de reacción de las mezclas mecánicas, los catalizadores de $\mathrm{Ni} / \mathrm{SiO}_{2}$ y ZrS2 se sometieron de manera individual a la prueba catalítica de la obtención de mentol a partir de citral. Los resultados obtenidos mostraron que el catalizador de $\mathrm{Ni} / \mathrm{SiO}_{2}$ presenta 
selectivamente la formación de citronelal al inicio de la reacción y que después de un cierto periodo el citronelal es hidrogenado a su correspondiente alcohol insaturado citronelol. Además se observó en muy baja cantidad la producción de isopulegol y mentol. Con el catalizador de ZrS2 se observó la presencia de compuestos de la isomerización y eterificación de citral con baja actividad catalítica, y además no se observaron compuestos de la hidrogenación de citral. El catalizador de Ni/ZrS2, que se utilizó en la obtención de mentol a partir de citronelal, se sometió a un tratamiento de reducción de $400{ }^{\circ} \mathrm{C}$ para utilizarlo en la obtención de mentol a partir de citral, pero este material presentó un desprendimiento de azufre en el proceso de reducción que ocasionó el envenenamiento del catalizador y como consecuencia no presentó actividad catalítica.

En la Figura 6.7 se observan los resultados de conversión de citral y distribución de productos reportada como selectividad para las mezclas mecánicas de $\mathrm{Ni} / \mathrm{SiO}_{2}+\mathrm{ZrS}$. En La Figura 6.7 se observa que la conversión de citral es de $100 \%$ para los tres sistemas catalíticos, alcanzado una más rápida conversión total con el material $\mathrm{Ni} / \mathrm{SiO}_{2}+\mathrm{ZrS2}$ 90:10 mientras que las mezclas $\mathrm{Ni} / \mathrm{SiO}_{2}+\mathrm{ZrS2} 80: 20$ y Ni/SiO${ }_{2}+\mathrm{ZrS2}$ 60:40 necesitaron mayor tiempo para alcanzar la conversión total de citral.

De acuerdo a lo observado en la Figura 6.7, con las tres mezclas mecánicas se obtienen los mismas productos pero con diferente distribución. La distribución inicial y final de los productos depende de la proporción de las especies catalíticas en la mezcla mecánica. Con la relación 90:10 y 80:20 se observa una mayor selectividad de citronelal inicial y con la relación 60:40 se observa que se lleva a cabo la reacción de ciclización con mayor rapidez debido a la mayor cantidad de ZrS2 en la mezcla mecánica. Existen productos de la ciclización de citral (cimeno, careno, mirceno, pineno, mentatrieno, limoneno) que se observan solo al inicio de la reacción debido a que en la reacción se toma el tiempo inicial cuando el sistema alcanza la temperatura establecida de $100 \stackrel{\circ}{C}$ y se inyecta el $\mathrm{H}_{2}$, durante este periodo de estabilización, la mezcla de reacción interacciona con el catalizador y específicamente el citral reacciona con los sitios ácidos de la ZrS2 y produce los componentes antes mencionados, sin embargo, estos componentes no tienen ninguna transformación durante el tiempo de reacción. 

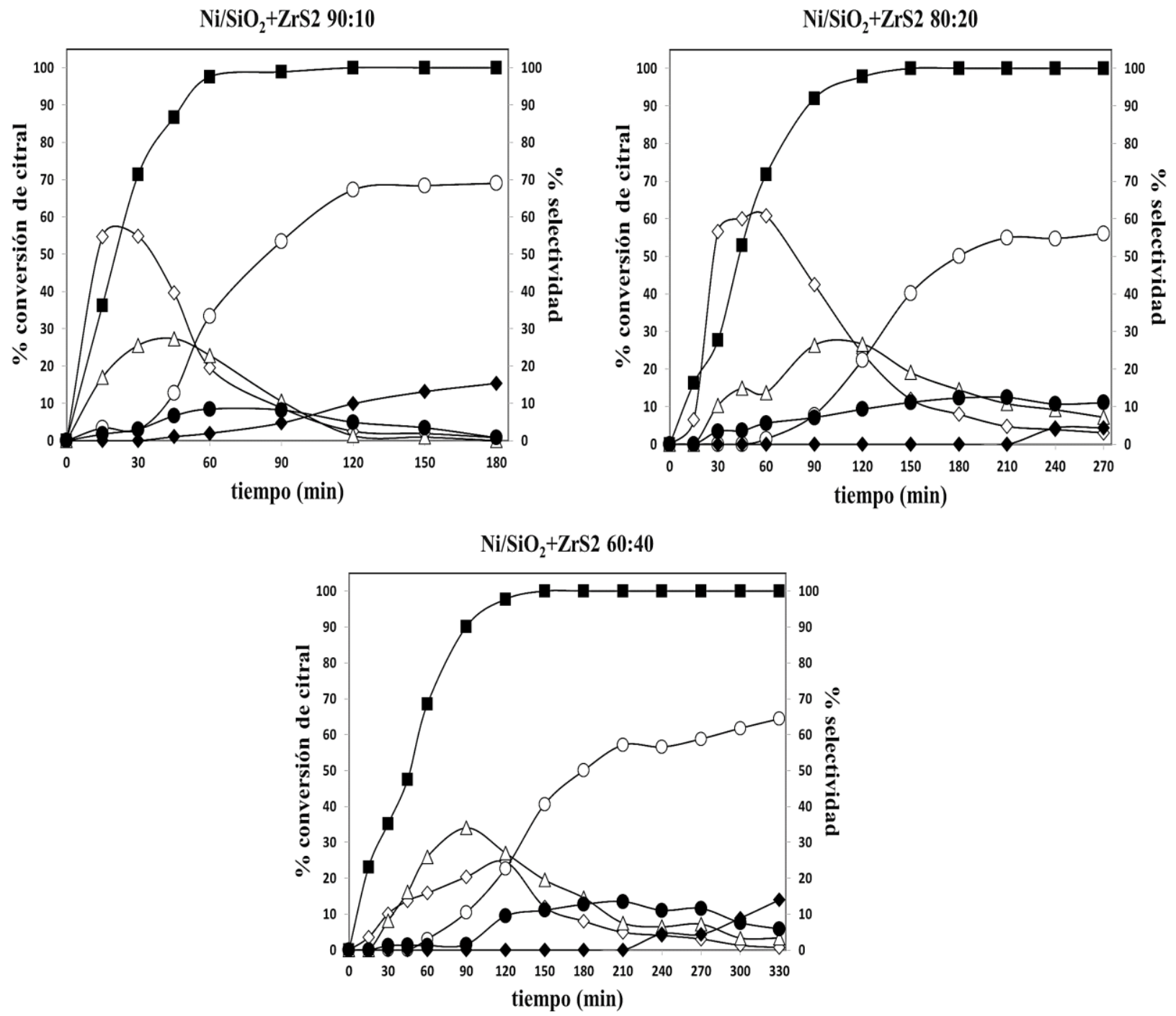

Figura 6.7. Porcentaje de conversión de citral y de selectividad de productos como función del tiempo. Condiciones de reacción: $100{ }^{\circ} \mathrm{C}, 1.4 \mathrm{MPa}$ de $\mathrm{H}_{2}, 500 \mathrm{mg}$ de catalizador, $0.1 \mathrm{M}$ citral/CHEX. Econversión de citral; selectividad: $\diamond$ citronelal, $\triangle$ isopulegol, $\bigcirc$ mentol, Ocitronelol, $\diamond$ 3,7-dimetil-1-octanol.

De la información de la literatura [10-12] se conoce ampliamente que $\mathrm{Ni} / \mathrm{SiO}_{2}$ es un catalizador selectivo hacia la obtención de citronelal a partir de citral. En el caso de la zirconia sulfatada se determinó, con los resultados anteriormente presentados en este trabajo, que es un catalizador ácido con las características para llevar a cabo la ciclización de citronelal con un $100 \%$ de selectividad hacia isopulegol. Por lo tanto, con las mezclas mecánicas de $\mathrm{Ni} / \mathrm{SiO}_{2}$ y ZrS2 se puede plantear el siguiente esquema de reacción mostrado en la Figura 6.8, que presenta la ruta hidrogenación de citral para producir citronelal en el catalizador de $\mathrm{Ni} / \mathrm{SiO}_{2}$, ciclización de citronelal para obtener isopulegol en $\mathrm{ZrS} 2$, y finalmente hidrogenación de isopulegol para producir mentol en $\mathrm{Ni} / \mathrm{SiO}_{2}$. 


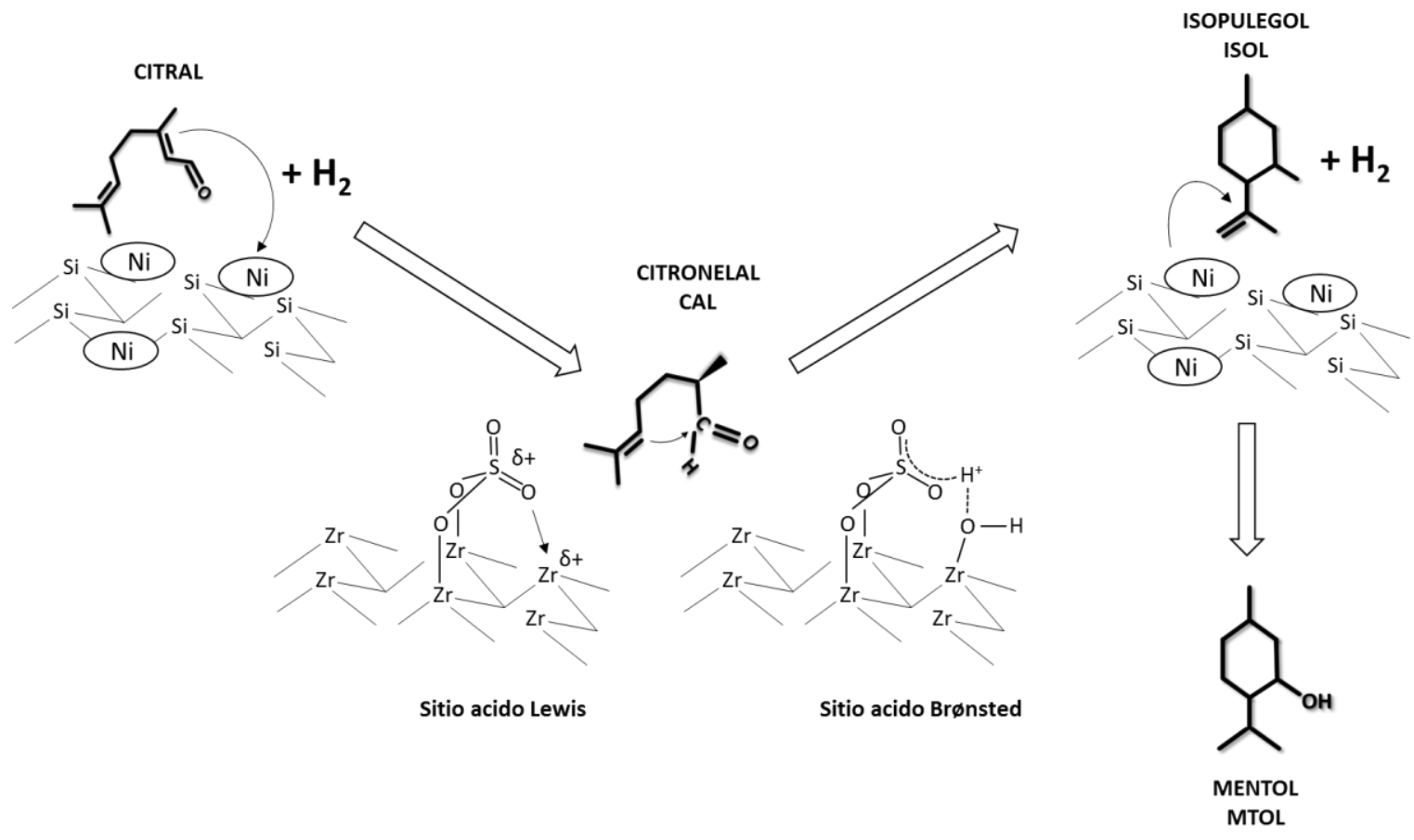

Figura 6.8. Esquema de reacción para la obtención de mentol a partir de citral, donde el citral se adsorbe en un sitio hidrogenante para producir citronelal como primer paso, posteriormente el citronelal se adsorbe en un sitio ácido para producir isopulegol y finalmente el isopulegol se adsorbe en un sitio hidrogenante para producir mentol.

La Figura 6.8 esquematiza la ruta de reacción efectiva para producir mentol a partir de citral, es decir, sin reacciones paralelas de citral o reacciones consecutivas de productos. Como se mencionó en los antecedentes, la adición de hidrógeno en la molécula de citral puede producir 3 compuestos dependiendo de dónde se lleve a cabo dicha adición (sustitución en $\mathrm{C}=\mathrm{O}$ : geraniol-nerol; sustitución en $\mathrm{C}=\mathrm{C}$ conjugado: citronelal; sustitución en $\mathrm{C}=\mathrm{C}$ aislado: 3,7-dimetil-1-octanal). El níquel metálico tiene la capacidad de llevar a cabo la hidrogenación selectiva de citral por el doble enlace $\mathrm{C}=\mathrm{C}$ conjugado produciendo citronelal [10-12]. Con las mezclas mecánicas de $\mathrm{Ni} / \mathrm{SiO}_{2}+\mathrm{ZrS} 2$ se obtiene una rápida conversión de citral a citronelal minimizando la producción de dihidrocitronelal (3,7-dimetil-1-octenal) y no se producen los alcoholes insaturados geraniol y nerol. Con el sistema $\mathrm{Ni} / \mathrm{SiO}_{2}+\mathrm{ZrS2}$ 90:10, no se observó la aparición de componentes producidos de la interacción de citral en sitios ácidos, pero con los materiales $\mathrm{Ni} / \mathrm{SiO}_{2}+\mathrm{ZrS2}$ 80:20 y Ni/SiO${ }_{2}+\mathrm{ZrS2} 60: 40$ al inicio de la reacción se observan compuestos tales como d-careno, p-cimeno y p-mentatrieno, que son producto de la ciclización de citral en sitios ácidos. Después de este periodo de inducción, los compuestos antes mencionados no aumentan su concentración y la reacción en un solo paso de hidrogenación-ciclización-hidrogenación se lleva a cabo preponderantemente. La 
aparición de los compuestos producidos por la ciclización de citral causa que la selectividad de mentol al final de la reacción disminuya.

En la Tabla 6.3 se observan los resultados del tiempo en el cual la reacción llega al 100\% de conversión de citral y la selectividad al tiempo de conversión total de citral y al tiempo final de la reacción. El catalizador de $\mathrm{Ni} / \mathrm{SiO}_{2}+\mathrm{ZrS2}$ 90:10 es el sistema catalítico que permite mayor actividad y selectividad hacia mentol y una cantidad menor, en comparación a los otros sistemas catalíticos, de compuestos no deseados que se incluyen en \% de selectividad de otros, cuyos componentes son citronelol, 3,7-dimetil-1-octanol y los componentes que se generaron en el periodo de inducción inicial de ciclización de citral. En el sistema 90:10, después de un tiempo de reacción de 180 minutos solo se tiene la mezcla de mentol, 3,7-dimetil-1-octanol y los componentes considerados como otros (d-careno, pcimeno y p-mentatrieno) que ya se mencionó que son producidos en el periodo de inicio de la reacción, caso contrario a los sistemas 80:20 y 60:40 que después de 300 minutos de proceso aun aparecen citronelal e isopulegol en la mezcla de reacción.

Tabla 6.3. Resultados de conversión de citral y selectividad de productos en la obtención de mentol a partir de citral con mezcla mecánica $\mathrm{Ni} / \mathrm{SiO}_{2}+\mathrm{ZrS} 2$.

\begin{tabular}{|c|c|c|c|c|c|c|c|c|c|}
\hline \multirow{2}{*}{$\mathrm{Ni} / \mathrm{SiO}_{2}+\mathrm{ZrS} 2$} & \multirow{2}{*}{$\begin{array}{l}\text { Tiempo (min) } \\
\left(X_{\text {citral }}=100 \%\right)^{a}\end{array}$} & \multicolumn{4}{|c|}{$\%$ Selectividad ${ }^{\mathrm{b}}$} & \multicolumn{4}{|c|}{$\%$ Selectividad $^{c}$} \\
\hline & & CAL & ISO & MTOL & otros & CAL & ISO & MTOL & otros \\
\hline $90: 10$ & 90 & 9 & 10 & 54 & 27 & 0 & 0 & 71 & 29 \\
\hline $80: 20$ & 120 & 24 & 26 & 23 & 27 & 3 & 7 & 56 & 34 \\
\hline $60: 40$ & 120 & 24 & 27 & 23 & 26 & 0 & 3 & 63 & 34 \\
\hline
\end{tabular}

aTiempo en el que se alcanza la conversión de $100 \%$ de citral

belectividad a conversión de $100 \%$ de citral

'Selectividad al final de la reacción ( conversión total de citronelal)

Con respecto a la estereoselectividad y enantioselectividad, los resultados de la Tabla 6.4 muestran que la variación de la composición de la mezcla mecánica no tiene un efecto en la proporción de los estereoisómeros y enantiómeros de mentol. En diversos estudios se establece que no existe un interconversión entre enantiómeros o incluso estereoisómeros de isopulegol [19], por lo tanto dado que cada par enantiomérico de mentol proviene directamente de la hidrogenación de isopulegol, se observa mediante los resultados aquí obtenidos, que la relación de estereoisómeros y enantiómeros de isopulegoles es la misma que la de mentoles. 
Tabla 6.4. Resultados de estereoselectividad de mentoles y enantioselectividad de (-)-mentol y (+)-mentol al final de la reacción con mezcla mecánica de $\mathrm{Ni} / \mathrm{SiO}_{2}+\mathrm{ZrS} 2$

\begin{tabular}{|c|c|c|c|c|c|c|}
\hline \multirow{2}{*}{$\mathrm{Ni} / \mathrm{SiO}_{2}+\mathrm{ZrS} 2$} & \multicolumn{4}{|c|}{$\%$ estereoselectividad } & \multicolumn{2}{|c|}{$\%$ enantioselectividad } \\
\hline & $\mathbf{A}$ & B & $\mathbf{C}$ & D & (-)-MTOL & (+)-MTOL \\
\hline $90: 10$ & 60 & 35 & 5 & 0 & 88 & 12 \\
\hline $80: 20$ & 57 & 36 & 7 & 0 & 88 & 12 \\
\hline $60: 40$ & 57 & 36 & 7 & 0 & 88 & 12 \\
\hline
\end{tabular}

De las especies observadas y sus concentraciones se plantea un análisis cinético correspondiente a las especies catalíticas presentes (sitio hidrogenante en $\mathrm{Ni} / \mathrm{SiO}_{2}$ y sitio ácido en ZrS2), con el siguiente esquema representado en la Figura 6.9. Inicialmente se observa la hidrogenación de citral para producir selectivamente citronelal para posteriormente llevarse a cabo la ciclización de citronelal y producir isopulegol, finalmente se lleva a cabo la hidrogenación de isopulegol para producir mentol. Una segunda ruta se deriva de la hidrogenación de citronelal para producir citronelol y 3,7-dimetil-octanal (dihidrocitronelal) y una posterior hidrogenación de estos componentes para producir el alcohol saturado 3,7-dimetil-octanol.

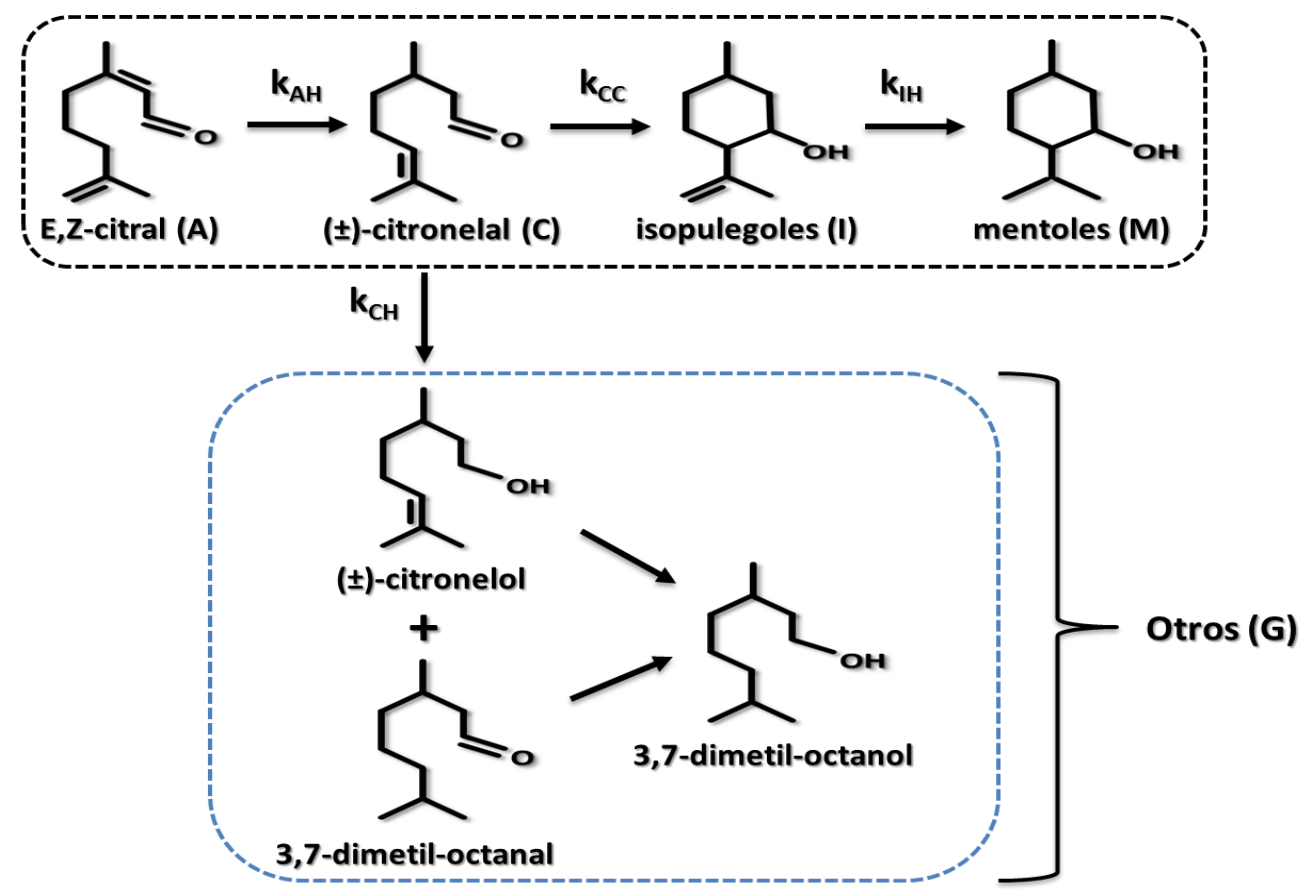

Figura 6.9. Rutas observadas en la obtención de mentol a partir de citral en una sola etapa con mezclas mecánicas de $\mathrm{Ni} / \mathrm{SiO}_{2}+\mathrm{ZrS2}$. 
De acuerdo a lo anterior y tomando en cuenta el mecanismo cinético propuesto por Vannice y col. [10] y complementado con lo propuesto por Piña-Victoria [59] en su tesis de maestría, se propone lo siguiente:

Hidrogenación de citral (A) a citronelal (C) en sitio hidrogenante (S)

1) Etapa de disociación de $\mathrm{H}_{2}$

$H_{2}+2 S \stackrel{K_{1}}{\leftrightarrow} 2 H S \quad K_{1}=\frac{\Theta_{H S}^{2}}{C_{H} \Theta_{S}^{2}}$

2) Etapa de adsorción de $A$
$A+S \stackrel{K_{2}}{\leftrightarrow} A S$
$K_{2}=\frac{\Theta_{A S}}{C_{A} \Theta_{S}}$

3) Primera etapa de hidrogenación de A
$A S+H S \stackrel{K_{3}}{\leftrightarrow} H A S+S$
$K_{3}=\frac{\Theta_{H A S} \Theta_{S}}{\Theta_{A S} \Theta_{H S}}$

4) Segunda etapa de hidrogenación de A para dar lugar a $C$
$H A S+H S \stackrel{K_{4}}{\leftrightarrow} C S+S$
$K_{4}=\frac{\Theta_{C S} \Theta_{S}}{\Theta_{H A S} \Theta_{H S}}$

5) Etapa de desorción de $C$
$C S \stackrel{1 / K_{5}}{\longleftrightarrow} C+S$
$\frac{1}{K_{5}}=\frac{C_{C} \Theta_{S}}{\Theta_{C S}}$

Ciclización de citronelal (c) para dar isopulegol (I) en sitio ácido (X)
$C+X \stackrel{K_{6}}{\leftrightarrow} C X$
$K_{6}=\frac{\Theta_{C X}}{C_{C} \Theta_{X}}$
$C X \stackrel{K_{7}}{\leftrightarrow} I X$
$K_{7}=\frac{\Theta_{I X}}{\Theta_{C X}}$
$I X \stackrel{1 / K_{8}}{\longleftrightarrow} I+X$
$\frac{1}{K_{8}}=\frac{C_{I} \Theta_{X}}{\Theta_{I X}}$ 
Donde:

$S$ : sitio activo de hidrogenación

$X$ : sitio activo ácido

$\Theta_{j H}$ : fracción de sitios hidrogenantes ocupado por componente $j$

$\Theta_{H}$ : fracción de sitios hidrogenantes ocupado por $\mathrm{H}_{2}$

$\Theta_{k H:}$ fracción de sitios ácidos ocupados por componente $\mathrm{k}$

El mismo mecanismo cinético de hidrogenación se propone para citronelal $(\mathrm{C})$ para obtener otros $(\mathrm{G})$ y la hidrogenación de isopulegol (I) para dar mentol (M).

Dentro de las suposiciones, de acuerdo a los resultados observados, es que la fracción de sitios ocupados en sitios activos hidrogenantes de citronelal, mentol y otros es menor a la fracción de sitios ocupados de citral, es decir $\Theta_{H}, \Theta_{C H}, \Theta_{M H}, \Theta_{G H}<<\Theta_{A H}$, para la primer etapa de hidrogenación. En la segunda etapa de hidrogenación de isopulegol a mentol no se desprecia $\Theta_{M H}$ con respecto a $\Theta_{A H}$ ya que en esta segunda etapa la concentración de mentol mayor que la de citral. Por otro lado, para la reacción de ciclización en sitios activos ácidos $\Theta_{I C}<<\Theta_{C C}$ ya que se considera que una vez convertido el citronelal en isopulegol, éste último no vuelve a adsorberse y no existe una competencia por los sitios ácidos. Además, la concentración de hidrógeno se considera constante en todo el tiempo en el que se lleva a cabo la reacción. Ahora para completar el esquema de reacción y las ecuaciones a resolver se propone lo siguiente:

\section{a) Balance de materia. De acuerdo a la Figura 6.8}

citral (A)

$\frac{d C_{A}}{d t}=-r_{A H}$

citronelal (C)

$\frac{d C_{C}}{d t}=r_{A H}-r_{C H}-r_{C C}$

Isopulegol (I)

$\frac{d C_{I}}{d t}=r_{C C}-r_{I H}$ 
Mentol (M)

$\frac{d C_{M}}{d t}=r_{I H}$

$\operatorname{Otros}(\mathrm{G})$

$\frac{d C_{G}}{d t}=r_{C H}$

b) Mecanismo tipo Langmuir-Hinshelwood (El mecanismo cinético se desarrolla completamente en el Apéndice A).

Velocidad de hidrogenación de citral

$r_{A H}=\frac{k_{A H} C_{A} C_{H_{2}}}{\left(1+\sum_{i} K_{i} C_{i}\right)^{2}}$

Velocidad de hidrogenación de citronelal

$r_{C H}=\frac{k_{C H} C_{C} C_{H_{2}}}{\left(1+\sum_{i} K_{i} C_{i}\right)^{2}}$

Velocidad de ciclización de citronelal

$r_{C C}=\frac{k_{C C} C_{C}}{1+\sum_{j} K_{j}^{\prime} C_{j}}$

Velocidad de hidrogenación de isopulegol

$r_{I H}=\frac{k_{I H} C_{I} C_{H_{2}}}{\left(1+\sum_{i} K_{i} C_{i}\right)^{2}}$

Donde:

$\sum_{i} K_{i} C_{i}=K_{A} C_{A}+K_{C} C_{C}+K_{M} C_{M}+K_{G} C_{G}+\sqrt{K_{1} C_{H_{2}}}$

$\sum_{j} K_{j}^{\prime} C_{j}=K_{C}^{\prime} C_{C}+K_{I}^{\prime} C_{I}$

Siendo $K_{i}, K_{j}^{\prime}$ y $K_{1}$ las constantes de adsorción de los compuestos en sitios hidrogenante, sitio ácido e hidrógeno, respectividamente. 
El balance de materia, en conjunto con las expresiones tipo Langmuir-Hinshelwood, corresponde a un sistema de ecuaciones diferenciales sujeto a las condiciones iniciales $\mathrm{C}_{\mathrm{A}}$ $=0.1 \mathrm{~mol} / \mathrm{l}$ y $\mathrm{C}_{\text {org }}=0$ para los demás reactivos y productos. La solución al sistema de ecuaciones diferenciales no lineales se obtuvo numéricamente, mediante un algoritmo de Euler modificado el cual tiene una tolerancia de $10^{-6}$, con las contantes cinéticas y de adsorción como parámetros ajustables. La estimación de parámetros cinéticos se llevó a cabo mediante el método Simplex-Levenberg-Marquart, el cual minimiza la suma de residuos al cuadrado entre la concentración experimental y el estimado:

$$
Q=\sum\left(C_{i}^{\text {exp }}(t)-C_{i}^{\text {calc }}(t)\right)^{2}
$$

El ajuste del modelo matemático con los resultados de concentración experimentales se muestra en el Apéndice B. Los valores de los parámetros ajustados se muestran en la Tabla 6.5.

Tabla 6.5. Parámetros estimados para la obtención de mentol a partir de citral en una sola etapa con mezclas mecánicas de $\mathrm{Ni} / \mathrm{SiO}_{2}+\mathrm{ZrS} 2$

\begin{tabular}{c|c|c|c}
\hline \multirow{2}{*}{ Parámetro } & \multicolumn{3}{|c}{$\mathrm{Ni} / \mathrm{SiO}_{2}+\mathrm{ZrS2}$} \\
\cline { 2 - 4 } & $\mathbf{9 0 : 1 0}$ & $\mathbf{8 0 : 2 0}$ & $\mathbf{6 0 : 4 0}$ \\
\hline$k_{A H}\left(\mathrm{~min}^{-1}\right)$ & 0.0407 & 0.0226 & 0.0181 \\
\hline$k_{C H}\left(\mathrm{~min}^{-1}\right)$ & 0.0136 & 0.0072 & 0.0417 \\
\hline$k_{I H}\left(\mathrm{~min}^{-1}\right)$ & 0.0404 & 0.0156 & 0.0129 \\
\hline$k_{C C}\left(\mathrm{~min}^{-1}\right)$ & 0.0646 & 0.0211 & 0.1288 \\
\hline$K_{A}\left(\mathrm{lt} / \mathrm{mol}^{\prime}\right)$ & 16.602 & 12.852 & 0.0016 \\
\hline$K_{C}^{\prime}(\mathrm{lt} / \mathrm{mol})$ & 40.437 & 18.117 & 107.22 \\
\hline$K_{M}(\mathrm{lt} / \mathrm{mol})$ & 8.274 & 6.924 & 0.0007 \\
\hline
\end{tabular}

El ajuste para las concentraciones experimentales generadas de la mezcla $\mathrm{Ni} / \mathrm{SiO}_{2}+\mathrm{ZrS} 2$ 90:10 es satisfactorio, sin embargo, para las demás proporciones de la mezcla mecánica no se presentan buenos ajustes. Esto se debe a que en el periodo de inducción inicial se producen muchos componentes de la reacción de citral en sitios ácidos, presentando concentraciones sin tendencia regular que dificulta su trazado por el modelo cinético propuesto (Ver Apéndice B).

Los resultados del estudio cinético nos permiten cuantificar las velocidades de reacción específicas de hidrogenación de citral y citronelal y ciclización de citronelal y así observar la contribución de cada tipo de sitio, ya sea hidrogenante o ácido, en la obtención de mentol 
a partir de citral. En la Tabla 6.6 se muestra la velocidad de reacción inicial observada (a $10 \%$ de conversión) para cada etapa de reacción y para cada sistema catalítico $\left(\mathrm{R}_{\mathrm{AO}}\right.$ para hidrogenación de citral; $\mathrm{R}_{\mathrm{C}} \mathrm{H}$ para hidrogenación de citronelal; $\mathrm{R}_{\mathrm{C}} \mathrm{C}$ para ciclización de citronelal) ; también se puede observar la actividad catalítica inicial por sitio activo hidrogenante para citral $\left(\mathrm{TOF}_{\mathrm{AO}}\right)$, sitio activo hidrogenante para citronelal $\left(\mathrm{TOF}_{\mathrm{C}} \mathrm{H}\right)$ y sitio activo ácido para citronelal ( TOF $_{C} \mathrm{C}$ ), estos últimos determinados por quimisorción y termodesorción de piridina, respectivamente.

Los resultados de velocidad de reacción inicial y de TOF $_{A 0}$ para la hidrogenación de citral de la Tabla 6.6 muestran que no existe una dependencia con la cantidad de catalizador o sitios activos hidrogenantes de $\mathrm{Ni} / \mathrm{SiO}_{2}$ en la mezcla mecánica. En el caso de la ciclización de citronelal se observa que el valor de TOF $_{\mathrm{C}} \mathrm{H}$ es mayor para la mezcla 90:10 y esto se ve reflejado en la mayor rapidez de formación de citronelol que las mezclas 80:20 y 60:40. Como se puede observar de la Tabla 6.3 entre mayor es la cantidad de ZrS2, mayor es la cantidad de componentes no deseados producidos en el periodo de inducción, lo que hace que en la cuantificación de la cantidad de productos, la selectividad de mentol disminuya al final de la reacción. En la Tabla 6.6 se observa que conforme aumenta la cantidad de ZrS2 la actividad de ciclización disminuye, esto se debe a que al inicio de la reacción, con las mezclas 80:20 y 60:40, se obtiene una mayor cantidad de compuestos no deseados como careno, pineno y mentatrieno y estos compuestos pueden estar inhibiendo la actividad de ZrS2. No se ha determinado aún que efecto tienen este tipo de compuestos en la actividad de hidrogenación y ciclización de citral o citronelal.

Tabla 6.6. Resultados de velocidad de reacción inicial y de frecuencia de recambio (TOF) para las reacciones de hidrogenación de citral, hidrogenación de citronelal y ciclización de citronelal con catalizadores de $\mathrm{Ni} / \mathrm{SiO}_{2}+\mathrm{ZrS} 2$ en la obtención de mentol a partir de citral.

\begin{tabular}{|c|c|c|c|c|c|c|}
\hline $\mathrm{Ni} / \mathrm{SiO}_{2}+\mathrm{ZrS} 2$ & $\begin{array}{c}R_{A 0} \times 10^{6} \\
\left(\mathrm{~mol} / \mathrm{g}_{\mathrm{cat}} \cdot \mathrm{s}\right)\end{array}$ & $\begin{array}{c}\text { TOF }_{A 0} \\
\left(\mathbf{s}^{-1}\right)\end{array}$ & 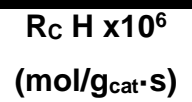 & $\begin{array}{c}R_{c} C \times 10^{6} \\
\left(\mathrm{~mol} / \mathrm{g}_{\mathrm{cat}} \cdot \mathrm{s}\right)\end{array}$ & $\begin{array}{c}\text { TOFc } H \\
\left(\mathbf{s}^{-1}\right)\end{array}$ & $\begin{array}{c}\text { TOFc C } \\
\left(\mathbf{s}^{-1}\right)\end{array}$ \\
\hline $90: 10$ & 4.78 & 0.0498 & 10.4 & 29.6 & 0.1082 & 0.1922 \\
\hline $80: 20$ & 4.77 & 0.0497 & 8.93 & 5.35 & 0.0930 & 0.0347 \\
\hline $60: 40$ & 4.88 & 0.0509 & 7.11 & 3.45 & 0.0741 & 0.0224 \\
\hline
\end{tabular}

En relación a la proporción de las especies catalíticas en la mezcla mecánica, es deseable que la actividad de ciclización sea mayor que la actividad de hidrogenación debido a que es el paso limitante en la obtención de altas selectividades de mentol, ya que una mayor actividad de hidrogenación causa una mayor producción de citronelol o 3,7-dimetil-octanal. 
Si bien con la relación 90:10 se produce una alta selectividad de mentol, conforme varía la relación $\mathrm{Ni} / \mathrm{SiO}_{2}+\mathrm{ZrS} 2$, la selectividad se modifica, en primer lugar por la presencia de una mayor cantidad de compuestos no deseados provenientes de la interacción de citral con sitios ácidos, en segundo lugar porque la actividad de hidrogenación es mayor que la actividad de ciclización causando una mayor producción de compuestos tales como citronelol y 3,7-dimetil-octanol.

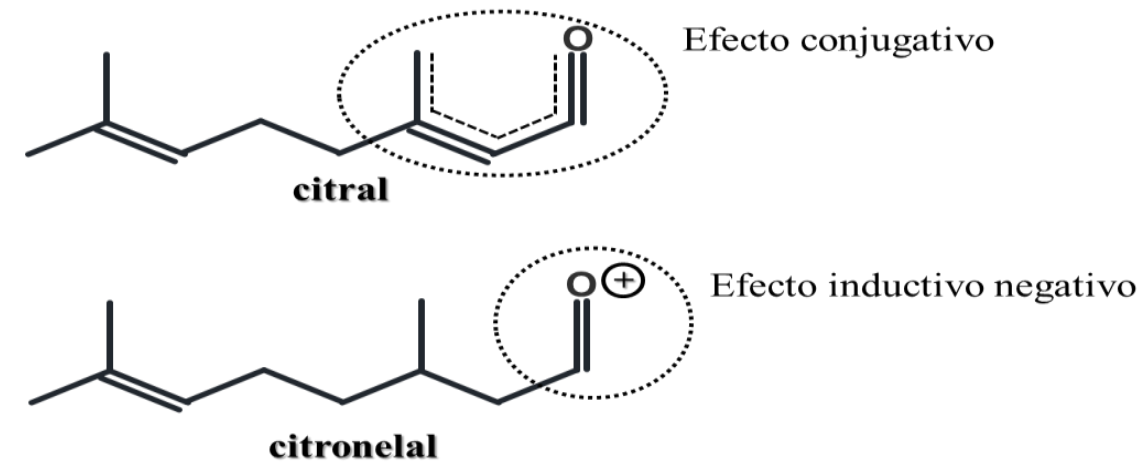

Figura 6.10. Representación esquemática del efecto conjugativo de citral y el efecto inductivo negativo en citronelal en presencia de sitios ácidos Lewis.

De acuerdo a la estructura de la molécula de citral y citronelal, mostradas en la Figura 6.10, se han realizado estudios de funcionales de densidad, en donde se determina cual es el efecto que promueve un ácido tipo Lewis en la reactividad de ciertas moléculas modelo, como formaldehido y propeno, para la reacción de ciclización-ene. De acuerdo a lo mencionado por Yang y col. [58] existen efectos que pueden modificar la reactividad de una molécula en presencia de sitios de Lewis tales como el efecto inductivo negativo (-I) y el efecto conjugativo positivo $(+\mathrm{C})$. En el caso de citral se puede decir que por la presencia del doble enlace $\mathrm{C}=\mathrm{C}$ conjugado presenta un efecto $(+\mathrm{C})$ y el citronelal presenta en efecto (-I) en presencia de sitios ácidos Lewis. De acuerdo a lo descrito por Yang y col. [58], el efecto $(+\mathrm{C})$ hace que la molécula sea de citral menos reactiva ante la presencia de sitios Lewis por presentar resonancia de electrones debido a la presencia de dobles enlaces $\mathrm{C}=\mathrm{C}$ y $\mathrm{C}=\mathrm{O}$ conjugados. La molécula de citronelal que ha perdido una instauración, también ha perdido el efecto de resonancia de electrones, y en esta condición se presenta el efecto inductivo negativo (-I) que promueve una mayor reactividad ante sitios ácidos Lewis. Esto explica porque el citral no reacciona en mayor medida en sitios ácidos como lo hace ante sitios hidrogenantes y que el citronelal prefiere reaccionar en mayor medida en sitios ácidos que en sitios hidrogenantes, por lo que el mecanismo cinético propuesto en la Figura 6.7 se 
lleva a cabo de manera eficiente en mezclas mecánicas de $\mathrm{Ni} / \mathrm{SiO}_{2}+\mathrm{ZrS} 2$. En este trabajo se propone que la actividad de la dualidad de sitios ácidos Lewis y Brønsted es la que actúa para poder convertir a la molécula de citral en compuestos productos de la interacción de citral con este tipo de sitios, ya que en un trabajo previo [6] se estableció que catalizadores tales como PtSn crean una polarización de la molécula de citral para que sea adsorbida de manera preferencial hacia el doble enlace $\mathrm{C}=\mathrm{O}$. En el caso de los sitios ácidos Lewis, estos también cumplen con la función de adsorber de manera preferencial a la molécula de citral pero los sitios ácidos Brønsted son los que convierten al citral en los componentes no deseados ya mencionados.

Existen catalizadores bifuncionales, como los mencionados en los antecedentes, que permiten llevar a cabo la obtención de mentol a partir de citral. Específicamente un catalizador bifuncional de Ni soportado en zirconia sulfata no es activo para la misma ruta de reacción. Una mezcla mecánica que incluye Ni como agente hidrogenante y zirconia sulfatada con funcionalidad ácida pueden llevar de manera concertada la reacción de hidrogenación de citral produciendo citronelal, la ciclización de citronelal para producir isopulegol y la hidrogenación de isopulegol para producir mentol, estas tres reacciones siendo altamente selectivas hacia la ruta especifica que se plantea como objetivo. La ruta concertada por la mezcla mecánica no solo se atribuye a las características propias de cada especie catalítica dentro de la mezcla sino también a la reactividad de cada una de las moléculas presentes en cada etapa de la reacción. Además la relación entre los constituyentes de la mezcla mecánica juega un papel importante, ya que se puede hacer la variación de cada especie catalítica hasta lograr un balance adecuado para la reacción de hidrogenación de citral y de ciclización de citronelal que permite obtener altos rendimientos de mentol, tal es el caso de la mezcla mecánica Ni/SiO ${ }_{2}+\mathrm{ZrS2}$ 90:10.

\section{Efecto de la zirconia sulfatada en la obtención de mentol}

A manera de resumen se tiene que la zirconia sulfatada se empleó en tres diferentes de reacciones, la ciclización de citronelal, la obtención de mentol a partir de citronelal y la obtención de mentol a partir de citral. En dichas reacciones el paso determinante es la ciclización de citronelal, ya que de ésta se desprenden los compuestos que pueden llevar a obtener altos rendimientos de mentol. En las reacciones donde se involucra la reacción de hidrogenación, la inclusión de Ni en la zirconia sulfatada llevó de manera satisfactoria a 
la obtención de altos rendimientos de mentol a partir de citronelal siempre que el Ni se encontrara en especie de óxido. En la obtención de mentol a partir de citral, el requerimiento de $\mathrm{Ni}$ en estado metálico soportado en la zirconia sulfatada le llevo al material al envenenamiento y a la pérdida total de la actividad catalítica, pero el empleo de una fase metálica de $\mathrm{Ni}$ soportada en $\mathrm{SiO}_{2}$ para llevar a cabo la hidrogenación selectiva de citral; y el uso de la zirconia sulfatada para llevar a cabo la ciclización otorgó resultados satisfactorios cuando se aplicaron como una mezcla mecánica. La Tabla 6.7 presenta las velocidades inicial de reacción de ciclización de citronelal $(\mathrm{CAL})$ utilizando ZrS2 para cada una de las reacciones mencionadas en este apartado.

Tabla 6.7. Velocidad de reacción inicial de ciclización de CAL en las distintas reacciones donde se utilizó ZrS2 como catalizador.

\begin{tabular}{|c|c|c|}
\hline Catalizador & Reacción & $\mathbf{R}_{0, \mathrm{CAL}}\left(\mathrm{mol} / \mathrm{g}_{\text {cat }} \cdot \mathrm{s}\right)$ \\
\hline ZrS2 & Ciclización de CAL & $33 \times 10^{-5}$ \\
\hline $\mathrm{Ni} / \mathrm{ZrS2}$ & Obtención de MTOL a partir de CAL & $12 \times 10^{-6}$ \\
\hline $\mathrm{Ni} / \mathrm{SiO} 2+\mathrm{ZrS2} 90: 10$ & Obtención de MTOL a partir de citral & $30 \times 10^{-6}$ \\
\hline
\end{tabular}

Las diferencias en actividad se deben a que en la reacción de ciclización de CAL se tiene una concentración inicial determinada de citronelal. En la obtención de mentol a partir de $\mathrm{CAL}$, la adición de $\mathrm{Ni}$ a la zirconia sulfatada aumenta la cantidad de sitios ácidos Lewis con respecto a la cantidad de sitios ácidos Brønsted y como se discutió anteriormente esto causa una disminución drástica en la actividad catalítica. En la obtención de mentol a partir de citral, la actividad de la zirconia sulfatada en la mezcla mecánica depende de la concentración de citronelal en una reacción en serie que tiene como primera etapa la producción de citronelal a partir de citral por lo tanto la actividad de ZrS2 depende de la cantidad de citronelal y esto se ve reflejado como la disminución de la actividad catalítica. Con respecto a la selectividad de mentol la zirconia sulfatada permite obtener mentol en cualquiera de los sistemas en los que se emplea, con resultados destacados cuando se utiliza en combinación con $\mathrm{Ni} / \mathrm{SiO}_{2}$ dentro de una mezcla mecánica cuando se obtiene mentol a partir de citral $(71 \%$ de selectividad de mentol). Con respecto a la estereoselectividad, la máxima estereoselectividad obtenida de ( \pm )-mentol fue cuando se utilizó la zirconia sulfatada en presencia de Ni como fase activa hidrogenante $(65 \%$ de estereoselectividad de ( \pm )-mentol). 


\section{CONCLUSIONES}

En el presente trabajo se investigó la actividad catalítica de la zirconia sulfata en la ciclización de citronelal y en la obtención de mentol a partir de citronelal y de citral. Además se analizó el efecto de la variación de la relación molar de $\mathrm{S} / \mathrm{Zr}$ en las propiedades fisicoquímicas de los materiales y en la actividad catalítica y se concluye lo siguiente:

1. Los materiales presentan características diferentes al variar la cantidad de sulfatos en la zirconia. El área superficial específica se ve favorecida para los materiales con relación molar de $S / Z r$ de 0.1 y 0.2 , no así para la relación molar $S / Z r$ de 0.5 .

2. Las características ácidas son distintas para cada relación molar $S / Z r$, bajo contenido de sulfatos presenta mayor cantidad de sitios ácidos Lewis, alto contenido de sulfatos muestra mayor cantidad de sitios Brønsted.

3. Se puede considerar que ambos tipos de sitios ácidos Lewis y Brønsted son fuertes y que esta condición no varía con respecto a la relación $S / Z$ r.

4. La adición de $\mathrm{Ni}$ a los materiales de ZrS le otorga mayor cantidad de sitios ácidos Lewis por la presencia de $\mathrm{NiO}$ que puede actuar como sitios Lewis por la polarización de Ni por el $\mathrm{O}$, creándose una especie deficiente de electrones en el $\mathrm{Ni.}$

En la ciclización de citronelal se tienen las siguientes conclusiones:

1. La actividad se ve favorecida para materiales con mayor cantidad de sitios ácidos Bronsted que Lewis. Esto indica que la variación en la relación Lewis/Brønsted tiene un efecto importante en la actividad catalítica y que el mecanismo de reacción puede llevarse a cado considerando dualidad de sitios.

2. La variación en la relación molar de $\mathrm{S} / \mathrm{Zr}$ en los materiales de $\mathrm{ZrS}$ le otorgan diferencias en las propiedades acidas (densidad de sitios, tipo de sitio ácido y acidez) que no tienen un efecto en la selectividad de isopulegol, ya que la selectividad fue de $100 \%$ para todos los materiales.

3. Para la relación molar $S / Z r$ de 0.1 y 0.2 no tienen efecto en la estereoselectividad de ( \pm )-isopulegol con respecto a los demás isopulegoles. La relación S/Zr modifica la estereoselectividad de $( \pm$ )-isopulegol con respecto a la de $( \pm)$-neo-isopulegol, esto parece indicar que la mayor cantidad de sitios Brønsted favorece la formación de 
especies menos estables de isopulegol como lo es ( \pm )-neo-isopulegol con respecto a ( \pm )-isopulegol.

Con respecto a la obtención de mentol a partir de citronelal se concluye lo siguiente:

Los materiales de Ni/ZrS2 y NiZrS2 permiten llevar a cabo la obtención de mentol en una sola etapa a partir de citronelal con altas velocidades de reacción y altas selectividades hacia la mezcla de mentoles. La función acida permite obtener altas selectividades de isopulegol que posteriormente se hidrogena para producir mentol sin obtener compuestos no deseados.

Con respecto a la obtención de mentol a partir de citral:

Las mezclas mecánicas de $\mathrm{Ni} / \mathrm{SiO}_{2}$ y ZrS2 permiten obtener altas conversiones de citral y altas selectividades de mentol. Los compuestos no deseados son producto de la hidrogenación de citral y se observa que la zirconia sulfatada no produce compuestos propios de la función acida del material. Al inicio de la reacción se observa una gran cantidad de compuestos no deseados que se atribuyen a la interacción de citral con la zirconia sulfatada. Después de iniciada la reacción de hidrogenación se observa que estos compuestos no se producen más durante el tiempo que dura la reacción. 


\section{REFERENCIAS}

[1] H. Rudolph y M. L. Brian, Natural and Synthetic Menthol, Mint The Genus Mentha, CRC Press Taylor \& Francis Group, 2007, p. 556

[2] J. Leffingwell y D. Leffingwell, Chiral chemistry in flavours \& fragances, Specialty Chemicals Magazine, 31, 2001, p.3.

[3] A. Stolle, T. Gallert, C. Schmöger y B. Ondruschka, Hydrogenation of citral: a widespread model reaction for selective reduction of $\alpha, \beta$-unsaturated aldehydes, $R S C$ Advances, 3, 2013, p. 2112.

[4] J. McMurry, Química orgánica, Quinta edición, 2001.

[5] E. J. Leonardão, G. V. Botteselle, F. de Azambuja, G. P. Perin y R. G. Jacob, Citronellal as key compound in organic synthesis, Tetrahedron, 63 (2007) p. 6671.

[6] C. Barrales, Estudio de la hidrogenación de citral con catalizadores de Pt y PtSn soportados, Tesis de maestría, UAMI, 2007.

[7] U. K. Singh y A. Vannice, Liquid-Phase Hydrogenation of Citral over $\mathrm{Pt} / \mathrm{SiO}_{2}$ Catalysts, I. Temperature Effects on Activity and Selectivity, J. Catal., 191 (2000) p. 165.

[8] U. K. Singh y A. Vannice, Liquid-Phase Hydrogenation of Citral over $\mathbf{P t} / \mathrm{SiO}_{2}$ Catalysts, II. Hydrogenation of Reaction Intermediate Compounds, J. Catal., 191 (2000) p. 181.

[9] S. Santiago-Pedro, V. Tamayo-Galvan y T. Viveros-García, Effect of the acid-base properties of the support on the performance of $\mathrm{Pt}$ catalysts in the partial hydrogenation of citral, Catalysis Today, 213 (2013), p. 101.

[10] U. K. Singh y A. Vannice, Liquid-Phase Citral Hydrogenation over $\mathbf{S i O}_{2}$-Supported Group VIII metals, J. Catal., 199 (2001) p. 73.

[11] P. Maki-Arvela, L. Tiainen, A. K. Neyestanaki, R. Sjoholm, T. Rantakyla, E. Laine, T. Salmi y D. Y. Murzin, Liquid phase hydrogenation of citral: suppression of side reactions, Appl. Catal. A: Gen., 237 (2002), p.181.

[12] P. Maki-Arvlela, L. Tiainen, M. Lindblad, K. Demirkan, N. Kumar, R. Sjoholm, T. Ollonqvist, J. Vaynyren, T. Salmi y D. Yu. Murzin, Liquid-phase hydrogenation of citral for production of citronellol: catalyst selection, Appl. Catal. A. Gen., 241 (2003) p. 271.

[13] F. Delbeq, P. Sautet, A Density Functional Study of Adsorption Structures of Unsaturated Aldehydes on Pt(111): A Key Factor for Hydrogenation Selectivity, J. Catal., 211 (2002) p. 398. 
[14] C. S. Fadley, D. A. Shirley, $3^{\text {rd }}$ Material Research Symposium-Electronic Density of States, Nov. 3-6, 1969, Gaithersburg, M.D., Obtenido de: U. K. Singh y A. Vannice, Liquid-Phase Citral Hydrogenation over $\mathrm{SiO}_{2}$-Supported Group VIII metals, J. Catal., 199 (2001) p. 73.

[15] A. A. Wismeijer, A. P. G. Kieboom, H. Van Bekkum, Selective hydrogenation of citrolellal to citronellol over $\mathrm{Ru} / \mathrm{TiO}_{2}$ as compared to $\mathrm{Ru} / \mathrm{SiO}_{2}$, Appl. Catal., 25 (1986), p. 181.

[16] C. Milone, C. Gangemi, R. Ingoglia, G. Neri, S. Galvagno, Role of the support in the hydrogenation of citronellal on ruthenium catalysts, Appl. Catal. Gen: A., 184 (1999) p. 89.

[17] N. Ravasio, M. Antenori, F. Babudri, M. Gargano, Intramolecular Ene reactions promoted by mixed cogels, Heterogeneous Catalysis in Fine Chemicals IV, 1997, p. 625.

[18] M. Fuentes, J. Magraner, C. de las Pozas, R. Roque-Malherbe, J. Perez Pariente, A. Corma, Cyclizacion of Citronellal to Isopulegol by Zeolite Catalysis, Appl. Catal., 47 (1989) p. 367.

[19] P. Maki-Arvela, N. Kumar, V. Nieminen, R. Sjoholm, T. Salmi, D. Yu. Murzin, Cyclization of citronellal over zeolites and mesoporous meterials for production of isopulegol. J. Catal., 225 (2004), p. 155.

[20] S. Imachi, K. Owada, M. Onaka, Intramolecular carbonyl-ene reaction of citronellal to isopulegol over $\mathrm{ZnBr}_{2}$-loading mesoporous silica catalysts, J. Mol. Catal. A: Chem., 272 (2007) p. 174.

[21] C. Milone, A. Perri, A. Pistone, G. Neri, S. Galvagno, Isomerization of (+) citronellal over Zn(II) supported catalysts, Appl. Catal. A: Gen., 233 (2002) p. 151.

[22] G. K. Chuah, S. H. Liu, S. Jaenicke, L. J. Harrison, Cyclization of Citronellal to Isopulegol Catalyzed by Hydrous Zirconia and Other Solid Acids, J. Catal., 200 (2001) p. 352.

[23] A. F. Trasarti, A. J. Marchi, C. R. Apesteguía, Design of catalyst systems for the onepot synthesis of menthols from citral, J. Catal., 247 (2007) p.155.

[24] Q. Yang, X. Tong, W. Zhang, Influence of Lewis acids and substituents on carbonylene reactions: A density functional theory study, J. Mol. Struct.: THEOCHEM, 957 (2010), p. 84.

[25] K. Tanabe, T. Sumiyoshi, K. Shibata, T. Kiyoura, J. Kitagawa, A New Hypothesis Regarding the Surface of Binary Metal Oxides, Bull. Chem. Soc. Jpn., 47, 1064-1066, (1974).

[26] Y. Nie, W. Niah, S. Jaenicke, G. K. Chuah, A tandem cyclization and hydrogenation of ( \pm )-citronellal to menthol over bifunctional $\mathrm{Ni} / \mathrm{Zr}$-beta and mixed $\mathrm{Zr}$-beta and Ni/MCM-41, J. Catal., 248 (2007) p. 1. 
[27] F. Neatu, S. Coman, V. I. Parvulescu, G. Poncelet, D. De Vos, P. Jacobs, Heterogeneous Catalytic Transformations of Citronellal to Menthol in a Single Step on Ir-Beta Zeolite Catalysts, Top. Catal., 52 (2009), p. 1292.

[28] N. Ravasio, N. Poli, R. Psaro, M. Saba, F. Zaccheria, Bifunctional copper catalysts. Part II. Stereoselective synthesis of (-)-menthol starting from (+) citronellal, Top. Catal., 13 (2000) p. 195.

[29] C. Milone, C. Gangemi, G. Neri, A. Pistone, S. Galvagno, Selective one step synthesis of (-) menthol from (+) citronellal on Ru supported on modified $\mathrm{SiO}_{2}$, Appl. Catal. A: Gen., 199 (2000) p. 239.

[30] A. F. Trasarti, A. J. Marchi, C. R. Apesteguía, Synthesis of menthols from citral on $\mathrm{Ni} / \mathrm{SiO}_{2}-\mathrm{Al}_{2} \mathrm{O}_{3}$ catalysts, Catal. Commun., 32 (2013) p. 62.

[31] P. Maki-Arvela, N. Kumar, D. Kubicka, A. Nasir, T. Heikkila, V. Lehto, R. Sjoholm, T. Salmi, D. Yu. Murzin, One-pot citral transformation to menthol over bifunctional micro- and mosoporous metal modified catalysts: Effect of catalyst support and metal, J. Mol. Catal. A: Chem., 240 (2005) p. 72.

[32] Ishida T., Yamaguchi T., Tanabe K., Acid property of sulfur-promoted zirconium oxide on silica as solid superacid, Chem. Lett., 1869-1872, (1988).

[33] C. Morterra, G. Cerrato, S. Ardizzone, C. L. Bianchi, M. Signoretto, F. Pinna, Surface features and catalytic activity of sulfated zirconia catalysts from hydrothermal precursors, Phys. Chem. Chem. Phys., 4 (2002) p. 3136.

[34] U. Ciesla, M. Froba, G. Stucky, F. Schuth, Highly Ordered Porous Zirconias from Surfactant-Controlled Syntehsis: Zirconium Oxide-Sulfate and Zirconium Oxo Phosphate, Chem. Mater., 11 (1999), p. 227.

[35] T. Kanougi, T. Atogichi, S. Yao, Periodic density functional study of superacidity of sulfated zirconia, J. Mol. Catal. A: Chem., 117 (2002), p. 289.

[36] Yamaguchi T., Jin T., Ishida T., Tanabe K., Structural identification of acid sites of sulfur-promoted solid super acid and construction of its structure on silica support, Mat. Chem. Phys., 17, 3-19, (1987).

[37] Boyse R. A., Ko E. I., Preparation and characterization of zirconia-phosphate aerogels, Cat. Lett., 38, 225-230, (1996).

[38] Rodríguez R. G, Tesis de maestría, Síntesis y caracterización de óxidos mixtos sílice-zirconia sintetizados por el método de sol-gel, UAM-Iztapalapa, 2003.

[39] Yadav G., Fair J., Sulfated zirconia and its modified versions as promising catalysts for industrial processes, Microporous and Mesoporous Materials, 33, 1-48, (1999).

[40] Akkari R., Ghorbel A., Essayem N., Figueras F., Synthesis and characterization of mesoporous silica-suppoted nano-crystalline sulfated zirconia catalysts prepared by a sol-gel process: Effect of the S/Zr molar ratio, Appl. Catal. A: Gen., 328, 43-51, (2007). 
[41] Tzompantzi F. J., Manriquez M. E., Padilla J. M., Del Angel G., Gomez R., Mantilla A., One pot preparation of $\mathrm{NiO} / \mathrm{ZrO}_{2}$ sulfated catalysts and its evaluation for isobutene oligomerization, Catal. Today, 133-135, 154-159, (2008).

[42] K. Ebitani, J. Tsuji, H. Hattori, H. Kita, Dynamic modification of surface acid properties with hydrogen molecule for zirconium oxide promoted by platinum and sulfate ions, J. Catal., 135 (1992), p. 609.

[43] S. Ji, M. Yu, Y. Ren, A. Buekens, S. Lu, K. Cen, X. Li, Combined Catalytic Oxidation and Activated Carbon Adsorption of Dioxins, AICHE, 2014.

[44] A. Karelovic, P. Ruiz, Improving the Hydrogenation Function of $\mathrm{Pd} / \mathrm{Y}-\mathrm{Al}_{2} \mathrm{O}_{3}$ Catalyst by $\mathrm{Rh} / \mathrm{Y}-\mathrm{Al}_{2} \mathrm{O}_{3}$ Addition in $\mathrm{CO}_{2}$ Methanation at Low Temperature, ACS Catal. 3 (2013) 2799-2812.

[45] S. Melada, S. A. Ardizzone, C. L. Bianchi, Sulphated zirconia by sol-gel. The effects of the preparative variables, Microporous and Mesoporous Materials, 73 (2004), p. 203.

[46] R. Srinivasan, R. A. Keogh, D. R. Milburn, B. H. Davis, Sulfated Zirconia Catalysts: Characterization by TGA/DTA/Mass Spesctroscopy, J. Catal., 153 (1995), p. 123.

[47] D. A. ward, E. I. Ko, One-Step Synthesis and Characterization of Zirconia-Sulfate Aerogels as Solid Superacids, J. Catal., 150 (1994), p. 18.

[48] IUPAC. Reporting Physisorption Data for Gas/Solid Systems. With Special Reference to the Determination of Surface Area and Porosity. 11, 1982, Pure and Applied Chemistry, Vol. 54, p. 2201.

[49] C. J. Brinker, G. W. Scherer, SOL-GEL SCIENCE, The Physics and Chemistry of SolGel Processing, 1990, Academic Press.

[50] A. F. Bedilo, K. J. Kablunde, Synthesis of Catalytically Active Sulfated Zirconia Aerogels, J. Catal., 176 (1998), p. 448.

[51] B. Li, R. D. Gonzalez, Sol-Gel Synthesis and Catalytic Properties of Sulfated Zirconia Catalysts, Ind. Eng. Chem. Res., 35 (1996), p. 3141.

[52] C. J. Norman, P. A. Goulding, I. McAlpine, Role of anions in the surface area stabilization of zirconia, Catal. Today, 20 (1994), p. 313.

[53] T. Jin, T. Yamaguchi, K. Tanabe, Mechanism of acidity generation on sulfurpromoted oxides, J. Phys. Chem., 90 (1986) 4794, 4796.

[54] D. Jackson, J. S. J. Hargreaves, Metal Oxide Catalysis volume 2, WILEY-VCH Verlag Gmbh \& Co. 2009.

[55] J. Navarrete, T. Lopez, R. Gomez, Surface Acidity of Sulfated TiO2-SiO2 sol-gels, Langmuir, 12 (1996), p. 4385. 
[56] C. A. Emeis, Determination of Integrated Molar Extinction Coefficients for infrared Absorption Bands of Pyridine Adsorbed on Solid Acid Catalysts, J. Catal., 141 (1993) 347-354.

[57] B. H Davis, R. A. Keogh, S. Alerasool, D. J. Zalewski, D. E. Day, P. K. Doolin, Infrared Study of Pyridine Adsorbed on Unpromoted and Promoted Sulfated Zirconia, J. Catal., 183 (1999) 45-52.

[58] Q. Yang, X. Tong, W. Zhang, Influence of Lewis acid and substituents on carbonylene reactions: A density functional theory study, J. Mol. Struct: THEOCHEM, 957 (2010), p. 84.

[59] J. C. Piña Victoria, Tesis de maestría, Síntesis, caracterización y actividad catalítica de $\mathrm{Ni} / \mathrm{ZrO}_{2}-\mathrm{PO}_{4}$ en la síntesis de mentol a partir de citral, UAM Iztapalapa, 2012. 


\section{Apéndice A}

Cinética de reacción para la obtención de mentol a partir de citral.

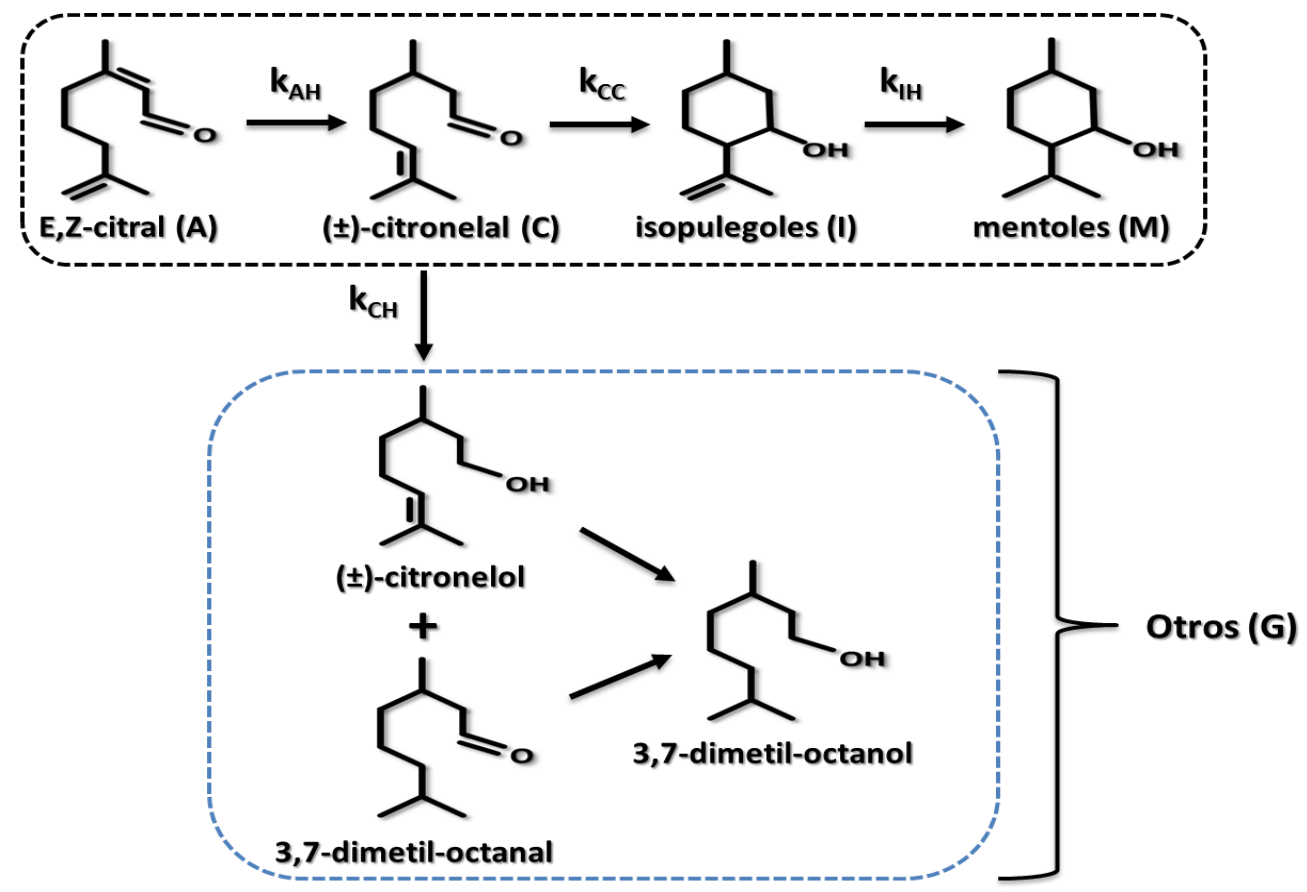

Figura A1. Rutas observadas en la obtención de mentol a partir de citral en una sola etapa con mezclas mecánicas de $\mathrm{Ni} / \mathrm{SiO}_{2}+\mathrm{ZrS2}$.

De acuerdo a la Figura A1 se plantea el mecanismo cinetico de reaccion de hidrogenacion de citral y citronelal, ciclizacion de citronelal e hidrogenacion de isopulegol para obtener finalmente el mentol.

La hidrogenacion de citral se considera que se lleva a cabo en un sitio hidrogenante $\mathrm{S}$. En el mismo sitio se lleva a cabo la reaccion disociativa de $\mathrm{H}_{2}$.

Hidrogenación de citral (A) a citronelal (C) en sitio hidrogenante (S)

1) Etapa de disociación de $\mathrm{H}_{2}$

$H_{2}+2 S \stackrel{K_{1}}{\leftrightarrow} 2 H S$

$$
K_{1}=\frac{\Theta_{H S}^{2}}{C_{H} \Theta_{S}^{2}}
$$

2) Etapa de adsorción de $A$

$A+S \stackrel{K_{2}}{\leftrightarrow} A S$

$$
K_{2}=\frac{\Theta_{A S}}{C_{A} \Theta_{S}}
$$


3) Primera etapa de hidrogenación de A

$$
A S+H S \stackrel{K_{3}}{\leftrightarrow} H A S+S \quad K_{3}=\frac{\Theta_{H A S} \Theta_{S}}{\Theta_{A S} \Theta_{H S}}
$$

4) Segunda etapa de hidrogenación de A para dar lugar a $C$

$$
H A S+H S \stackrel{K_{4}}{\leftrightarrow} C S+S \quad K_{4}=\frac{\Theta_{C S} \Theta_{S}}{\Theta_{H A S} \Theta_{H S}}
$$

5) Etapa de desorción de $C$

$$
C S \stackrel{1 / K_{5}}{\longleftrightarrow} C+S \quad \frac{1}{K_{5}}=\frac{C_{C} \Theta_{S}}{\Theta_{C S}}
$$

Se considera que la segunda etapa de adición de hidrógeno es la etapa limintante, entonces en cada parte de la red de reacciones se pueden obtener las ecuaciones de la reaccion de la siguiente manera:

Hidrogenacion de citral: $\quad r_{A}=k_{A R} \Theta_{H A S} \Theta_{H S}$

Donde: $r_{j}$ es la velocidad de reacción superficial y $k_{j R}$ es la constante de reacción superficial del componente $j$.

\section{Hidrogenación de citronelal (C) a otros (G) en sitio hidrogenante (S)}

1) Etapa de disociación de $\mathrm{H}_{2}$

$$
H_{2}+2 S \stackrel{K_{1}}{\leftrightarrow} 2 H S \quad K_{1}=\frac{\Theta_{H S}^{2}}{C_{H} \Theta_{S}^{2}}
$$

2) Etapa de adsorción de $C$

$$
C+S \stackrel{K_{6}}{\leftrightarrow} C S \quad K_{6}=\frac{\Theta_{C S}}{C_{C} \Theta_{S}}
$$

3) Primera etapa de hidrogenación de $C$

$$
C S+H S \stackrel{K_{7}}{\leftrightarrow} H C S+S \quad K_{7}=\frac{\Theta_{H C S} \Theta_{S}}{\Theta_{C S} \Theta_{H S}}
$$


4) Segunda etapa de hidrogenación de $C$ para dar lugar a $G$

$$
H C S+H S \stackrel{K_{8}}{\leftrightarrow} G S+S \quad K_{8}=\frac{\Theta_{G S} \Theta_{S}}{\Theta_{H G S} \Theta_{H S}}
$$

5) Etapa de desorción de G

$$
G S \stackrel{1 / K_{9}}{\longleftrightarrow} g+S \quad \frac{1}{K_{9}}=\frac{C_{G} \Theta_{S}}{\Theta_{G S}}
$$

Hidrogenacion de citronelal: $r_{C}=k_{C R} \Theta_{H C S} \Theta_{H S}$

Hidrogenación de Isopulegol (I) a mentol (M) en sitio hidrogenante (S)

1) Etapa de disociación de $\mathrm{H}_{2}$

$$
H_{2}+2 S \stackrel{K_{1}}{\leftrightarrow} 2 H S \quad K_{1}=\frac{\Theta_{H S}^{2}}{C_{H} \Theta_{S}^{2}}
$$

2) Etapa de adsorción de I

$$
I+S \stackrel{K_{10}}{\leftrightarrow} I S \quad K_{10}=\frac{\Theta_{I S}}{C_{I} \Theta_{S}}
$$

3) Primera etapa de hidrogenación de I

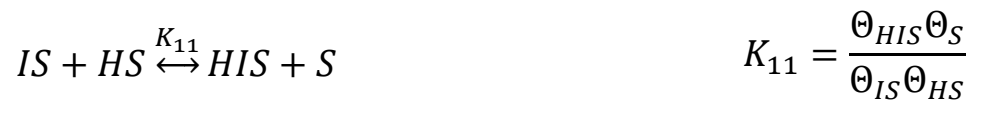

4) Segunda etapa de hidrogenación de I para dar lugar a M

$$
H I S+H S \stackrel{K_{12}}{\longleftrightarrow} M S+S \quad K_{12}=\frac{\Theta_{M S} \Theta_{S}}{\Theta_{H I S} \Theta_{H S}}
$$

5) Etapa de desorción de $M$

$$
M S \stackrel{1 / K_{13}}{\longleftrightarrow} C+S \quad \frac{1}{K_{13}}=\frac{C_{M} \Theta_{S}}{\Theta_{M S}}
$$

Hidrogenacion de isopulegol: $\quad r_{I}=k_{I R} \Theta_{H I S} \Theta_{H S}$ 
Reacomodando las ecuaciones A1-A5

$\Theta_{H S}=\Theta_{S} \sqrt{K_{1} C_{H}}$

$\Theta_{A S}=K_{2} C_{A} \Theta_{S}$

$\Theta_{H A S}=K_{3} \frac{\Theta_{A S} \Theta_{H S}}{\Theta_{S}}$

Se realiza el mismo procedimiento para la hidrogenación de $\mathrm{C}$ y $\mathrm{I}$

Expresando las concentraciones de las especies adsorbidas en terminos de variables medibles tenemos:

$\Theta_{H S}=K_{1}^{1 / 2} C_{H_{2}}^{1 / 2} \Theta_{S}$

$\Theta_{A S}=K_{2} C_{A} \Theta_{S}$

$\Theta_{H A S}=K_{3} K_{2} K_{1}^{1 / 2} C_{A} C_{H_{2}}^{1 / 2} \Theta_{S}$

Realizando el balance de sitios se obtiene la siguiente ecuacion:

$\Theta_{S}=1-\left(\Theta_{H S}+\Theta_{A S}+\Theta_{H A S}+\Theta_{C S}+\Theta_{H C S}+\Theta_{I S}+\Theta_{H I S}+\Theta_{G S}+\Theta_{M S}\right)$

$\Theta_{S}=1-\left(K_{1}^{1 / 2} C_{H_{2}}^{1 / 2} \Theta_{S}+K_{2} C_{A} \Theta_{S}+K_{3} K_{2} K_{1}^{1 / 2} C_{A} C_{H_{2}}^{1 / 2} \Theta_{S}+K_{6} C_{C} \Theta_{S}+K_{7} K_{6} K_{1}^{1 / 2} C_{C} C_{H_{2}}^{1 / 2} \Theta_{S}+\right.$

$\left.K_{10} C_{I} \Theta_{S}+K_{11} K_{10} K_{1}^{1 / 2} C_{I} C_{H_{2}}^{1 / 2} \Theta_{S}+K_{9} C_{G} \Theta_{S}+K_{13} C_{M} \Theta_{S}\right)$

$\Theta_{S}=\frac{1}{1+K_{A} C_{A}+K_{C} C_{C}+K_{I} C_{I}+K_{G} C_{G}+K_{M} C_{M}+\sqrt{K_{1} C_{H_{2}}}}$

Haciendo el balance de sitios ácidos:

$\Theta_{X}=1-\Theta_{C X}+\Theta_{I X}$ 
Sustituyendo la concentración de sitios ocupados por concentraciones medibles:

$\Theta_{X}=1-K_{C}^{\prime} C_{C} \Theta_{X}+K_{I}^{\prime} C_{I} \Theta_{X}$

$\Theta_{X}=\frac{1}{1+K_{C}^{\prime} C_{C}+K_{F}^{\prime} C_{F}}$

Realizando las sustituciones correspondientes se obtienen las siguientes expresiones de velocidad de reacción:

$r_{A}=k_{A R} K_{3} K_{2} K_{1} C_{A} C_{H_{2}} \Theta_{S}^{2}$

$r_{A}=\frac{k_{A R} K_{3} K_{2} K_{1} C_{A} C_{H_{2}}}{\left(1+K_{A} C_{A}+K_{C} C_{C}+K_{I} C_{I}+K_{G} C_{G}+K_{M} C_{M}+\sqrt{K_{1} C_{H_{2}}}\right)^{2}}$

$r_{A H}=\frac{k_{A H} C_{A} C_{H_{2}}}{\left(1+K_{A} C_{A}+K_{C} C_{C}+K_{I} C_{I}+K_{G} C_{G}+K_{M} C_{M}+\sqrt{K_{1} C_{H_{2}}}\right)^{2}}$

$r_{C H}=\frac{k_{C R} K_{7} K_{6} K_{1} C_{C} C_{H_{2}}}{\left(1+K_{A} C_{A}+K_{C} C_{C}+K_{I} C_{I}+K_{G} C_{G}+K_{M} C_{M}+\sqrt{K_{1} C_{H_{2}}}\right)^{2}}$

$r_{C H}=\frac{k_{C H} C_{C} C_{H_{2}}}{\left(1+K_{A} C_{A}+K_{C} C_{C}+K_{I} C_{I}+K_{G} C_{G}+K_{M} C_{M}+\sqrt{K_{1} C_{H_{2}}}\right)^{2}}$

$r_{I H}=\frac{k_{I R} K_{11} K_{10} K_{1} C_{C} C_{H_{2}}}{\left(1+K_{A} C_{A}+K_{C} C_{C}+K_{I} C_{I}+K_{G} C_{G}+K_{M} C_{M}+\sqrt{K_{1} C_{H_{2}}}\right)^{2}}$

$r_{I H}=\frac{k_{I H} C_{I} C_{H_{2}}}{\left(1+K_{A} C_{A}+K_{C} C_{C}+K_{I} C_{I}+K_{G} C_{G}+K_{M} C_{M}+\sqrt{K_{1} C_{H_{2}}}\right)^{2}}$

$r_{C C}=\frac{k_{C I} C_{C}}{1+K_{C}^{\prime} C_{C}+K_{I}^{\prime} C_{I}}$ 


\section{Apéndice B}

Ajuste de parámetros cinéticos en la obtención de mentol a partir de citral
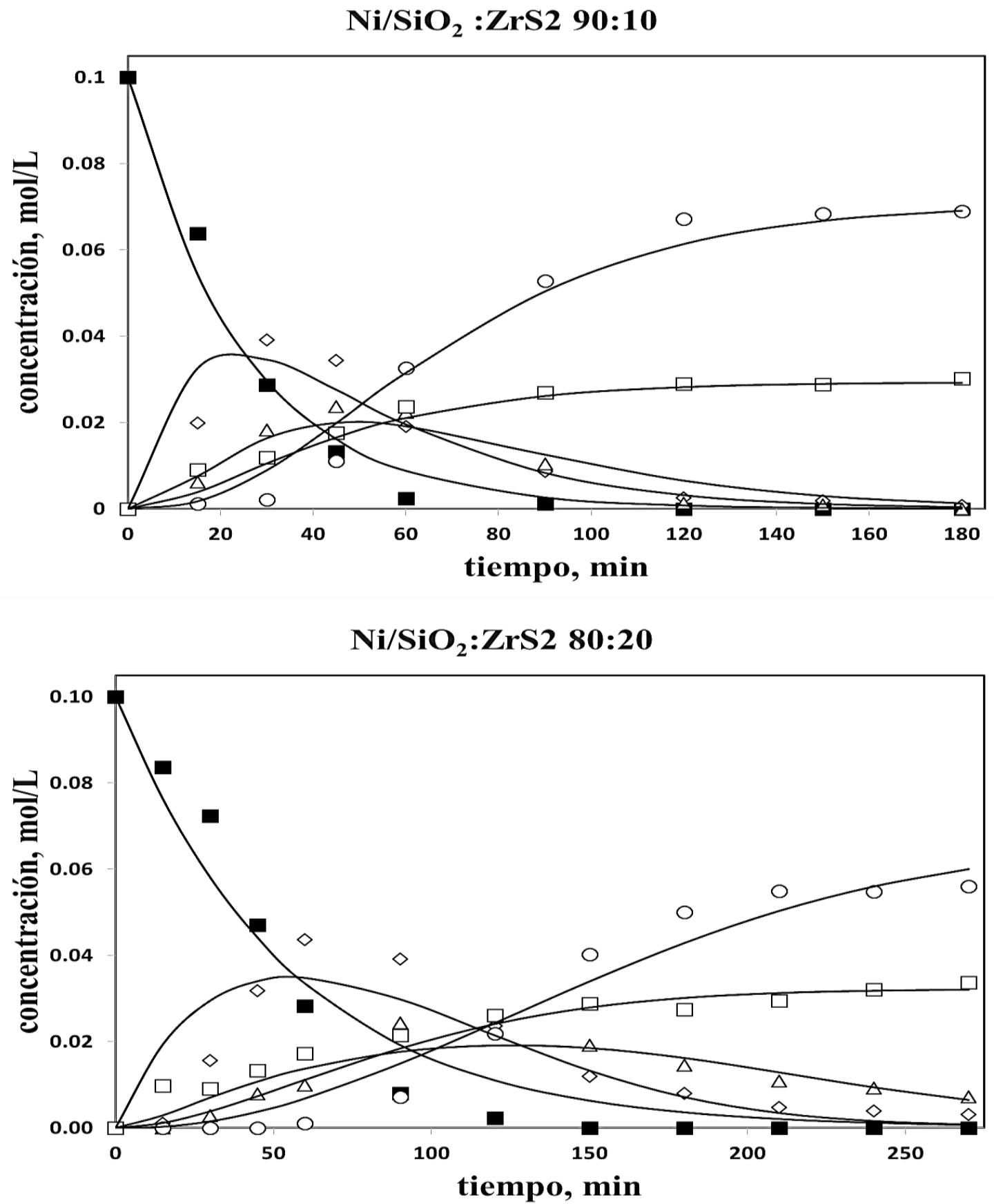


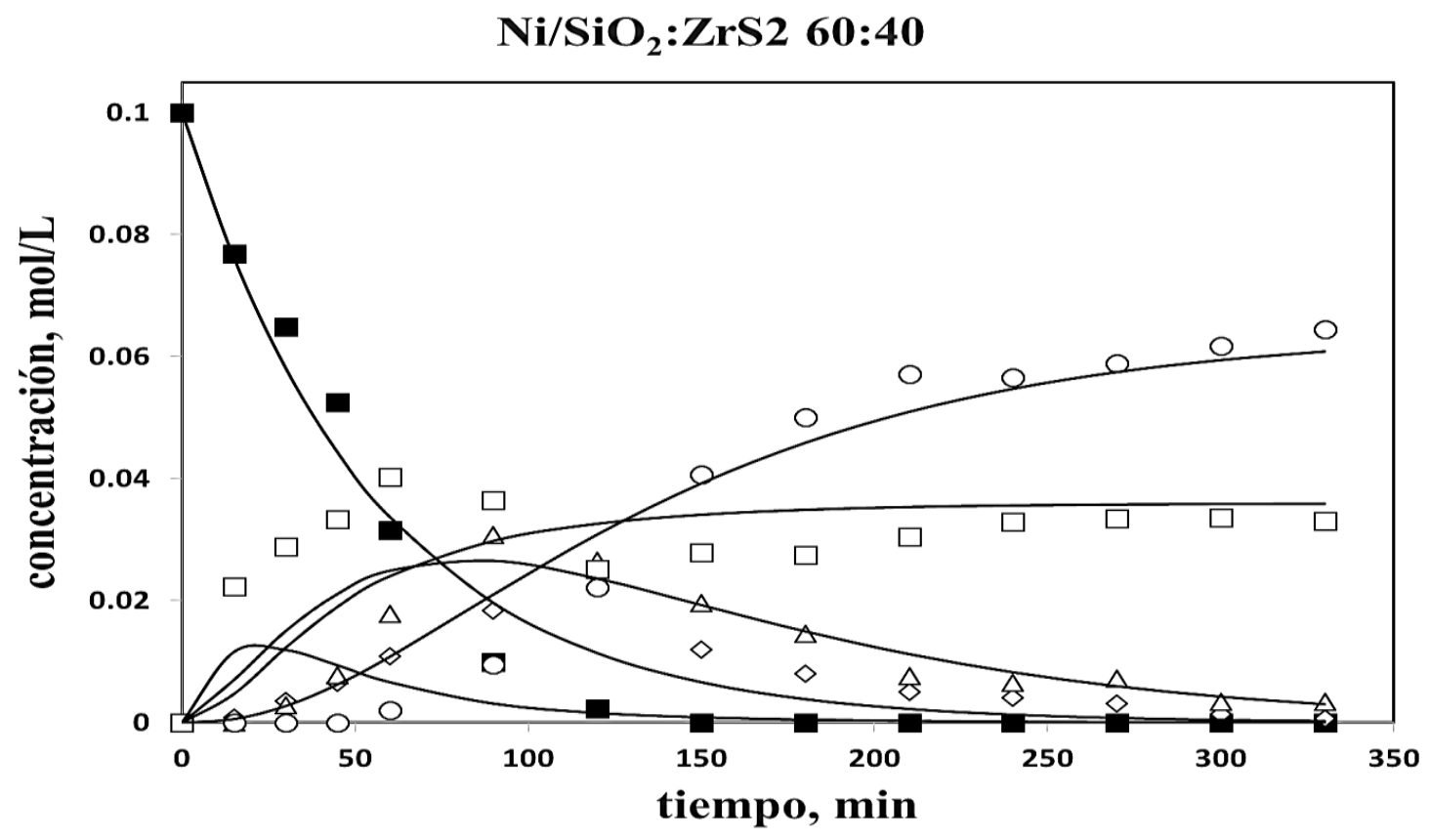

La línea solida representa el resultado del ajuste de los parámetros cinéticos donde se incluyen las concentraciones calculadas a partir del modelo cinético propuesto. Los puntos en la gráfica representan las concentraciones experimentales. Đconversión de citral; selectividad: $\diamond$ citronelal, $\triangle$ isopulegol, $\bigcirc$ mentol, @citronelol, $\gg$ 3,7-dimetil-1-octanol. 